\title{
The interaction between inflammatory properties of diet and genetic variation in body weight regulation
}

Citation for published version (APA):

Freitag, H. (2021). The interaction between inflammatory properties of diet and genetic variation in body weight regulation. [Doctoral Thesis, Maastricht University]. Penerbit Andi. https://doi.org/10.26481/dis.20211209hm

Document status and date:

Published: 01/01/2021

DOI:

10.26481/dis.20211209hm

Document Version:

Publisher's PDF, also known as Version of record

\section{Please check the document version of this publication:}

- A submitted manuscript is the version of the article upon submission and before peer-review. There can be important differences between the submitted version and the official published version of record.

People interested in the research are advised to contact the author for the final version of the publication, or visit the DOI to the publisher's website.

- The final author version and the galley proof are versions of the publication after peer review.

- The final published version features the final layout of the paper including the volume, issue and page numbers.

Link to publication

\footnotetext{
General rights rights.

- You may freely distribute the URL identifying the publication in the public portal. please follow below link for the End User Agreement:

www.umlib.nl/taverne-license

Take down policy

If you believe that this document breaches copyright please contact us at:

repository@maastrichtuniversity.nl

providing details and we will investigate your claim.
}

Copyright and moral rights for the publications made accessible in the public portal are retained by the authors and/or other copyright owners and it is a condition of accessing publications that users recognise and abide by the legal requirements associated with these

- Users may download and print one copy of any publication from the public portal for the purpose of private study or research.

- You may not further distribute the material or use it for any profit-making activity or commercial gain

If the publication is distributed under the terms of Article $25 \mathrm{fa}$ of the Dutch Copyright Act, indicated by the "Taverne" license above, 


\section{THE INTERACTION BETWEEN \\ INFLAMMATORY PROPERTIES OF DIET AND \\ GENETIC VARIATION IN \\ BODY WEIGHT REGULATION}

Harry Freitag Luglio Muhammad

PENERBIT ANDI 


\section{VARIATION IN BODY WEIGHT REGULATION}

Oleh: Harry Freitag Luglio Muhammad

Hak Cipta @2021 pada penulis

Editor : : Erang Risanto

Setter :Vanio Praba

Desain Cover : Andang Suhana

Korektor : Robertus Ari

Hak Cipta dilindungi undang-undang.

Dilarang memperbanyak atau memindahkan sebagian atau seluruh isi buku ini dalam bentuk apa pun, baik secara elektronis maupun mekanis, termasuk memfotokopi, merekam atau dengan sistem penyimpanan lainnya, tanpa izin tertulis dari penulis.

\section{Diterbitkan oleh Penerbit ANDI (Anggota IKAPI)}

Jl. Beo 38-40, Telp. (0274) 561881 (Hunting), Fax (0274) 588282 Yogyakarta 55281

\section{Percetakan : CV ANDI OFFSET}

J. Beo 38-40, Telp. (0274) 561881 (Hunting), Fax (0274) 588282 Yogyakarta 55281

Muhammad, Harry Freitag Luglio

THE INTERACTION BETWEEN INFLAMMATORY PROPERTIES OF DIET AND GENETIC VARIATION IN BODY WEIGHT REGULATION/ Harry Freitag Luglio Muhammad

- Ed. I. - Yogyakarta: ANDI;

$30-29-28-27-26-25-24-23-22-21$

$\mathrm{x}+134 \mathrm{hlm} . ; 16 \times 23 \mathrm{~cm}$.

$\begin{array}{llllllllll}10 & 9 & 8 & 7 & 6 & 5 & 4 & 3 & 2 & 1\end{array}$

ISBN: 978-623-01-1893-7

I. Judul

1. Dietetics 


\title{
THE INTERACTION BETWEEN INFLAMMATORY PROPERTIES OF DIET AND GENETIC VARIATION IN BODY WEIGHT REGULATION
}

\begin{abstract}
DISSERTATION
To obtain the degree of Doctor at the Maastricht University, on the authority of the Rector Magnificus, Prof. dr. Rianne M. Letschert, in accordance with the decision of the Board of Deans, to be defended in Public on Thursday 9 December 2021, at 10.00 hours.
\end{abstract}

By

Harry Freitag Luglio Muhammad

Born July 11, 1986, Dili, Timor Leste 


\section{PhD Candidate}

Harry Freitag Luglio Muhammad

\section{Supervisor}

Prof. dr. M. A van Baak

Prof. dr. E. C. M. Mariman

\section{Assessment Committee}

Prof. dr. E.E. Blaak, Maastricht University

Prof. dr. J. Plat, Maastricht University

Prof. dr. A. Salis, University of Western Australia

Dr. ir. R. Stienstra, Wageningen University and RadboudMC

The PhD has been supported by various of Travel and Research Grants

- Scope School Scholarship, World Obesity Federation

- NuGO Student Exchange Grant

- European Association for the Study Obesity Travel grant 
This thesis is dedicated to all disadvantaged kids with a dream to make a difference in the world. 
BETWEEN INFLAMMATORY PROPERTIES OF DIET AND GENETIC VARIATION IN BODYWEIGHT REGULATION 


\section{ABSTRACT}

Inflammation might play a part in body weight regulation. Previous studies showed that circulating inflammatory markers, inflammatory properties of the diet, and genetic variation in inflammatory markers are associated with obesity. To date, it is not known whether the interaction between inflammation and obesity could also be evaluated in the context of weight change during and after a weight loss program and whether diet might influence this association.

The general objective of this thesis was to evaluate the influence of diet and inflammatory gene variations on inflammation and body weight changes in obesity. The objective was specified into 4 aims: 1) To evaluate the association of the inflammatory properties of the diet with weight regain after a weight loss program as well as with the risk for obesity in a population-based study; 2) To develop a new low calorie dietary regime with low inflammatory property (LCID) for weight loss and evaluate the association between the inflammatory properties of the diet and weight regain; 3) To examine the influence of inflammatory gene variations on the association between obesity and inflammation; 4) To evaluate the interaction between inflammatory gene variations and diet composition and its effect on weight regain after weight loss.

We showed that the inflammatory property of the diet is associated with adipose tissue inflammation, marked by leptin concentration. In a weight loss program, we reported that the inflammatory property of the diet partially explains the variation in weight regain following weight loss. The modification of a standard low-calorie diet (LCD) for weight loss to lower its inflammatory properties (LCID), reduces hs-CRP compared to the $L C D$, but does not influence changes TNF-alpha, IL6 , or weight. However, the LCID had a positive impact on improving genomic health by elongation of relative telomere length. We showed that variations in the genes for inflammation markers such as CRP, TNFA, and IL6 influenced the correlation between obesity and inflammation. Variations in these genes also influenced the correlation between diet composition and weight regain following weight loss. All in all, these data support the hypothesis that inflammation plays a role in the regulation of body weight. This effect is either direct or indirect through interaction with dietary intake. 
BETWEEN INFLAMMATORY PROPERTIES OF DIET AND GENETIC VARIATION IN BODYWEIGHT REGULATION 


\section{TABLE OF CONTENTS}

ABSTRACT

vii

CHAPTER 1 General Introduction and Outline of the Thesis .1

CHAPTER 2 Dietary Inflammatory Index Score and Its Association with Body Weight, Blood Pressure, Lipid Profile, and Leptin in Indonesian Adults 11

CHAPTER 3 Dietary Intake after Weight Loss and the Risk of Weight Regain: Macronutrient Composition and Inflammatory Properties of the Diet 29

CHAPTER 4 Low Calorie Low Inflammatory Diet is Beneficial to Reduce hs-CRP during a Weight Loss Intervention among Individuals with Obesity.

CHAPTER 5 The Effect of a Low Calorie Low Inflammatory Diet on Relative Telomere Length and Mitochondrial DNA Copy Number among Obese Indonesian Adults. .67

CHAPTER 6 Interactions between SNPs at Pro-inflammatory Genes, Adiposity and C-reactive Protein and Their Association with Colorectal Cancer Risk

CHAPTER 7 The Interaction of Inflammatory Gene Variations with the Association between Diet, hs-CRP, and Weight Regain in the DiOGenes Trial

CHAPTER 8 General Discussion 113 
BETWEEN INFLAMMATORY PROPERTIES OF DIET AND GENETIC VARIATION IN BODYWEIGHT REGULATION 
CHAPTER 1

General Introduction and Outline of the Thesis 


$$
\text { Q6: }
$$


before weight loss can predict individual resistance towards a weight loss program as well as weight regain following weight loss [11]. Because previous reports have shown the potential role of inflammation in regulating body weight, reducing inflammation might be an important component of a sustainable weight loss program.

\section{INFLAMMATION AND OBESITY: ONE COIN WITH 2 SIDES}

Obesity has been associated with increased systemic and adipose tissue inflammation. The excess of adipose tissue is associated with immune cell infiltration and higher production of pro-inflammatory cytokines [12]. In addition, there is a remarkable reduction in anti-inflammatory immune cells in adipose tissue of individuals with obesity. This combination leads to an increment of the inflammatory state of the adipose tissue as well as in the circulation [12]. Studies from a broad range of populations have reported that systemic pro-inflammatory markers, such as high sensitive C-reactive protein (hs-CRP), are higher among individuals with obesity [13]. In addition, several reports suggested that weight loss is associated with a reduction in hs-CRP [14-16].

Interestingly, findings from recent decades indicated that inflammation might also induce obesity and weight gain. First, in a cohort study conducted among 5,062 adult women living in Italy, it was shown that hs-CRP was a predictor of weight gain. Women with a hs-CRP concentration above the median value had a higher risk to increase body weight $>14 \mathrm{~kg}$ within 20 years [17]. Second, observational studies across different populations showed that variations in pro-inflammatory genes such as TNFA, CRP, and IL6 were associated with the risk of obesity [18-20]. Lastly, in a weight loss program, higher baseline inflammation markers were associated with weight loss resistance and higher risk of weight regain [11].

\section{DIET, INFLAMMATION, AND OBESITY}

Inflammation is a biological process which involves a variety of cells including immune cells and internal organs. Inflammation plays a crucial part in the host defense system against pathogens [21]. In the last few decades, it has become clear that inflammation is also an important component of the physiological processes, including the body repair system [22] as well as inter-organ communication [23]. Recent scientific developments suggest that inflammation is involved in the pathophysiological process of non-communicable diseases such as atherosclerosis, dyslipidemia, and insulin resistance [24]. In addition, inflammation is also shown to influence genomic health by reducing telomere length [25] and mitochondrial DNA copy number [26]. These alterations are important links between inflammation and the development of chronic diseases [24]. 
Inflammation is influenced by environmental (e.g., lifestyle, diet, physical activity) factors [27]. It has been reported that the dietary pattern affects circulating inflammatory markers in adults [28]. There are several tools to assess the inflammatory properties of the diet, such as the dietary inflammatory index (DII) [29], the dietary inflammation score [30], and the food-based index of dietary inflammatory potential [31]. Population-based studies in recent years have reported that those scores are associated with systemic inflammation [30-33]. A recent meta-analysis showed that a higher DII was associated with increased body mass index and risk for obesity [34], suggesting that dietary patterns which increase inflammatory markers, could also increase the risk for obesity (Figure 1.2).
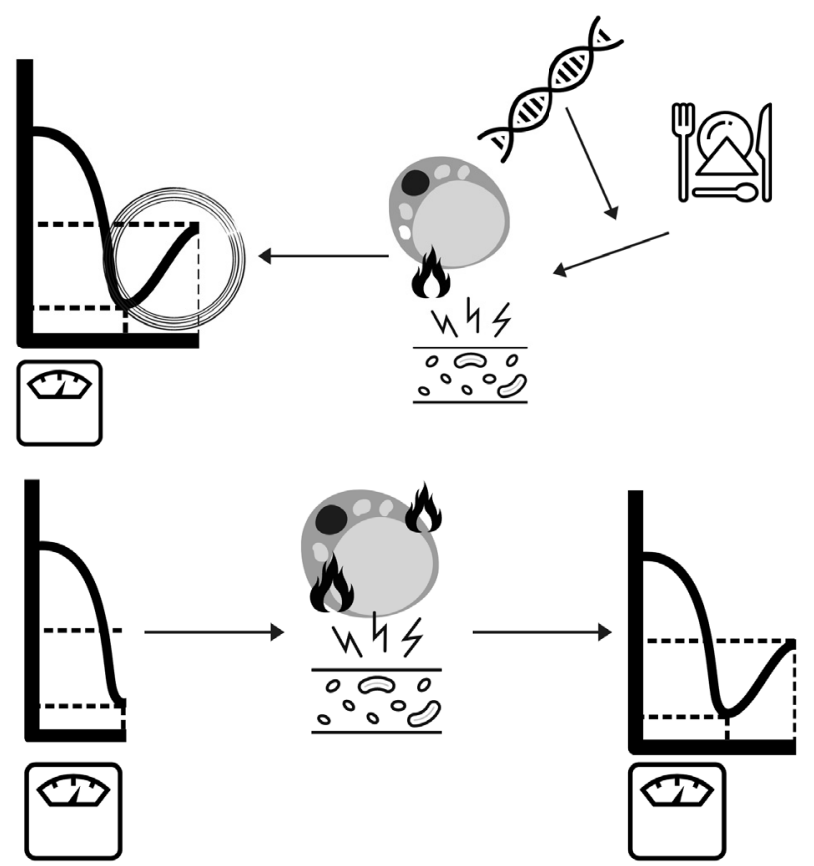

Figure 1.2. Theoretical framework of the interaction between diet and genes on inflammation and its impact on weight regain. During a weight loss program, adipose tissue shrinks and releases inflammatory and stress signals locally and into the blood (below). This is one of the factors that may lead to weight regain after weight loss. There are several factors that influence the adipose tissue inflammation response to weight loss, including diet and genetics (above). Those factors might interact, leading to variation in weight changes following the weight-loss period. 
In the calculation of DII, the intake of nutrient and non-nutrient components of the diet are calculated and compiled into an index. Components with pro-inflammatory activity (such as energy, saturated fat, and trans fat) will add to the score, while components with anti-inflammatory properties (such as vitamin C, magnesium, and folate) will reduce the score. After those components are summarized, individuals with the higher score tend to have more circulating inflammatory markers while individuals with a lower score tend to have less [29].

Increased inflammation might play a role in the disruption of several molecular signatures such as mitochondrial function and telomere length. Increased inflammation is associated with the reduction of mitochondrial DNA copy number (mtDNA-CN), an indicator of mitochondrial biogenesis and function [35]. In addition, increased inflammation is associated with more extensive shortening of telomere length [36,37]. Interestingly, it also has been shown that mIDNA-CN and RTL are related to weight gain $[38,39]$. Thus, it might be argued that mIDNA-CN and RTL are influenced by systemic inflammation due to increased adiposity.

\section{GENES, INFLAMMATION, AND OBESITY}

In addition to the environment, inflammation can also be influenced by genetic factors. Population-based studies revealed that certain variations in pro-inflammatory genes are associated with increased inflammation. Gene variations in TNFA, IL6, and CRP have been associated with interindividual differences in proneness to inflammation due to higher circulatory concentration of TNF-alpha, IL-6, and hs-CRP, respectively [40-42]. Furthermore, those gene variations were also reported to be associated with increased risk of obesity [18-20]. This suggests that the risk of obesity can be modulated by variations in genes involved in the inflammation process.

\section{THE INTERACTION BETWEEN GENETIC VARIATION AND DIET AND OBESITY}

The mechanism underlying how gene variations in inflammation genes influence the risk of obesity is not well understood. Joffe et al. [43] suggested that dietary intake and variations in TNFA and IL6 genes interact to influence obesity and its comorbidities. For example, among those with the A allele of the TNFA -308 G > A gene variation ( $r$ 1800629), higher dietary fat intake was associated with a greater risk for obesity compared to those without the A allele (GG). This might explain differences in the individual capacities to increase or reduce inflammation due to a specific dietary regime because of their genetic make-up. 


\section{GAP OF KNOWLEDGE}

It has previously been shown that the inflammatory properties of the diet are associated with risk of obesity [34]. However, it is not known whether this also applies to the context of weight change during and after a weight loss program. Further, studies also reported that gene variations in inflammation markers are associated with obesity $[19,20]$. Nevertheless, it is not clear if and how inflammation could regulate body weight and whether the gene variations have an impact on the interaction between diet and inflammation. The studies in this thesis tried to expand knowledge on some of these issues.

\section{AIMS AND OUTLINE OF THE THESIS}

Weight regain following weight loss is a major concern in obesity treatment, thus a better dietary approach to prevent weight regain is warranted. It has previously been shown that inflammation plays a role in the development of obesity as well as in the individual response to a weight loss program. Since diet is an important factor that affects systemic inflammation, it seems obvious to evaluate the association between the inflammatory property of diet and weight changes during and after a weight loss program or with adiposity in a population-based study. It might be important to develop a weight loss program with the aim to not only reduce calorie intake but also inflammation. As gene variations in inflammation markers play a role in the development of obesity, studying the potential interaction between gene variations (TNFA, IL6, and CRP) and diet may help to explain the interindividual variations in body weight loss and weight regain.

The general objective of this study was to evaluate the influence of diet and gene variations on inflammation and body weight. The objective is specified into 4 aims: 1) To evaluate the association between the inflammatory property of diet and weight regain after a weight loss program as well as the risk for obesity in a population-based study; 2) To develop a new dietary regime with low calorie - low inflammatory properties for weight loss and evaluate its impact on weight loss and regain; 3) To examine the influence of gene variations on the correlation between obesity and inflammation; 4) To evaluate the relation between gene-diet interaction and weight regain after weight loss.

In Chapter 2, we provide insight in how inflammatory properties of the diet (DII) could affect adiposity measures and leptin, a marker for adipose tissue inflammation in a cross-sectional study among Indonesian adults. A further investigation was done to evaluate whether the inflammatory properties of the diet affected weight changes following a weight loss program in participants of the Dutch YoYo study (Chapter 3 ).

In Chapter 4, we studied a new dietary regime for a weight loss program called low calorie low inflammatory diet (LCID) in Indonesian adults with overweight or obesity. The aim of LCID was not only to induce a negative energy balance but 
also to reduce inflammation during a weight loss program. We further investigated the effect of LCID in Chapter 5. In this chapter, we evaluated the effect of the new dietary regime on genome health as marked by relative telomere length (RTL) and mitochondrial DNA copy number (mt-DNA CN) in the weight loss study in Indonesian adults with overweight or obesity.

In Chapter 6 we studied the influence of variations in inflammatory genes (TNFA, IL6, and CRP) on systemic inflammation, marked by hs-CRP, and on adiposity measures in a cross-sectional study among adults living in North-East England. To confirm findings reported in Chapter 6 , an additional analysis with similar genotypes was done to evaluate the influence of variations in inflammation genes (TNFA, IL6, and CRP) on the connection between diet and weight changes after a weight loss program in the DiOGenes study (Chapter 7). The DloGenes study was a large European trial among individuals with obesity. Participants first lost weight with an energy-restricted diet, and were then randomised to different weight maintenance diets.

The thesis concludes with Chapter 8 , in which we provide a summary of all of our findings and discuss suggestions for future research as well as its societal impact.

\section{REFERENCES}

1. GBD 2015 Obesity Collaborators, et al. Health Effects of Overweight and Obesity in 195 Countries over 25 Years. N Engl J Med 2017, 377, 13-27.

2. Tremmel M, Gerdtham UG, Nilsson PM, Saha S. Economic Burden of Obesity: A Systematic Literature Review. Int J Environ Res Public Health 2017, 14, 435.

3. González-Muniesa P, Mártinez-González MA, Hu FB, et al. Obesity. Nat Rev Dis Primers 2017, 3, 17034.

4. Luglio HF, Sulistyoningrum DC, Apriliana NL, et al. The effect of a combination of aerobic and strength training on a weight loss and metabolic profile: Development an effective lifestyle based weight loss program. Top Clin Nutr 2017, 32, 152-160.

5. Kraschnewski JL, Boan J, Esposito J, et al. Long-term weight loss maintenance in the United States. Int J Obes 2010, 34, 1644-1654.

6. Neiberg RH, Wing RR, Bray GA, et al. Patterns of weight change associated with long-term weight change and cardiovascular disease risk factors in the Look AHEAD Study. Obesity (Silver Spring) 2012, 20(10), 2048-2056.

7. Larsen TM, Dalskov SM, van Baak M, et al. Diets with High or Low Protein Content and Glycemic Index for Weight-Loss Maintenance. N Engl J Med 2010, 363(22), 2102-2113.

8. Sacks FM, Bray GA, Carey VJ, et al. Comparison of weight-loss diets with different compositions of fat, protein, and carbohydrates. N Engl J Med 2009, 360(9), 859-73.

9. Roumans NJ, Vink RG, Fazelzadeh P, et al. A role for leukocyte integrins and extracellular matrix remodeling of adipose tissue in the risk of weight regain after weight loss. Am J Clin Nutr 2017, 105, 1054-1062. 
10. Roumans NJ, Camps SG, Renes J, et al. Weight loss- induced stress in subcutaneous adipose tissue is related to weight regain. Br J Nutr 2016, 115, 913-920.

11. Kong LC, Wuillemin PH, Bastard JP, et al. Insulin resistance and inflammation predict kinetic body weight changes in response to dietary weight loss and maintenance in overweight and obese subjects by using a Bayesian network approach. Am J Clin Nutr 2013, 98(6), 1385-1394.

12. Han JM, Levings MK. Immune regulation in obesity-associated adipose inflammation. $J$ Immunol 2013, 191(2), 527-32.

13. Choi J, Joseph L, Pilote L. Obesity and C-reactive protein in various populations: a systematic review and meta-analysis. Obes Rev 2013, 14(3), 232-244.

14. Nicklas JM, Sacks FM, Smith SR, et al. Effect of dietary composition of weight loss diets on high-sensitivity c-reactive protein: the Randomized POUNDS LOST trial. Obesity 2013, 21(4), 681-689.

15. Gögebakan O, Kohl A, Osterhoff MA, et al. Effects of weight loss and long-term weight maintenance with diets varying in protein and glycemic index on cardiovascular risk factors: the diet, obesity, and genes (DiOGenes) study: a randomized, controlled trial. Circulation 2011, 124(25), 2829-2838.

16. Selvin E, Paynter NP, Erlinger TP. The effect of weight loss on C-reactive protein: a systematic review. Arch Intern Med 2007, 167(1), 31-9.

17. Gentile M, Panico S, Rubba F, et al. Obesity, overweight, and weight gain over adult life are main determinants of elevated hs-CRP in a cohort of Mediterranean women. Eur J Clin Nutr 2010, 64(8), 873-878.

18. Sookoian SC, González C, Pirola CJ. Meta-analysis on the G-308A tumor necrosis factor alpha gene variant and phenotypes associated with the metabolic syndrome. Obes Res 2005, 13(12), 2122-2131.

19. Hu M, Yu Z, Luo D, et al. Association between $-174 G>C$ polymorphism in the IL- 6 promoter region and the risk of obesity: A meta-analysis. Medicine (Baltimore) 2018 97(33), e11773.

20. Martínez-Calleja A, Quiróz-Vargas I, Parra-Rojas I, et al. Haplotypes in the CRP gene associated with increased BMI and levels of CRP in subjects with type 2 diabetes or obesity from Southwestern Mexico. Exp Diabetes Res 2012, 2012, 982683.

21. Muralidharan S, Mandrekar P. Cellular stress response and innate immune signaling: integrating pathways in host defense and inflammation. J Leukoc Biol 2013, 94(6), 11671184.

22. Koh TJ, DiPietro LA. Inflammation and wound healing: the role of the macrophage. Expert Rev Mol Med 2011, 13, e23.

23. Robinson MW, Harmon C, O'Farrelly C. Liver immunology and its role in inflammation and homeostasis. Cell Mol Immunol 2016, 13(3), 267-276. 
24. Tsoupras A, Lordan R, Zabetakis I. Inflammation, not Cholesterol, Is a Cause of Chronic Disease. Nutrients 2018, 10.

25. Wong JY, De Vivo I, Lin X, et al. The relationship between inflammatory biomarkers and telomere length in an occupational prospective cohort study. PLoS One 2014, 9(1), e87348.

26. Wu IC, Lin CC, Liu CS, et al. Interrelations Between Mitochondrial DNA Copy Number and Inflammation in Older Adults. J Gerontol A Biol Sci Med Sci 2017, 72(7), 937-944.

27. Pankow JS, Folsom AR, Cushman M, et al. Familial and genetic determinants of systemic markers of inflammation: The NHLBI family heart study. Atherosclerosis 2001, 154, 681689.

28. Cavicchia PP, Steck SE, Hurley TG, et al. A New Dietary Inflammatory Index Predicts Interval Changes in Serum High-Sensitivity C-Reactive Protein. J Nutr 2009, 139, 2365-2372.

29. Shivappa N, Steck SE, Hurley TG, et al. Designing and developing a literature- derived, population-based dietary inflammatory index. Public Health Nutr 2014, 17, 1689-1696.

30. Byrd DA, Judd SE, Flanders WD, et al. Development and Validation of Novel Dietary and Lifestyle Inflammation Scores. J Nutr 2019, 149(12), 2206-2218

31. Na W, Yu TY, Sohn C. Development of a food-based index of dietary inflammatory potential for Koreans and its relationship with metabolic syndrome. Nutr Res Pract 2019, 13(2), 150-158.

32. Shivappa N, Steck SE, Hurley TG, et al. A population- based dietary inflammatory index predicts levels of C-reactive protein in the Seasonal Variation of Blood Cholesterol Study (SEASONS). Public Health Nutr 2014, 17, 1825-1833.

33. Shivappa N, Hébert JR, Rietzschel ER, et al. Associations between dietary inflammatory index and inflammatory markers in the Asklepios Study. Br J Nutr 2015, 113, 665-671.

34. Varkaneh $\mathrm{KH}$, Fatahi S, Tajik S, et al. Dietary inflammatory index in relation to obesity and body mass index: A meta-analysis. Nutr Food Sci 2018, 48, 702-721.

35. Wu IC, Lin CC, Liu CS, et al. Interrelations Between Mitochondrial DNA Copy Number and Inflammation in Older Adults. J Gerontol A Biol Sci Med Sci 2017, 72(7), 937-944.

36. Wong JY, De Vivo I, Lin X, et al. The relationship between inflammatory biomarkers and telomere length in an occupational prospective cohort study. PLoS One. 2014; 9(1): e87348.

37. Yang $\mathrm{M}$, Jiang $\mathrm{P}$, Jin $\mathrm{C}$, et al. Longer Telomere Length and its Association with Lower Levels of C-Peptide. Front Endocrinol (Lausanne) 2017, 8, 244.

38. Zole E, Ranka R. Mitochondrial DNA copy number and telomere length in peripheral blood mononuclear cells in comparison with whole blood in three different age groups. Arch Gerontol Geriatr 2019, 83, 131-137. 
39. Meng S, Wu S, Liang L, et al. Leukocyte mitochondrial DNA copy number, anthropometric indices, and weight change in US women. Oncotarget 2016, 7(37), 60676-60686.

40. Sheu WH, Wang WC, Wu KD, et al. CRP-level-associated polymorphism rs 1205 within the CRP gene is associated with 2-hour glucose level: The SAPPHIRe study. Sci Rep 2017, 7(1), 7987.

41. Song Z, Song Y, Yin J, et al. Genetic variation in the TNF gene is associated with susceptibility to severe sepsis, but not with mortality. PLoS One 2012, 7(9), e46113.

42. Rana BK, Flatt SW, Health DD, et al. The IL-6 Gene Promoter SNP and Plasma IL-6 in Response to Diet Intervention. Nutrients 2017, 9(6), 552.

43. Joffe YT, Collins M, Goedecke JH. The relationship between dietary fatty acids and inflammatory genes on the obese phenotype and serum lipids. Nutrients 2013, 5(5), 1672-705. 


\section{CHAPTER 2}

\section{Dietary Inflammatory Index Score and Its Association with Body Weight, Blood Pressure, Lipid Profile, and Leptin in Indonesian Adults}

Harry Freitag Luglio Muhammad ${ }^{1,2}$, Marleen A. van Baak², Edwin C. Mariman², Dian Caturini Sulistyoningrum ${ }^{1}$, Emy Huriyati ${ }^{1}$, Yi Yi Lee ${ }^{3}$,

Wan Abdul Manan Wan Muda

${ }^{1}$ Department of Nutrition and Health, Universitas Gadjah Mada, Yogyakarta, Indonesia

${ }^{2}$ NUTRIM School of Translational Nutrition and Metabolism, Department of Human Biology, Maastricht Medical Centre+, Maastricht, The Netherlands

${ }^{3}$ United Nations University, Kuala Lumpur, Malaysia

${ }^{4}$ Kyoto University, Kyoto, Japan

Published in Nutrients 2019, 11, 148; doi:10.3390/nu11010148 


\section{ABSTRACT}

It was previously reported that dietary intake is an important trigger for systemic inflammation and one of the lifestyle factors for the development of cardiovascular diseases. The aim of this study was to evaluate the association between Dietary Inflammatory Index (DII) score and body weight, blood pressure, lipid profile and leptin in an Indonesian population. This was a cross-sectional study conducted in 503 Indonesian adults. The DII score was calculated based on data of 30 nutrients and food components. Anthropometric profile, blood pressure, lipid profile, and leptin were measured. The association of these variables with the DII score was analyzed. The DII score was not associated with body weight, body mass index (BMI), body fat, waist circumference, hip circumference, systolic and diastolic blood pressure, triglycerides, and high-density lipoprotein (HDL) (both unadjusted and after adjustment for covariates). However, plasma leptin concentration was significantly associated with the DII score $(B=0.096, p=0.020)$. Plasma leptin also increased significantly across tertiles of the DII score (ANCOVA, $p=0.031$ ). This positive association between the DII score and plasma leptin concentration suggests a role for the inflammatory properties of the diet in regulating adipose tissue inflammation.

Keywords: dietary inflammatory index; obesity; triglyceride; HDL; leptin 


\section{INTRODUCTION}

Obesity affects millions of adults and children and this state of over-nutrition is responsible for an increasing economic and health burden worldwide $[1,2]$. Adiposity is associated with increased risk for non-communicable diseases (NCDs) such as type 2 diabetes mellitus, dyslipidemia, heart disease, and hypertension [1]. One of the mechanisms which may explain the interaction between obesity and the development of NCDs is systemic and adipose tissue inflammation [3,4]. The excess of adipose tissue induces increments in the production of leptin and pro-inflammatory cytokines as well as immune cell infiltration [4]. In addition, a reduction in antiinflammatory immune cells in adipose tissue of individuals with obesity has been reported $[5,6]$. This combination leads to an inflammatory state in adipose tissue as well as the circulation of individuals with obesity [4].

Inflammation is also influenced by environmental factors (e.g., lifestyle, diet, physical activity) and genetic background [7]. It has been reported previously that the dietary pattern has an important role in affecting circulating inflammatory markers in adults [8]. Recently, a new tool has been developed to assess the inflammatory properties of the diet: the Dietary Inflammatory Index (DII) [9]. In this index, intake of nutrient and non-nutrient components of the diet are calculated and compiled into an index. The score on this index has been shown to be associated with systemic inflammation [10-12]. In the cross-sectional Spanish PREDIMED (Prevención con Dieta Mediterránea) study the DII score was associated with body weight and other anthropometric measures [13]. In the Spanish SUN (Seguimiento Universidad de Navarra) cohort, the DII score was associated with annual weight gain [14]. We have shown that the DII score was associated with weight regain following a weight loss program in Dutch overweight and obese individuals [15].

Inflammation is associated with the development of chronic diseases and is an important link between obesity and cardiovascular diseases $[3,16]$. It was previously suggested that inflammation plays an important role in the disturbance of blood pressure and lipid profile $[3,16,17]$. This notion is supported by several studies in western societies which showed that the inflammatory properties of the diet were associated with early predictors of cardiovascular diseases such as hypertension, and higher plasma triglyceride and lower high-density lipoprotein (HDL) cholesterol concentrations [18-20].

Currently, there is limited evidence on the application of the DII in Asian countries. To our knowledge, there is only one report from a small cross-sectional study conducted in female school teachers in Myanmar, which found no association between the DII score and overweight [21]. Evaluation of the DII in different population settings is important because dietary practices vary amongst cultures and 
might have an impact on the DII value. Additionally, because other factors such as environments, lifestyle, and genetic background are also different among population settings, this might influence the relationship between the DII score and metabolic health. Therefore, the aim of this study was to evaluate the associations between the DII score and body weight, blood pressure, lipid profile, and leptin in an Indonesian population.

\section{MATERIALS AND METHODS}

These analyses are part of an Indonesian cohort study that investigates the effect of lifestyle and genetic variation on metabolic syndrome in adults. It is a secondary cross-sectional analysis of baseline data of this study that was carried out among adult men and women between 19 and 56 years of age, living in the urban area of Yogyakarta, Indonesia. A total of 503 individuals, stratified for sex, were recruited from randomly selected neighborhoods from five sub-districts which were selected

The inclusion criteria were: permanent residence (at least 2 years) in the area and agreement to become subject of this study by signing the informed consent. The exclusion criteria were: diagnosis of chronic diseases such as diabetes, cardiovascular disease, or cancer, pregnancy at the time the study was conducted, current or prior cigarette smoker status, strict diet, and problems with walking or conducting physical activity in the prior 6 months. Subjects who consumed drugs to treat the clinical features of cardiovascular diseases (such as blood pressure-, lipid-, and/or glucose-lowering drugs) were also excluded from this study. Ethical clearance was obtained from the Medical and Health Research Ethics Committee (MHREC) Faculty of Medicine, Universitas Gadjah Mada, Indonesia (KE/FK/791/EC/2015). This study followed the ethical guidelines of the 1975 Declaration of Helsinki.

Obesity status was defined by body mass index (BMI) and calculated by dividing body weight with the square of height. Body composition was defined by percent body fat. Body weight and body fat were measured using a digital body mass scale and bioelectrical impedance (0.01 kg precision, Omron Karada Scan HBF-375, Osaka, Japan). Height was measured using a wall-mounted tape measure $(0.1 \mathrm{~cm}$ precision, GEA medical, Jakarta, Indonesia). Waist and hip circumference were measured using a non-elastic tape $(0.1 \mathrm{~cm}$ precision). All anthropometric measurements were done by trained personnel using calibrated instruments.

Blood pressure was measured using Omron HEM 7120 Automatic Blood Pressure (Omron, Japan). This measurement was done after at least 10 minutes rest from recent activity and the participants were asked to sit in a comfortable sitting position with their left arm fully exposed and resting on a supportive surface at the heart level. Blood pressures were measured on the left arm using appropriate cuff size. 
Data on dietary intake were collected using a validated Semi-Quantitative Food Frequency Questionnaire (SQ-FFQ) and the analysis was based on Indonesian food database and United States Department of Agriculture [22]. Data of habitual consumption of food items that were collected using the SQ-FFQ were translated into daily intake [23]. Data collection for dietary intake was done by a face-to-face interview between trained nutritionists and subjects.

The Dietary inflammatory Index $\left(D I^{\circledR}\right)$ score is a calculated parameter that gives an overall picture of the inflammatory properties of the diet. An individual's diet is considered more pro-inflammatory when the DII score is more positive, while the diet is considered more anti-inflammatory when the DII score is more negative. The DII score was calculated according to Shivappa et al. [9]. The calculation of the dietary inflammatory index score was based on 30 nutrients and food components including total energy, protein, carbohydrate, total fat, saturated fat, trans fat, monounsaturated fatty acid (MUFA), poly-unsaturated fatty acid (PUFA), omega-3 fatty acid, omega- 6 fatty acid, cholesterol, fibre, magnesium, iron, selenium, zinc, vitamin $A$, vitamin $C$, vitamin D, vitamin E, thiamin, riboflavin, vitamin B6, vitamin B12, folate, niacin, beta-carotene, alcohol, caffeine, and tea. No data were available for the other dietary factors included by Shivappa et al. [9] in their dietary inflammation index such as rosemary, oregano, pepper, turmeric, saffron, onion, ginger, garlic, and polyphenols (i.e., isoflavones and anthocyanidins). To derive the individual DII scores, the global average intake (taken from Shivappa et al. [9]) was subtracted from the reported daily intake of each nutrient in the FFQ and divided by the standard deviation of the global daily intake, rendering a z-score which was converted into a centered percentile score. This score was then multiplied with an overall inflammatory effect score. All 30 (out of 48 ) included individually calculated nutrient-specific effect scores were then summed to obtain the DII score.

Data on physical activity was collected using the International Physical Activity Questionnaire (IPAQ) [24]. This questionnaire contains information on the intensity and duration of several activities including work/job, transportation, house-related work and maintenance, recreation, exercise and leisure-time physical activity. Each activity has a unique metabolic equivalent of task (MET) score, which represents the amount of energy used for a certain type of activity. In order to obtain an overall picture of the individual's physical activity, all the activities that have been reported in IPAQ are transformed into MET-minutes/week. The SQ-FFQ and IPAQ were developed, validated and used before [23-25].

From each participant a $10-\mathrm{mL}$ blood sample was collected in ethylenediaminetetraacetic acid (EDTA)-containing tubes. After collection, blood plasma and buffy coat were separated by centrifugation. Plasma HDL cholesterol 
and triglyceride concentration were measured using the cholesterol oxidase phenol 4-aminoantipyrine peroxidase (CHOD-PAP) and glycerol phosphate oxidase (GPO) methods, respectively (Diasys, Holzheim, Germany). Plasma leptin concentration was measured using an enzyme-linked immunosorbent assay (DRG, Springfield Township, NJ, USA).

Statistical analyses were conducted using JASP (University of Amsterdam, the Netherlands) [26]. The relationships between the DII score as independent variable and body weight, blood pressure, lipid profile and leptin concentration as dependent variables were analyzed by linear regression analysis (Model 0 , unadjusted). Adjustments for age, sex, physical activity and energy intake, and BMI where relevant, were done. Model I represents a regression analysis with adjustment for age, sex, and BMI (for blood pressure, triglycerides, HDL and leptin). Model II represents a regression analysis with adjustment for age, sex, energy intake, physical activity and BMI (for blood pressure, triglycerides, HDL and leptin). In addition, we made groups based on tertiles of the DII score and compared the variables by ANOVA (analysis of variance) or ANCOVA (Analysis of covariance). The ANCOVA analysis adjusted for age, sex, energy intake, and physical activity when analyzing differences in anthropometric measures among DII score tertiles. For analysis of blood pressure, lipid profile, and leptin differences between DII score tertiles, ANCOVA adjusting for age, sex, body mass index, energy intake, and physical activity was used.

\section{RESULTS}

Characteristics of study participants are shown in Table 2.1. In this study, 503 adults (men 50.1\% and women 49.9\%) living in Yogyakarta were investigated. Data on the characteristics of men and women separately can be found in Supplementary Table 2.1. Data of dietary intake of study participants are shown and compared with global data of dietary intake based on Shivappa et al. [9] (Table 2.2). Compared to global averages, participants in this study had a relatively high intake of pro-inflammatory components such as total energy, carbohydrate, iron, and vitamin B12. They had a relatively low intake of anti-inflammatory components such as omega 3 fatty acid, omega 6 fatty acid, niacin, vitamin A, vitamin D, vitamin E, alcohol, and caffeine, but a relatively high intake of other anti-inflammatory components such as fiber, magnesium, selenium, vitamin $\mathrm{C}$, folic acid, and tea. 
Table 2.1. Characteristics of study participants.

\begin{tabular}{|c|c|}
\hline & All $(n=503)$ \\
\hline Age (years) & $41.6 \pm 10.2$ \\
\hline \multicolumn{2}{|l|}{ Anthropometric measures } \\
\hline Body weight $(\mathrm{kg})$ & $62.6 \pm 13.1$ \\
\hline Height (cm) & $158.5 \pm 9.0$ \\
\hline Body mass index $\left(\mathrm{kg} / \mathrm{m}^{2}\right)$ & $24.9 \pm 5.0$ \\
\hline Body fat (\%) & $27.5 \pm 8.7$ \\
\hline Waist circumference $(\mathrm{cm})$ & $86.2 \pm 12.7$ \\
\hline Hip circumference $(\mathrm{cm})$ & $93.9 \pm 11.2$ \\
\hline \multicolumn{2}{|l|}{ Blood pressure } \\
\hline Systolic $(\mathrm{mmHg})$ & $128.6 \pm 25.2$ \\
\hline Diastolic (mmHg) & $79.7 \pm 14.8$ \\
\hline \multicolumn{2}{|l|}{ Metabolic profile } \\
\hline Triglycerides (mmol/L) & $1.57 \pm 0.82$ \\
\hline $\mathrm{HDL}(\mathrm{mmol} / \mathrm{L})$ & $1.18 \pm 0.47$ \\
\hline TG/HDL ratio & $1.48 \pm 1.02$ \\
\hline Leptin $(\mathrm{ng} / \mathrm{mL})$ & $7.3 \pm 8.8$ \\
\hline Physical activity (METS-min./week) & $5781 \pm 5932$ \\
\hline \multicolumn{2}{|l|}{ Dietary intake } \\
\hline Energy (kj/day) & $10838 \pm 4789$ \\
\hline Protein (\%) & $12.5 \pm 3.4$ \\
\hline Fat (\%) & $23.1 \pm 10.6$ \\
\hline Carbohydrate (\%) & $64.3 \pm 10.8$ \\
\hline Dietary inflammatory index & $1.01 \pm 7.29$ \\
\hline$\%$ overweight ${ }^{a}$ & 45.9 \\
\hline$\%$ obese $^{b}$ & 14.9 \\
\hline
\end{tabular}

Values are presented as mean \pm standard deviation, $p$. value of difference between men and women (2-sample t-test), abody mass index $\geq 25$ $\mathrm{kg} / \mathrm{m}^{2}$ or higher, ${ }^{b}$ body mass index $\geq 30 \mathrm{~kg} / \mathrm{m}^{2}$ or higher, ${ }^{\mathrm{a}, \mathrm{b}}$ percent in comparison to total study participants, * independent t-test, ^Mannwithney test, "Chi-square test. 
Table 2.2. Comparison of global dietary intake and dietary intake of Indonesian adults.

\begin{tabular}{|c|c|c|}
\hline & Global dietary intake & $\begin{array}{c}\text { Dietary intake of study } \\
\text { participants }\end{array}$ \\
\hline \multicolumn{3}{|c|}{ Pro-inflammatory components } \\
\hline Carbohydrate (g) & $272.2 \pm 40.0$ & $416.9 \pm 202.8$ \\
\hline Cholesterol (mg) & $279.4 \pm 51.2$ & $177.8 \pm 161.8$ \\
\hline Energy (kj) & $8606 \pm 1414$ & $10838 \pm 4789$ \\
\hline Iron (mg) & $13.35 \pm 3.71$ & $18.1 \pm 9.8$ \\
\hline Protein (g) & $79.4 \pm 13.9$ & $80.8 \pm 41.9$ \\
\hline Saturated fat (g) & $28.6 \pm 8.0$ & $25.7 \pm 19.6$ \\
\hline Total fat (g) & $71.4 \pm 19.4$ & $66.6 \pm 45.9$ \\
\hline Trans fatty acid (g) & $3.15 \pm 3.75$ & $2.82 \pm 4.72$ \\
\hline Vitamin $B_{12}(\mu \mathrm{g})$ & $5.15 \pm 2.70$ & $7.38 \pm 9.54$ \\
\hline \multicolumn{3}{|c|}{ Anti-inflammatory components } \\
\hline Alcohol (g) & $19.98 \pm 3.72$ & $0.03 \pm 0.07$ \\
\hline Beta - carotene $(\mu \mathrm{g})$ & $3718 \pm 1720$ & $3696 \pm 3721$ \\
\hline Caffeine (g) & $8.05 \pm 6.67$ & $0.09 \pm 0.10$ \\
\hline Fiber (g) & $18.8 \pm 4.0$ & $24.3 \pm 13.5$ \\
\hline Folic acid $(\mu \mathrm{g})$ & $273.0 \pm 70.7$ & $403.0 \pm 339.4$ \\
\hline Magnesium (mg) & $310.1 \pm 139.4$ & $392.1 \pm 278.2$ \\
\hline MUFA (g) & $27.0 \pm 6.1$ & $29.5 \pm 23.1$ \\
\hline Niacin (mg) & $25.9 \pm 11.8$ & $19.57 \pm 9.14$ \\
\hline Omega 3 fatty acids (g) & $1.06 \pm 1.06$ & $0.46 \pm 0.47$ \\
\hline Omega 6 fatty acids (g) & $10.80 \pm 7.50$ & $0.86 \pm 0.80$ \\
\hline PUFA (g) & $13.88 \pm 3.76$ & $13.40 \pm 9.64$ \\
\hline Riboflavin (mg) & $1.70 \pm 0.79$ & $1.97 \pm 1.72$ \\
\hline Selenium $(\mu \mathrm{g})$ & $67.0 \pm 25.1$ & $103.0 \pm 49.6$ \\
\hline Black/green tea (g) & $1.69 \pm 1.53$ & $2.36 \pm 2.60$ \\
\hline Thiamin (mg) & $1.70 \pm 0.66$ & $1.39 \pm 0.71$ \\
\hline Vitamin A (RE) & $983.9 \pm 518.6$ & $574.3 \pm 508.0$ \\
\hline Vitamin $B_{6}(m g)$ & $1.47 \pm 0.74$ & $4.59 \pm 3.71$ \\
\hline Vitamin C (mg) & $118.2 \pm 43.5$ & $152.3 \pm 145.5$ \\
\hline Vitamin D $(\mu \mathrm{g})$ & $6.26 \pm 2.21$ & $3.44 \pm 5.88$ \\
\hline Vitamin E (mg) & $8.73 \pm 1.49$ & $2.74 \pm 2.65$ \\
\hline Zinc (mg) & $9.84 \pm 2.19$ & $9.59 \pm 4.75$ \\
\hline
\end{tabular}

Data on the relationship between the DII score and anthropometric measures are shown in Table 2.3. We found that the DII score was not associated with any of the anthropometric measures (all $p>0$.05). This remained after adjustment for age, sex, physical activity and energy intake (Table 2.3). The DII score was also not associated with systolic and diastolic blood pressure, triglycerides and HDL cholesterol 
(all $\mathrm{p}>0.05$ ). These associations also remained non-significant after adjustment for covariates (Table 2.3). However, after correction for age, sex, BMI, energy intake, and physical activity we found that the DII score was positively associated with plasma leptin concentration (Table 2.3). The sex specific analyses of the relationship between the DII score and all measured parameters are shown in Supplementary Table 2.2. There were no sex-related differences in the relationships between the DII score and any of the measured parameters.

Table 2.3. Standardized regression coefficients (B) and their standard error (SE) and $p$-value of the association between DII score and anthropometric variables, blood pressure, lipid profile, and leptin concentration.

\begin{tabular}{|c|c|c|c|c|c|c|c|c|c|}
\hline \multirow{2}{*}{ Variables } & \multicolumn{4}{|c|}{ Model $0^{\mathrm{a}}$} & \multicolumn{2}{|c|}{ Model I ${ }^{\mathrm{b}}$} & \multicolumn{3}{|c|}{ Model II ${ }^{c}$} \\
\hline & $\mathbf{B}^{\mathbf{a}}$ & SE ${ }^{a}$ & $p^{a}$ & $\mathbf{B}^{\mathbf{b}}$ & $\mathrm{SE}^{\mathrm{b}}$ & $p^{b}$ & $B^{c}$ & SE ${ }^{\mathrm{c}}$ & $p^{c}$ \\
\hline Body weight $(\mathrm{kg})$ & -0.010 & 0.081 & 0.900 & -0.011 & 0.078 & 0.801 & -0.039 & 0.096 & $0.470 \wedge$ \\
\hline BMI $\left(\mathrm{kg} / \mathrm{m}^{2}\right)$ & -0.012 & 0.031 & 0.693 & -0.020 & 0.030 & 0.648 & -0.080 & 0.036 & $0.132 \wedge$ \\
\hline Body fat (\%) & -0.018 & 0.054 & 0.736 & -0.009 & 0.035 & 0.762 & -0.044 & 0.043 & $0.222 \wedge$ \\
\hline Waist circumference $(\mathrm{cm})$ & -0.079 & 0.078 & 0.311 & -0.048 & 0.074 & 0.251 & -0.046 & 0.091 & $0.379 \wedge$ \\
\hline Hip circumference (cm) & 0.012 & 0.069 & 0.857 & 0.006 & 0.064 & 0.878 & -0.049 & 0.079 & $0.347^{\wedge}$ \\
\hline Systolic BP (mmHg) & 0.221 & 0.154 & 0.153 & 0.066 & 0.134 & 0.088 & 0.034 & 0.165 & $0.481 *$ \\
\hline Diastolic BP (mmHg) & 0.128 & 0.091 & 0.159 & 0.065 & 0.082 & 0.107 & 0.046 & 0.102 & $0.355 *$ \\
\hline Triglycerides (mmol/L) & -0.004 & 0.005 & 0.407 & -0.037 & 0.005 & 0.388 & 0.045 & 0.006 & $0.406 *$ \\
\hline $\mathrm{HDL}$ cholesterol (mmol/L) & 0.0003 & 0.003 & 0.925 & 0.010 & 0.003 & 0.825 & -0.046 & 0.004 & $0.400 *$ \\
\hline Leptin ( $\mathrm{ng} / \mathrm{mL}$ ) & 0.101 & 0.061 & 0.102 & 0.105 & 0.042 & 0.002 & 0.096 & 0.052 & $0.020 *$ \\
\hline
\end{tabular}

${ }^{\mathrm{a}}$ Model 0, linear regression analysis without adjustment; ${ }^{\mathrm{b}}$ Model I, linear regression analysis with adjustment for age and sex; ${ }^{\mathrm{b}}$ Model II, linear regression analysis with correction for age, sex, energy intake, physical.

To further clarify the association between DII score, anthropometric measures, blood pressure, lipid profile and leptin, we divided subjects into three tertiles based on their DII score (Table 2.4). No significant differences among the 3 tertiles (ANOVA, all $p>0.05$ ) were found. However, after adjustment for age, sex, energy intake, physical activity and body mass index, the increase in leptin concentration across DII score tertiles was statistically significant (ANCOVA, $p=0.031$ ). 
Table 2.4. The differences on anthropometric measures, lipid profile, blood pressure and leptin among DII score tertiles.

\begin{tabular}{|c|c|c|c|c|c|}
\hline Variables & $\begin{array}{l}\text { DII Score Tertile } 1 \\
(<-1.0)(n=169)\end{array}$ & $\begin{array}{l}\text { DII Score Tertile } \\
2(1.0-5.1)(n= \\
168)\end{array}$ & $\begin{array}{l}\text { DII Score Tertile } 3 \\
(>5.1)(n=164)\end{array}$ & $\boldsymbol{p}_{\text {ANOVA }} *$ & $\boldsymbol{p}_{\text {ANCOVA }}$ \\
\hline \multicolumn{6}{|l|}{ Anthropometric measures } \\
\hline Body weight (kg) & $61.9 \pm 13.9$ & $63.5 \pm 11.0$ & $62.3 \pm 14.2$ & 0.538 & $0.840 \wedge$ \\
\hline Body mass index $\left(\mathrm{kg} / \mathrm{m}^{2}\right)$ & $24.7 \pm 4.8$ & $25.3 \pm 4.7$ & $24.9 \pm 5.5$ & 0.523 & $0.470 \wedge$ \\
\hline Body fat (\%) & $27.4 \pm 8.6$ & $27.5 \pm 8.7$ & $27.7 \pm 9.0$ & 0.937 & $0.543 \wedge$ \\
\hline Waist circumference (cm) & $86.2 \pm 12.7$ & $87.1 \pm 12.4$ & $85.4 \pm 13.2$ & 0.467 & $0.395 \wedge$ \\
\hline Hip circumference (cm) & $93.1 \pm 10.3$ & $95.0 \pm 10.7$ & $93.7 \pm 12.5$ & 0.301 & $0.209 \wedge$ \\
\hline Systolic blood pressure $(\mathrm{mmHg})$ & $126.9 \pm 25.2$ & $129.3 \pm 24.5$ & $129.5 \pm 25.9$ & 0.590 & $0.847^{\#}$ \\
\hline Diastolic blood pressure $(\mathrm{mmHg})$ & $79.1 \pm 14.3$ & $80.2 \pm 14.4$ & $79.9 \pm 15.8$ & 0.773 & $0.790 \#$ \\
\hline Triglycerides (mmol/L) & $1.6 \pm 0.9$ & $1.6 \pm 0.8$ & $1.5 \pm 0.8$ & 0.479 & $0.413^{\#}$ \\
\hline HDL cholesterol (mmol/L) & $1.2 \pm 0.5$ & $1.1 \pm 0.4$ & $1.2 \pm 0.5$ & 0.378 & $0.572^{\#}$ \\
\hline Leptin (ng/mL) & $6.2 \pm 6.9$ & $7.1 \pm 8.5$ & $8.6 \pm 10.7$ & 0.071 & $0.031^{\#}$ \\
\hline
\end{tabular}

* ANOVA analysis across DII score tertiles; ^ ANCOVA analysis across DIl score tertiles with adjustment for age, sex, energy intake and physical activity; ${ }^{*}$ ANCOVA analysis across DIl score tertiles with adjustment for age, sex, body mass index, energy intake, and physical activity.

\section{DISCUSSION}

This study was aimed to evaluate the relationship between DII score, body weight, blood pressure, lipid profile and leptin in Indonesian adults. We found that DII score was not correlated with any of the anthropometric measures, blood pressure or lipid profile. Interestingly, we showed that the DII was positively correlated with plasma leptin concentration after correction for age, sex and BMI, energy intake and physical activity.

We compared the intake of the components of the DII in our Indonesian population with the global averages described by Shivappa [9]. Participants in this study had higher intake of pro-inflammatory components such as total energy, carbohydrates, iron and vitamin B12 and a lower intake of anti-inflammatory components such as omega 3 fatty acids, omega 6 fatty acids, niacin, vitamin A, vitamin $D$, and vitamin $E$. The mean energy intake of men was $11,285 \mathrm{~kJ} /$ day and this matches the Indonesian dietary recommendation for male adults $(11,406 \mathrm{~kJ} /$ day) [27]. The mean energy intake of women was $10,277 \mathrm{~kJ} /$ day and this was slightly 
higher than the Indonesian dietary recommendation for female adults ( $9418 \mathrm{~kJ} /$ day) [27]. Results from this study provide a practical implication that can help reduce the inflammatory properties of diet of individuals in the study population. This can be done by reducing the consumption of carbohydrate rich foods (e.g., rice, sugar and wheat-based products) and increasing consumption of unsaturated fat and protein rich foods (such as eggs and fatty fish). This is because, although protein is considered as pro-inflammatory nutrient, it has a lower inflammatory effect score than carbohydrate [9]. Additionally, unsaturated fats are anti-inflammatory nutrients and foods that are rich in unsaturated fats usually also contain fat soluble vitamins such as vitamin A, D, and E [22]. Those vitamins were reported to be lower in these study participants compared to the global dietary intake.

This study was initiated by our earlier finding that in overweight/obese Caucasian men and women who undertook a weight loss program, the DII score was correlated with weight regain during follow-up [15]. In this study we showed that the DII score was not correlated with body weight in Indonesian adult men and women. The relationship between the DII score and obesity indices has also been evaluated elsewhere. In a cross-sectional analysis of the Spanish PREDIMED trial, the DII score was associated with BMI only in women but not in men [13]. In Myanmar, a small cross-sectional study among overweight and non-overweight female school teachers showed that the DII score was not associated with overweight [21]. A role for DII in the development of obesity was indicated by Ramallal et al. [14]. They showed that in a non-overweight adult Spanish cohort the DII score was not associated with $\mathrm{BMI}$ at baseline, but a higher DII score was associated with a higher body weight increment after 8 years of follow up and a higher risk of developing overweight or obesity. Based on these studies and our findings, the effect of the DII on body weight remains inconclusive. Well-controlled longer-term intervention studies are required to shed more light on the role of DII in body weight regulation.

There is more convincing evidence that inflammation is an important link between obesity and its cardiovascular co-morbidities [3-6]. Previously it was suggested that low-grade inflammation was associated with the development of dyslipidemia [3]. In this study, we found that the DII score was not correlated with components of the lipid profile, such as triglycerides and HDL. In contrast, Neufcourt et al. showed in a large $(n=3726)$ cohort of French adults [18] that at baseline, the DII score was positively associated with triglyceride level, but not with HDL cholesterol level. After a follow up of 13 years, the DII score was significantly associated with higher triglyceride and lower HDL cholesterol levels. The association between the DII score and lipid profile was also confirmed by a small scale study $(n=90)$ in Colombia [19]. These investigators showed that study participants with a 
higher pro-inflammatory diet (based on DII score calculation) had a significantly lower HDL level. Our intermediate size study in Indonesian adults could not confirm these findings. On the other hand, there was also no increased risk for low HDL cholesterol or elevated triglyceride concentrations with increasing DII score in a study in 447 U.S. police officers [28]. Dyslipidemia or disturbance of lipid profile including triglyceride and cholesterol levels have long been used as an early biomarker of cardiovascular diseases. However, this concept is now being challenged. Inflammation may be a more important biomarker of cardiovascular diseases [16]. This shift of paradigm is necessary because this might affect dietary approaches for cardiovascular diseases prevention. Instead of aiming to lower cholesterol and triglycerides, it might be more beneficial to lower the inflammatory properties of the diet as a means of prevention of cardiovascular diseases.

In this study we also showed that the DII score was not associated with blood pressure, neither in men nor women. This finding differs from studies previously reporting that the DII score was associated with increased risk for developing hypertension among middle-aged Australian women [20] and Polish adults [29]. On the other hand, Wirth et al. [28] also found no higher risk of elevated blood pressure with increasing DII score in U.S. police officers.

We cannot exclude the possibility that the lack of association between the DII score and lipid profile and blood pressure is due to our inclusion criteria. We only included subjects without a clinical diagnosis cardiovascular diseases, diabetes, or treatment for dyslipidemia or high blood pressure, because we were interested in investigating the role of diet in the early onset development of chronic diseases and thus our population can be regarded as relatively healthy compared to the general Indonesian population.

In this study, we showed that the DII score was positively associated with plasma leptin concentration after adjustment for age, sex, BMI, energy intake, and physical activity. This finding was confirmed by analysis based on DII score tertiles, which showed that leptin concentration increased significantly across the tertiles. Leptin is produced by adipose tissue and its production increases with the progression of adiposity [30]. In the past few decades, there has been a growing interest in understanding the interaction between leptin, inflammation and oxidative stress. Leptin is a cytokine which is produced by adipocytes with an ability to induce inflammation. The pro-inflammatory properties of leptin have been suggested to be similar to those of immune cell-derived cytokines such as tumor necrosis factor alpha (TNF-alpha) and interleukin 6 (IL-6) [31,32]. In addition to inflammation, it was suggested that leptin plays an important role in the development of oxidative stress in obesity by inducing production of reactive intermediates such as $\mathrm{H} 2 \mathrm{O} 2$ and hydroxyl radicals [33]. The accumulation of these processes can induce development 
of cardiovascular diseases. This is supported by several studies, which showed that a higher leptin concentration was associated with increased risk for cardiovascular diseases [34-36]. To our knowledge, only one other study has investigated the relationship between DII score and leptin [28]. In this cross-sectional study in U.S. police officers, the DII score was not associated with leptin concentration.

There are several strengths and limitations in this study. The strengths of this study are the relatively large sample size and the non-Western population. However, there are several limitations to this study. First, because data collection was done using a SQ FFQ for Indonesian food consumption with limited data on bioactive components of foods, we cannot provide data on the intake of a number of herbs/ seasonings (such as oregano, rosemary, pepper, saffron, garlic, onion, and ginger) as well as polyphenols (such as flavonol, anthocyanidins, and eugenol), which are included in the original list provided by Shivappa et al. [9]. Additionally, there are some food components that have no known value for different types of PUFAs in the food databases used, which might have an impact on total omega 3 and 6 consumption. These might influence the relationships between DII score and outcomes in comparison to the full DII according to Shivappa et al. Second, we reported data on dietary intake amongst individuals who live in urban areas. Therefore, data from this study may not represent the intake of those that live in rural areas. Third, because of the design of this study, no conclusion about causality can be drawn. Fourth, measurements were performed at random times during the day and in the non-fasting state, which may have interfered with the potential association between the DII score and the outcome variables by increasing the variation. However, it was previously shown that in large cohorts the influence of normal food intake on changes in lipids, lipoproteins, and apolipoproteins is small and that the random nonfasting lipid profile remains a good predictor for cardiovascular diseases in humans [37]. However, leptin production has a diurnal variation [38] and is affected by fasting status [39], and therefore confirmation of our findings under better standardized conditions is needed.

In summary, we showed that the DII score was positively correlated with the plasma leptin concentration, which is one of the markers of adipose tissue inflammation. This might explain the connection between the DII score and increased systemic inflammation as well as cardiovascular diseases in other studies. Because of the potential importance of diet in the development of inflammation, intervention studies that investigate the effect of manipulation of the inflammatory properties of the diet on the inflammatory process are warranted. 


\section{Author contributions}

Conceptualization, H.F.L.M., D.C.S., E.H., Y.Y.L., and W.A.M.W.M.; Methodology, H.F.L.M., D.C.S., E.H., Y.Y.L., and W.A.M.W.M.; Software, H.F.L.M.; Validation, H.F.L.M., D.C.S., and E.H.; Formal Analysis, H.F.L.M., M.A.v.B., and E.C.M.; Investigation, H.F.L.M., D.C.S., E.H., Y.Y.L., and W.A.M.W.M.; Resources, H.F.L.M. and W.A.M.W.M.; Data Curation, H.F.L.M., M.A.v.B., and E.C.M.; Writing-Original Draft Preparation, H.F.L.M., M.A.v.B., and E.C.M.; Writing-Review and Editing, H.F.L.M., M.A.v.B., and E.C.M.; Visualization, H.F.L.M., M.A.v.B., and E.C.M.; Supervision, W.A.M.W.M.; Project Administration, H.F.L.M., and Y.Y.L.; Funding Acquisition, H.F.L.M., and W.A.M.W.M.

\section{Funding}

This study was funded by International Research Collaboration (IRec) Grant (IREC Grant No.: 1002/PPSK/ 910408) (Universiti Sains Malaysia) and Community FundFaculty of Medicine (Universitas Gadjah Mada).

\section{Acknowledgments}

We thank to Cita Eri Ayuningtyas, Satwika Arya Pratama and Maya Nurfitriani Hartono for their support with data collection.

\section{Conflicts of Interest}

The authors declare no conflict of interest.

\section{REFERENCES}

1. GBD 2015 Obesity Collaborators. Health Effects of Overweight and Obesity in 195 Countries over 25 Years. N Engl J Med 2017, 377, 13-27.

2. Tremmel M, Gerdtham UG, Nilsson PM, et al. Economic Burden of Obesity: A Systematic Literature Review. Int J Environ Res Public Health 2017, 14.

3. Monteiro R, Azevedo, I. Chronic inflammation in obesity and the metabolic syndrome. Mediators Inflamm 2010, 2010.

4. Han JM, Levings MK. Immune regulation in obesity-associated adipose inflammation. J Immunol 2013, 191, 527-532.

5. Lumeng CN, Bodzin JL, Saltiel AR. Obesity induces a phenotypic switch in adipose tissue macrophage polarization. J Clin Investig 2007, 117, 175-184.

6. Morris DL, Singer K, Lumeng CN. Adipose tissue macrophages: Phenotypic plasticity and diversity in lean and obese states. Curr Opin Clin Nutr Metab Care 2011, 14, 341-346.

7. Pankow JS, Folsom AR, Cushman M, et al. Familial and genetic determinants of systemic markers of inflammation: The NHLBI family heart study. Atherosclerosis 2001, 154, 681689. 
8. Cavicchia PP, Steck SE, Hurley TG, et al. A New Dietary Inflammatory Index Predicts Interval Changes in Serum High-Sensitivity C-Reactive Protein. J Nutr 2009, 139, 2365-2372.

9. Shivappa N, Steck SE, Hurley TG, et al. Designing and developing a literature- derived, population-based dietary inflammatory index. Public Health Nutr 2014, 17, 1689-1696.

10. Shivappa N, Steck SE, Hurley TG, et al. A population- based dietary inflammatory index predicts levels of C-reactive protein in the Seasonal Variation of Blood Cholesterol Study (SEASONS). Public Health Nutr 2014, 17, 1825-1833.

11. Shivappa N, Hébert JR, Rietzschel ER, et al. Associations between dietary inflammatory index and inflammatory markers in the Asklepios Study. Br J Nutr 2015, 113, 665-671.

12. Tabung FK, Smith-Warner SA, Chavarro JE, et al. An Empirical Dietary Inflammatory Pattern Score Enhances Prediction of Circulating Inflammatory Biomarkers in Adults. $J$ Nutr 2017, 147, 1567-1577.

13. Ruiz-Canela M, Zazpe I, Shivappa N, et al. Dietary inflammatory index and anthropometric measures of obesity in a population sample at high cardiovascular risk from the PREDIMED (PREvención con Dleta MEDiterránea) trial. Br J Nutr 2015, 113, 984-995.

14. Ramallal R, Toledo E, Martínez JA, et al. Inflammatory potential of diet, weight gain, and incidence of overweight/obesity: The SUN cohort. Obesity (Silver Spring) 2017, 25, 9971005.

15. Muhammad HFL, Vink RG, Roumans NJT, et al. Dietary Intake after Weight Loss and the Risk of Weight Regain: Macronutrient Composition and Inflammatory Properties of the Diet. Nutrients 2017, 9(11), 1205.

16. Tsoupras A, Lordan R, Zabetakis I. Inflammation, not Cholesterol, Is a Cause of Chronic Disease. Nutrients 2018, 10(5), 604.

17. Savoia C, Schiffrin EL. Vascular inflammation in hypertension and diabetes: Molecular mechanisms and therapeutic interventions. Clin Sci (Lond) 2007, 112, 375-384.

18. Neufcourt L, Assmann KE, Fezeu LK, et al. Prospective association between the dietary inflammatory index and metabolic syndrome: Findings from the SU.VI.MAX study. Nutr Metab Cardiovasc Dis 2015, 25, 988-996.

19. Camargo-Ramos CM, Correa-Bautista JE, Correa-Rodríguez M, et al. Dietary Inflammatory Index and Cardiometabolic Risk Parameters in Overweight and Sedentary Subjects. Int J Environ Res Public Health 2017, 14.

20. Vissers LET, Waller M, van der Schouw YT, et al. A pro-inflammatory diet is associated with increased risk of developing hypertension among middle-aged women. Nutr Metab Cardiovasc Dis 2017, 27, 564-570.

21. San KMM, Fahmida U, Wijaksono F, et al. Chronic low grade inflammation measured by dietary inflammatory index and its association with obesity among school teachers in Yangon, Myanmar. Asia Pac J Clin Nutr 2018, 27, 92-98.

22. United States Department of Agriculture. Available online: https://ndb.nal.usda.gov/ ndb/search/list (accessed on 3 January 2018). 
23. Steinemann N, Grize L, Ziesemer K, et al. Relative validation of a food frequency questionnaire to estimate food intake in an adult population. Food Nutr Res 2017, 61(1), 1305193.

24. Wanner M, Probst-Hensch N, Kriemler S, et al. Validation of the long international physical activity questionnaire: Influence of age and language region. Prev Med Rep 2016, 3, 250-256.

25. Luglio HF, Eurike D, Huriyati E, et al. Gene-lifestyle interaction: The role of SNPs in UCP2 -866G/A and UCP3 -55C/T on dietary intake and physical activity in Indonesian obese female adolescents. Med J Nutr Metab 2016, 9, 87-93.

26. University of Amsterdam: JASP 0.9.0.1. Available online: https://jasp-stats.org (accessed on 15 August 2018).

27. IndonesianMinistryofHealth.AngkaKecukupanGizi.2013.Availableonline:http://gizi.depkes.go.id/ download/Kebijakan\%20Gizi/PMK\%2075-2013.pdf (accessed on 29 April 2018).

28. Wirth MD, Burch J, Shivappa $\mathrm{N}$ et al. Association of a dietary inflammatory index with inflammatory indices and metabolic syndrome among police officers. J Occup Environ Med 2014, 56, 986-989.

29. Sokol A, Wirth MD, Manczuk M, et al. Association between the dietary inflammatory index, waist-to-hip ratio and metabolic syndrome. Nutr Res 2016, 36, 1298-1303.

30. Considine RV, Sinha MK, Heiman ML, et al. Serum immunoreactive-leptin concentrations in normal-weight and obese humans. N Engl J Med 1996, 334, 292-295.

31. likuni N, Lam QL, Lu L, et al. Leptin and Inflammation. Curr Immunol Rev 2008, 4, 70-79.

32. Wellen KE, Hotamisligil GS. Inflammation, stress, and diabetes. J Clin Investig 2005, 115, 1111-1119.

33. Fortuño A, Bidegain J, Baltanás $A$, et al. Is leptin involved in phagocytic NADPH oxidase overactivity in obesity? Potential clinical implications. J Hypertens 2010, 28, 1944-1950.

34. Hou N, Luo JD. Leptin and cardiovascular diseases. Clin Exp Pharmacol Physiol 2011, 38, 905-913.

35. Reilly MP, Iqbal $N$, Schutta $M$, et al. Plasma leptin levels are associated with coronary atherosclerosis in type 2 diabetes. J Clin Endocrinol Metab 2004, 89, 3872-3878.

36. Wallerstedt SM, Eriksson AL, Niklason A, et al. Serum leptin and myocardial infarction in hypertension. Blood Press 2004, 13, 243-246.

37. Langsted A, Freiberg JJ, Nordestgaard BG. Fasting and nonfasting lipid levels: Influence of normal food intake on lipids, lipoproteins, apolipoproteins, and cardiovascular risk prediction. Circulation 2008, 118, 2047-2056.

38. Langendonk JG, Pijl H, Toornvliet AC, et al. Circadian Rhythm of Plasma Leptin Levels in Upper and Lower Body Obese Women: Influence of Body Fat Distribution and Weight Loss. J Clin Endocrinol Metab 1998, 83, 1706-1712.

39. Korek E, Krauss $\mathrm{H}$, Gibas-Dorna $\mathrm{M}$, et al. Fasting and postprandial levels of ghrelin, leptin and insulin in lean, obese and anorexic subjects. Prz Gastroenterol 2013, 8, 383-389. 
Supplementary Table 2.1. The comparison of anthropometric measures, blood pressure, lipid profile, dietary intake, physical activity and leptin between men and women.

\begin{tabular}{|c|c|c|c|}
\hline & Men $(n=252)$ & Women $(n=251)$ & $\mathrm{p}$ \\
\hline Age (years) & $41.1 \pm 10.8$ & $42.1 \pm 9.6$ & $0.500^{\wedge}$ \\
\hline \multicolumn{4}{|l|}{ Anthropometric measures } \\
\hline Body weight $(\mathrm{kg})$ & $65.4 \pm 13.2$ & $59.7 \pm 12.3$ & $<0.001 \wedge$ \\
\hline Height $(\mathrm{cm})$ & $164.9 \pm 6.4$ & $152.0 \pm 6.2$ & $<0.001^{*}$ \\
\hline Body mass index $\left(\mathrm{kg} / \mathrm{m}^{2}\right)$ & $24.0 \pm 4.4$ & $25.9 \pm 5.4$ & $<0.001 \wedge$ \\
\hline Body fat (\%) & $21.1 \pm 6.0$ & $33.9 \pm 5.9$ & $<0.001 \wedge$ \\
\hline Waist circumference $(\mathrm{cm})$ & $84.4 \pm 11.8$ & $88.1 \pm 13.4$ & $0.003 \wedge$ \\
\hline Hip circumference $(\mathrm{cm})$ & $91.4 \pm 9.8$ & $96.5 \pm 11.9$ & $<0.001 \wedge$ \\
\hline Waist-to-hip ratio & $0.92 \pm 0.06$ & $0.91 \pm 0.07$ & $0.094 \wedge$ \\
\hline \multicolumn{4}{|l|}{ Blood pressure } \\
\hline Systolic (mmHg) & $131.0 \pm 26.5$ & $126.3 \pm 23.7$ & $0.020^{\wedge}$ \\
\hline Diastolic (mmHg) & $81.2 \pm 15.8$ & $78.2 \pm 13.6$ & $0.043 \wedge$ \\
\hline \multicolumn{4}{|l|}{ Metabolic profile } \\
\hline Triglycerides (mmol/L) & $1.71 \pm 0.91$ & $1.42 \pm 0.67$ & $0.003 \wedge$ \\
\hline HDL cholesterol (mmol/L) & $1.07 \pm 0.36$ & $1.30 \pm 0.54$ & $<0.001^{\wedge}$ \\
\hline Leptin (ng/mL) & $2.7 \pm 4.8$ & $11.4 \pm 9.6$ & $<0.001 \wedge$ \\
\hline Physical activity (METS-min/week) & $6815 \pm 6532$ & $4747 \pm 5071$ & $<0.001 \wedge$ \\
\hline \multicolumn{4}{|l|}{ Dietary intake } \\
\hline Energy (kJ/day) & $11394 \pm 4621$ & $10277 \pm 4898$ & $0.002^{\wedge}$ \\
\hline Protein (energy\%) & $12.5 \pm 3.3$ & $12.6 \pm 3.5$ & $0.664 \wedge$ \\
\hline Fat (energy\%) & $21.3 \pm 9.8$ & $25.0 \pm 11.1$ & $<0.001 \wedge$ \\
\hline Carbohydrate (energy\%) & $66.1 \pm 9.9$ & $62.5 \pm 11.4$ & $<0.001 \wedge$ \\
\hline Dietary Inflammatory Index score & $1.07 \pm 7.19$ & $0.95 \pm 7.4$ & $0.898^{\wedge}$ \\
\hline$\%$ overweight $^{\mathrm{a}}$ & 19.7 & 26.2 & $0.003^{\#}$ \\
\hline$\%$ obese $^{b}$ & 3.6 & 11.3 & $<0.001^{\#}$ \\
\hline
\end{tabular}

Values are presented as mean \pm standard deviation, $\mathrm{p}$ value of difference between men and women, abody mass index $\geq 25 \mathrm{~kg} / \mathrm{m}^{2}$ or higher, ${ }^{b}$ body mass index $\geq 30$ $\mathrm{kg} / \mathrm{m}^{2}$ or higher, ${ }^{a, b}$ percent of total study participants, * independent t-test, ^MannWhitney test, \#Chi-square test. 
CHAPTER 2

Dietary Inflammatory Index Score and Its Association with Body Weight, Blood Pressure, Lipid Profile, and Leptin in Indonesian Adults

Supplementary Table 2.2. Linear regression analysis with the DII score as independent variable for men and women.

\begin{tabular}{|c|c|c|c|c|c|c|c|c|c|c|c|c|}
\hline & \multicolumn{6}{|c|}{ Men $(n=252)$} & \multicolumn{6}{|c|}{ Women $(n=251)$} \\
\hline & \multicolumn{2}{|c|}{ Model 0} & \multicolumn{2}{|c|}{ Model I } & \multicolumn{2}{|c|}{ Model II } & \multicolumn{2}{|c|}{ Model 0} & \multicolumn{2}{|c|}{ Model I } & \multicolumn{2}{|c|}{ Model II } \\
\hline & B & $p$ & B & $p$ & B & $p$ & B & $p$ & B & $p$ & B & $p$ \\
\hline Body weight (kg) & -0.157 & 0.180 & $-0.082^{a}$ & 0.194 & $-0.037^{b}$ & 0.643 & 0.121 & 0.249 & $0.062^{a}$ & 0.323 & $-0.020^{b}$ & 0.787 \\
\hline BMI $\left(\mathrm{kg} / \mathrm{m}^{2}\right)$ & -0.049 & 0.204 & $-0.076^{a}$ & 0.224 & $-0.049^{b}$ & 0.535 & 0.025 & 0.593 & $0.022^{a}$ & 0.720 & $-0.084^{b}$ & 0.257 \\
\hline Body fat (\%) & -0.040 & 0.446 & $-0.042^{a}$ & 0.487 & $-0.026^{b}$ & 0.731 & 0.023 & 0.650 & $0.015^{a}$ & 0.804 & $-0.075^{b}$ & 0.295 \\
\hline Waist circumference $(\mathrm{cm})$ & -0.127 & 0.227 & $-0.071^{a}$ & 0.245 & $-0.011^{b}$ & 0.891 & -0.031 & 0.789 & $-0.033^{a}$ & 0.578 & $-0.058^{b}$ & 0.414 \\
\hline Hip circumference $(\mathrm{cm})$ & -0.082 & 0.345 & $-0.054^{a}$ & 0.379 & $-0.036^{b}$ & 0.638 & 0.107 & 0.294 & $0.053^{a}$ & 0.381 & $-0.039^{b}$ & 0.596 \\
\hline Systolic BP (mmHg) & 0.173 & 0.460 & $0.049^{a}$ & 0.424 & $0.056^{c}$ & 0.440 & 0.261 & 0.196 & $0.066^{a}$ & 0.244 & $0.005^{c}$ & 0.938 \\
\hline Diastolic BP (mmHg) & 0.069 & 0.622 & $0.034^{a}$ & 0.589 & $0.052^{c}$ & 0.485 & 0.181 & 0.120 & $0.086^{a}$ & 0.156 & $0.039^{c}$ & 0.574 \\
\hline Triglycerides (mmol/L) & -0.009 & 0.263 & $-0.067^{a}$ & 0.300 & $-0.059^{c}$ & 0.448 & -0.0002 & 0.973 & $-0.008^{a}$ & 0.896 & $-0.044^{c}$ & 0.573 \\
\hline HDL cholesterol (mmol/L) & -0.005 & 0.160 & $-0.096^{a}$ & 0.136 & $-0.131^{c}$ & 0.102 & 0.006 & 0.230 & $0.084^{a}$ & 0.198 & $0.003^{c}$ & 0.971 \\
\hline Leptin (ng/mL) & 0.055 & 0.281 & $0.081^{a}$ & 0.263 & $0.157^{c}$ & 0.019 & 0.160 & 0.070 & $0.120^{a}$ & 0.078 & $0.110^{c}$ & 0.089 \\
\hline
\end{tabular}

Model 0 , linear regression analysis without adjustment; Model I and Model II, linear regression analysis with adjustment; alinear regression analysis with adjustment for age; blinear regression analysis with adjustment for age, energy intake and physical activity; clinear regression analysis with adjustment for age, sex, body mass index, energy intake and physical activity. BP: blood pressure. 


\section{CHAPTER 3}

\section{Dietary Intake after Weight Loss and the Risk of Weight}

Regain: Macronutrient Composition and Inflammatory Properties of the Diet

Harry Freitag Luglio Muhammad ${ }^{1,2}$, Roel G Vink², Nadia JT Roumans ${ }^{2}$, Laura AJ Arkenbosch², Edwin C Mariman² and Marleen A van Baak

${ }^{1}$ Department of Nutrition and Health, Faculty of Medicine, Universitas Gadjah Mada, Yogyakarta, Indonesia ${ }^{2}$ Department of Human Biology, NUTRIM School of Nutrition and Translational Research in Metabolism, Maastricht Medical Centre+, Maastricht, The Netherlands

Published in Nutrients 2017, 9, 1205; doi:10.3390/nu9111205 


\begin{abstract}
Weight regain after successful weight loss is a big problem in obesity management. This study aimed to investigate whether weight regain after a weight loss period is correlated with the macronutrient composition and/or the inflammatory index of the diet during that period. Sixty one overweight and obese adults participated in this experimental study. Subjects lost approximately $10 \%$ of their initial weight by means of very low-calorie diet for five weeks, or a low calorie diet for 12 weeks. After that, subjects in both groups followed a strict weight maintenance diet based on individual needs for four weeks, which was followed by a nine-month weight maintenance period without dietary counseling. Anthropometrics and dietary intake data were recorded before weight loss (baseline) and during the weight maintenance period. On average, participants regained approximately half of their lost weight. We found no evidence that macronutrient composition during the weight maintenance period was associated with weight regain. The dietary inflammatory index $(r=0.304$, $p=0.032$ ) was positively correlated with weight regain and remained significant after correction for physical activity $(r=0.287, p=0.045)$. Our data suggest that the inflammatory properties of diet play a role in weight regain after weight loss in overweight and obese adults.
\end{abstract}

Keywords: obesity; weight regain; macronutrient composition; inflammation 


\section{Introduction}

It has been estimated that a total of 107.7 million children and 603.7 million adults worldwide were obese in 2015 [1], and this state of over-nutrition was responsible for an increasing economic and health burden [1,2]. Effective actions to prevent the increasing rate of obesity and to treat those who already are obese are required. Lifestyle-based weight loss programs, which include an energy-restricted diet and increased physical activity, are by far the most commonly used weight loss methods. Effective lifestyle- based weight loss interventions have been developed in the last few decades, but maintaining the attained weight loss is not an easy task [3]. Studies have shown that overweight and obese individuals who lost weight through lifestyle modification are prone to weight regain [4-6].

Several theories have been proposed to explain this weight regain in which biologic and behavioral factors play an important role [7]. Reduction in basal and activity-related energy expenditure, changes in hunger- and satiety-associated hormone production, and an increase in fat cell stress in response to fat mass reduction have been suggested as potential factors associated with the tendency towards gaining weight after weight loss $[7,8]$. In addition, several eating-related behavioral factors, such as ability to control over-eating, binge eating and eating as a response to negative emotions have also been suggested to increase the risk of weight regain [9].

Several studies have been conducted to evaluate whether dietary factors are associated with weight regain. Several studies found that higher dietary protein content after weight loss was associated with less weight regain [10-14]. However, not all studies support this notion $[15,16]$. The role of other macronutrients in the prevention of weight regain has been less well studied.

Dietary intake not only has a direct impact on body weight, but may also have indirect effects that are important for body weight regulation. We have previously shown that weight regain after weight loss was correlated with the expression of genes related to adipose tissue stress and inflammation $[17,18]$. Because inflammation is also influenced by the dietary pattern [19], the inflammatory properties of the diet might play role in weight regain.

Therefore, this study aimed to investigate the influence of the macronutrient composition and inflammatory properties of the diet on weight regain during a weight maintenance period after weight loss of overweight and obese individuals. To analyze the correlation between the inflammatory properties of diet and weight regain we calculated the dietary inflammatory index (DII). The DII consists of a compilation of effects of intake of specific nutrients that have been shown to change inflammatory parameters in the blood, and provides a quantitative estimate of the inflammatory tendency of an individual's diet [19-22]. In addition, we analyzed the association between each individual component of the dietary inflammatory index and weight regain. 


\section{METHODS}

Subjects

Male ( $n=27,45.8 \%$ ) and female ( $n=30,54.2 \%$ ) Caucasian adults with overweight and obesity participated in this study. The recruitment process was done through advertisements. The inclusion criteria were body mass index more than $28 \mathrm{~kg} / \mathrm{m}^{2}$ with stable body weight in the past 2 months prior to the study. Those who had a current or previous history of cardiovascular disease, type 2 diabetes mellitus, liver or kidney disease, used medication that influences body weight regulation, were pregnant, smoking, or had marked alcohol consumption were excluded from the study. Subjects with elevated fasting glucose $(>6.1 \mathrm{mmol} / \mathrm{L})$, total cholesterol (>7.0 mmol/L) or triacylglycerol $(>3.0 \mathrm{mmol} / \mathrm{L}$ ) concentrations, or blood pressure (>160/100 $\mathrm{mmHg}$ ) prior to the intervention were also excluded. A total of 61 subjects started this study and provided their written informed consent before participation. The study was performed according to the Declaration of Helsinki and was approved by the Medical Ethics Committee of Maastricht University Medical Centre. This trial is registered at www.clinicaltrials.gov as NCT01559415. This study is a secondary analysis of a study of which the design and methods have been described in detail before [23].

\section{The Dietary Intervention Program}

The dietary intervention program was composed of three periods: weight loss period (WL), weight stable period (WS) and follow-up period (FU). The weight maintenance (WM) period is a combination of the weight stable and follow-up periods. During WL, subjects were divided into two groups: a low calorie diet (LCD, $1250 \mathrm{kcal} /$ day) group and a very low calorie diet (VLCD, $500 \mathrm{kcal} /$ day) group. The LCD group replaced one meal by a meal replacement (Modifast; Nutrition et Sante Benelux, Breda, The Netherlands). The other two meals were prepared by the participants themselves based on meal plans designed by a dietitian, based on the Dutch national dietary guidelines, and they consumed three in-between meal snacks. The VLCD group consumed three meal replacements per day with additional $100 \mathrm{~mL}$ instant broth drinks per day and an unrestricted amount of low calorie vegetables. The length of the WL period was 12 weeks in the LCD group and 5 weeks in the VLCD group in order to achieve a similar $10 \%$ weight reduction in both groups. After the WL period, subjects in both groups followed a strictly balanced diet based on their individual energy requirements for 4 weeks (WS period) according to the Dutch national dietary guidelines [24]. During the follow-up period of 9 months, subjects were advised to maintain their body weight, but they no longer received dietary consultation and were free to choose their diet. 


\section{Measurements}

Anthropometric measurements were done at 4 time points: before the intervention (M1), at the end of WL (M2), at the end of WS (M3) and at the end of FU (M4) (Figure 3.1). Weight regain was calculated as body weight at M4 minus body weight at M3. Anthropometric measurements were obtained successfully at M1, M2 and M3 in all subjects but only 55 (96.5\%) subjects were measured at M4 (Supplementary Table 3.1).

Height was measured using a stadiometer (Seca, Hamburg, Germany). Body weight was measured using a digital weighing scale (precision $0.1 \mathrm{~kg}$ ) (Seca, Hamburg, Germany). Waist circumference was measured above the umbilicus and hip circumference was measured at the widest part of the buttocks. Percent body fat mass was determined by air displacement plethysmography (BodPod, Cosmed, Italy).

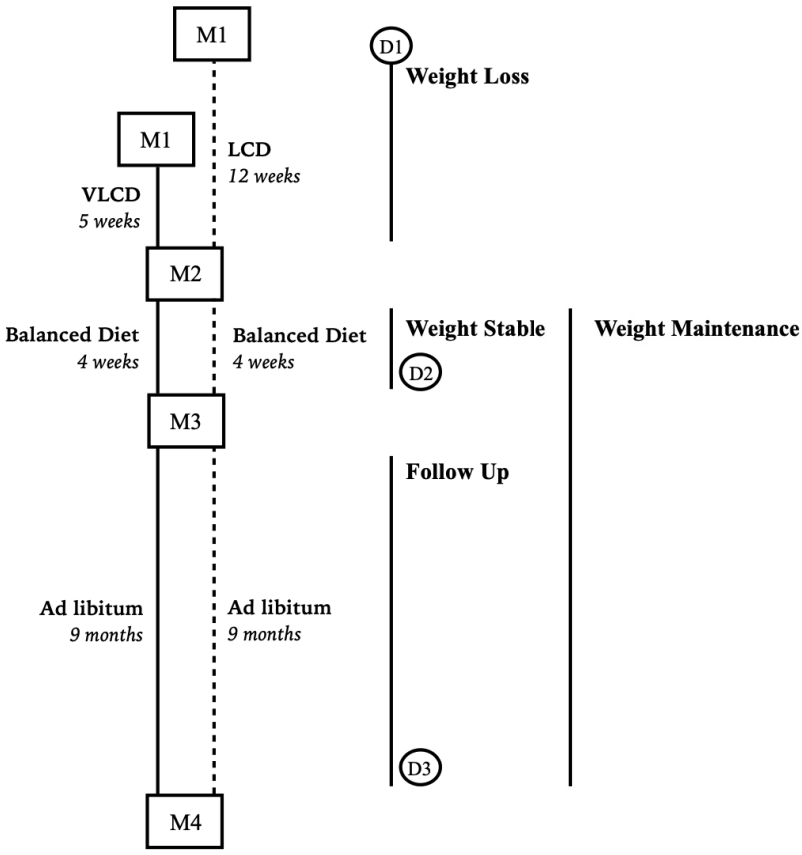

Figure 3.1. Schematic representation of study design and measurements. Anthropometric measurements M1: before intervention; M2: end of weight loss period; M3: end of weight stable period; M4: end of follow up period. Weight loss $(\mathrm{WL})=\mathrm{M} 2-\mathrm{M} 1$; weight regain $(\mathrm{WR})=\mathrm{M} 4-\mathrm{M} 3$. Baseline diet $=\mathrm{D} 1$, weight maintenance $(\mathrm{WM})$ diet $=$ average of D2 and D3. Physical activity was measured during $\mathrm{M} 1, \mathrm{M} 2, \mathrm{M} 3$ and $\mathrm{M} 4$. 
Measurements of dietary intake were conducted at 3 time points: before the weight loss intervention (D1), at the end of WS (D2) and at the end of FU (D3) (Figure 3.1). At each time point, 3-day food diaries (including 1 non-working day) were collected. All foods reported were linked to the 2011 Dutch food consumption table (NEVO online version 2011, RIVM, Bilthoven, The Netherlands) and nutrient intakes were calculated. Some of the dietary intakes and physical activity differed significantly between D2 and D3 (Supplementary Table 3.2). However, because we do not know the time course of the changes from D2 to D3, we have assumed that the changes were gradual and the mean of D2 and D3 would best reflect the overall level during the follow-up period. Thus, the nutrient intake values obtained at D2 and D3 were averaged to reflect dietary intake over the weight maintenance (WM) period. Nutrients intakes were corrected for total energy intake [25] and a dietary inflammatory index was calculated according to Tabung et al. [26], based on the work of Shivappa et al. [20]. The calculation of the dietary inflammatory index was based on 27 nutrients including total energy, protein, carbohydrate, total fat, saturated fat, trans fat, mono-unsaturated fatty acid, poly-unsaturated fatty acid, omega-3 fatty acid, omega- 6 fatty acid, cholesterol, fiber, alcohol, magnesium, iron, selenium, zinc, vitamin $A$, vitamin $C$, vitamin $D$, vitamin $E$, thiamin, riboflavin, vitamin $B 6$, vitamin B12, folate and niacin, because no data were available for the other dietary factors included by Shivappa et al. [20] in their dietary inflammation index. Data on dietary intake during weight maintenance were obtained in 52 subjects (91.2\%).

Subjects' total physical activity at baseline (M1), during the weight loss period (M2) and during weight maintenance period (M3 and M4) (Figure 3.1) was calculated using the sum score of occupational, leisure time and sports activity obtained from the Baecke questionnaire for habitual physical activity [27].

\section{Data Analysis}

Statistical analysis was performed with SPSS for Macintosh, Version 21 (Chicago, IL, USA). Data are presented as mean \pm standard error of the mean. Since no statistically significant differences were found between the VLCD and LCD groups, groups were combined for the correlation analyses. An independent t-test was used when comparing data on anthropometric, dietary and physical activity differences between the LCD and VLCD groups before and after the weight loss intervention. Paired t-tests were used when analyzing changes (anthropometric and dietary intake) within a group over a specific period of intervention. Wilcoxon signed ranks were used for non-normally distributed data. The correlation between nutrient intake, DII and weight regain was done using Pearson correlation tests for normally distributed data, and Spearman correlation tests for non-normally distributed data. Normality tests were performed using the Kolmogorov Smirnov normality test. In addition, partial correlations with correction for physical activity were determined. The analyses were considered statistically significant when $\mathrm{p}<0.05$ (2-tailed). 


\section{RESULTS}

A total of 61 obese subjects were initially recruited in this study, but four subjects withdrew because of health and personal circumstances not related to the study. Data on anthropometric measures are presented in Table 3.1. Gender was equally distributed $($ LCD group male $=48.3 \%$, VLCD group male $=46.4 \%$ ). There were no differences in body weight and other anthropometric measures at any time point (M1, M2, M3 and M4) between subjects in LCD and VLCD groups (Supplementary Table 3.1). Subjects significantly lost weight at the end of the weight loss period (M2 vs. M1) and gained weight at the end of follow up period (M4 vs. M3) (Table 3.1). Weight regain varied between $-3.8 \mathrm{~kg}$ and $+13.5 \mathrm{~kg}$.

Table 3.1. Changes in anthropometric data throughout the weight loss intervention.

${ }^{*} \mathrm{P}<0.05,{ }^{* *} \mathrm{P}<0.01,{ }^{* * *} \mathrm{P}<0.01$ paired sample t-test, change from M1 vs. M2, M2 vs. M3, and M3 vs. M4.

\begin{tabular}{lcccc}
\hline & $\begin{array}{c}\text { Baseline } \\
(\mathrm{M} 1)\end{array}$ & $\begin{array}{c}\text { Weight Loss Period } \\
(\mathrm{M} 2)\end{array}$ & $\begin{array}{c}\text { Weight Stable } \\
\text { Period }(\mathrm{M} 3)\end{array}$ & $\begin{array}{c}\text { Follow Up Period } \\
(\mathrm{M} 4)\end{array}$ \\
\hline Age (years) & $51.3 \pm 9.1$ & & & \\
\hline Height $(\mathrm{cm})$ & $172.3 \pm 8.9$ & & & \\
Weight $(\mathrm{kg})$ & $92.5 \pm 9.9$ & $83.9 \pm 1.2^{* * *}$ & $83.7 \pm 9.5$ & $88.3 \pm 10.2^{* * *}$ \\
\hline BMI $\left(\mathrm{kg} / \mathrm{m}^{2}\right)$ & $31.2 \pm 2.3$ & $28.3 \pm 0.3^{* * *}$ & $28.2 \pm 2.4$ & $29.6 \pm 2.7^{* * *}$ \\
\hline Fat mass $(\%)$ & $39.8 \pm 8.6$ & $34.8 \pm 1.4^{* * *}$ & $33.8 \pm 10.3^{* * *}$ & $36.3 \pm 9.8^{* * *}$ \\
\hline Fat free mass $(\%)$ & $60.2 \pm 8.6$ & $65.3 \pm 1.4^{* * *}$ & $66.2 \pm 10.3^{* * *}$ & $63.7 \pm 9.8^{* * *}$ \\
\hline Fat mass $(\mathrm{kg})$ & $36.4 \pm 7.8$ & $28.9 \pm 1.2^{* * *}$ & $27.9 \pm 8.8^{* * *}$ & $31.7 \pm 9.0^{* * *}$ \\
\hline Fat free mass $(\mathrm{kg})$ & $55.7 \pm 11.5$ & $54.6 \pm 1.5^{* * *}$ & $55.2 \pm 11.6^{* * *}$ & $56.0 \pm 11.6^{*}$ \\
Waist circumference $(\mathrm{cm})$ & $102.3 \pm 9.6$ & $94.7 \pm 1.2^{* * *}$ & $94.63 \pm 9.0$ & $98.1 \pm 9.2^{* * *}$ \\
\hline Hip circumference $(\mathrm{cm})$ & $111.0 \pm 6.2$ & $105.5 \pm 0.9^{* * *}$ & $104.7 \pm 6.3^{*}$ & $106.2 \pm 8.3^{* *}$ \\
\hline
\end{tabular}

There were no differences in energy intake and dietary composition between the LCD and VLCD group before and during WM (all p > 0.05) (Supplementary Table 3.2) (Table 3.2). Subjects in both groups had a significantly lower total energy intake during WM ( $p<0.001)$ compared to their initial energy intake. Protein and carbohydrate intake (as percent of total energy intake) increased (all $p<0.05$ ) with no change in \% energy from sugar consumption, whereas percentage of energy from fat was reduced, mainly due to a reduction in saturated fat (all $p<0.05$ ). Alcohol consumption (expressed as $\mathrm{g} / 1000 \mathrm{kcal}$ ) did not change significantly over the intervention period. The intake of fiber and several micronutrients (niacin, riboflavin, vitamin B6, folate, vitamin C, vitamin A, zinc, selenium, iron and magnesium), expressed as $\mathrm{g}$ or $\mathrm{mg} / 1000 \mathrm{kcal}$, was increased during the weight maintenance period. In addition, the dietary inflammatory index during the weight maintenance period was lower than the baseline $(p<0.001)$. There was no change in physical activity $(p=0.437)$ over the intervention period. 
The correlations between macronutrients, the dietary inflammatory index and its components, and weight regain are shown in Table 3.3. No significant correlations with the intake of the various macronutrients were found. The dietary inflammatory index and total energy intake were positively correlated with weight regain, while magnesium, riboflavin and folate intake were negatively correlated with weight regain. Gender $(r=0.036, p=0.794)$, body mass index $(r=-0.106, p=0.439)$, age $(r=$ $0.187, p=0.171)$ and initial weight loss $(r=0.008, p=0.955)$ were not correlated with weight regain, while physical activity $(r=-0.278, p=0.040)$ was negatively correlated. Therefore, partial correlation analyses were conducted to evaluate the correlations between dietary intake, dietary inflammatory index and weight regain, independent of physical activity. Energy and riboflavin intake, and the dietary inflammatory index remained significantly correlated with weight regain, but not magnesium and folate.

Table 3.2. Dietary intake and physical activity at baseline and during weight maintenance in the LCD and VLCD groups and both groups combined (All).

\begin{tabular}{|c|c|c|c|c|c|c|c|}
\hline & \multicolumn{3}{|c|}{$\begin{array}{l}\text { Baseline Diet } \\
\text { (D1) }\end{array}$} & \multicolumn{4}{|c|}{$\begin{array}{l}\text { Weight Maintenance } \\
\text { (D2 and D3) }\end{array}$} \\
\hline & LCD & VLCD & All & LCD & VLCD & All & $p^{*}$ \\
\hline Energy (kcal/day) & $1991 \pm 116$ & $2120 \pm 99$ & $2071 \pm 82$ & $1677 \pm 96$ & $1713 \pm 88$ & $1684 \pm 65$ & $<0.001$ \\
\hline Protein (\%) & $17.5 \pm 0.6$ & $17.7 \pm 0.9$ & $17.6 \pm 0.6$ & $19.7 \pm 0.8$ & $20.1 \pm 0.8$ & $20.1 \pm 0.6$ & $<0.001^{c}$ \\
\hline Carbohydrate (\%) ${ }^{\mathrm{a}}$ & $43.3 \pm 1.3$ & $45.0 \pm 1.5$ & $43.9 \pm 7.3$ & $48.0 \pm 1.3$ & $45.8 \pm 1.1$ & $46.8 \pm 6.2$ & 0.012 \\
\hline Sugars $(\%)^{\mathrm{a}}$ & $19.8 \pm 1.3$ & $20.3 \pm 1.2$ & $20.2 \pm 6.5$ & $21.6 \pm 1.2$ & $19.6 \pm 1.1$ & $20.4 \pm 6.3$ & 0.801 \\
\hline Fat $(\%)^{\mathrm{a}}$ & $37.0 \pm 1.3$ & $35.1 \pm 1.3$ & $36.3 \pm 6.8$ & $30.2 \pm 1.0$ & $32.3 \pm 1.1$ & $31.7 \pm 5.4$ & $<0.001$ \\
\hline Saturated fat (g/ $1000 \mathrm{kcal})^{\mathrm{b}}$ & $15.2 \pm 0.8$ & $14.6 \pm 0.8$ & $15.1 \pm 0.6$ & $11.7 \pm 0.5$ & $12.7 \pm 0.4$ & $12.2 \pm 0.4$ & $<0.001$ \\
\hline Trans fat $(\mathrm{g} / 1000 \mathrm{kcal})^{\mathrm{b}}$ & $1.17 \pm 0.09$ & $1.00 \pm 0.08$ & $1.08 \pm 0.06$ & $0.85 \pm 0.13$ & $0.95 \pm 0.07$ & $0.91 \pm 0.08$ & $0.041^{c}$ \\
\hline MUFA $(\mathrm{mg} / 1000 \mathrm{kcal})^{\mathrm{b}}$ & $13.8 \pm 0.6$ & $12.9 \pm 0.5$ & $13.5 \pm 0.4$ & $12.4 \pm 0.7$ & $12.4 \pm 0.4$ & $12.4 \pm 0.4$ & $0.104^{c}$ \\
\hline PUFA (mg/ $1000 \mathrm{kcal})^{\mathrm{b}}$ & $7.75 \pm 0.51$ & $7.67 \pm 0.44$ & $7.73 \pm 0.34$ & $6.85 \pm 0.35$ & $7.20 \pm 0.36$ & $7.05 \pm 0.25$ & $0.034^{c}$ \\
\hline Omega 3 fatty acids $(\mathrm{mg} / 1000 \mathrm{kcal})^{\mathrm{b}}$ & $0.89 \pm 0.09$ & $0.75 \pm 0.08$ & $0.83 \pm 0.06$ & $0.90 \pm 0.09$ & $0.84 \pm 0.06$ & $0.87 \pm 0.06$ & $0.584^{c}$ \\
\hline Omega 6 fatty acids $(\mathrm{mg} / 1000 \mathrm{kcal})^{\mathrm{b}}$ & $6.04 \pm 0.52$ & $6.26 \pm 0.43$ & $6.15 \pm 0.35$ & $5.27 \pm 0.28$ & $5.65 \pm 0.33$ & $5.48 \pm 0.21$ & 0.038 \\
\hline Cholesterol (mg/ $1000 \mathrm{kcal}^{\mathrm{b}}$ & $118.1 \pm 7.2$ & $110.7 \pm 8.1$ & $117.2 \pm 5.6$ & $108.1 \pm 8.4$ & $106.3 \pm 8.9$ & $107.5 \pm 6.1$ & 0.202 \\
\hline Fiber $(\mathrm{g} / 1000 \mathrm{kcal})^{\mathrm{b}}$ & $9.77 \pm 0.70$ & $11.03 \pm 0.64$ & $10.48 \pm 0.50$ & $13.28 \pm 0.55$ & $13.88 \pm 0.62$ & $13.56 \pm 0.42$ & $<0.001$ \\
\hline Alcohol $(\mathrm{g} / 1000 \mathrm{kcal})^{\mathrm{b}}$ & $3.17 \pm 1.02$ & $2.82 \pm 1.04$ & $3.12 \pm 0.77$ & $2.25 \pm 0.59$ & $2.30 \pm 0.72$ & $2.19 \pm 0.46$ & $0.185^{c}$ \\
\hline Magnesium (mg/ 1000 kcal)b & $145.8 \pm 7.84$ & $157.3 \pm 6.1$ & $152.2 \pm 5.3$ & $189.2 \pm 6.7$ & $182.3 \pm 5.8$ & $185.6 \pm 4.6$ & $<0.001$ \\
\hline Iron (mg/ $1000 \mathrm{kcal})^{\mathrm{b}}$ & $6.14 \pm 0.39$ & $5.89 \pm 0.31$ & $6.04 \pm 0.26$ & $7.16 \pm 0.33$ & $6.94 \pm 0.21$ & $7.07 \pm 0.20$ & $0.001^{c}$ \\
\hline Selenium (mg/ 1000 kcal) ${ }^{b}$ & $27.8 \pm 2.4$ & $25.6 \pm 2.0$ & $26.8 \pm 1.7$ & $33.3 \pm 2.4$ & $28.6 \pm 2.1$ & $31.1 \pm 1.6$ & $0.037^{c}$ \\
\hline Zinc $(\mathrm{mg} / 1000 \mathrm{kcal})^{\mathrm{b}}$ & $5.00 \pm 0.22$ & $5.33 \pm 0.34$ & $5.19 \pm 0.21$ & $5.88 \pm 0.23$ & $5.78 \pm 0.31$ & $5.86 \pm 0.2$ & $0.022^{c}$ \\
\hline Vitamin A $(\mu \mathrm{g} / 1000 \mathrm{kcal})^{\mathrm{b}}$ & $362.9 \pm 34.4$ & $360.6 \pm 41.5$ & $373.2 \pm 27.7$ & $375.2 \pm 28.2$ & $534.6 \pm 77.7$ & $449.5 \pm 40.9$ & $0.046^{c}$ \\
\hline Vitamin D (mg/ $1000 \mathrm{kcal})^{\mathrm{b}}$ & $2.31 \pm 0.42$ & $1.77 \pm 0.18$ & $2.07 \pm 0.25$ & $1.99 \pm 0.18$ & $2.11 \pm 0.25$ & $2.05 \pm 0.15$ & $0.362^{c}$ \\
\hline Vitamin E (mg/ $1000 \mathrm{kcal})^{\mathrm{b}}$ & $6.58 \pm 0.52$ & $6.89 \pm 0.49$ & $6.79 \pm 0.37$ & $6.83 \pm 0.39$ & $6.48 \pm 0.48$ & $6.65 \pm 0.31$ & 0.667 \\
\hline Thiamin (mg/ $1000 \mathrm{kcal})^{\mathrm{b}}$ & $0.64 \pm 0.04$ & $0.73 \pm 0.06$ & $0.69 \pm 0.04$ & $0.84 \pm 0.05$ & $0.72 \pm 0.05$ & $0.79 \pm 0.04$ & $0.037^{c}$ \\
\hline Riboflavin (mg/ $1000 \mathrm{kcal})^{\mathrm{b}}$ & $0.79 \pm 0.07$ & $0.78 \pm 0.06$ & $0.79 \pm 0.04$ & $0.99 \pm 0.06$ & $0.92 \pm 0.07$ & $0.97 \pm 0.05$ & $0.003^{c}$ \\
\hline Vitamin B6 (mg/ $1000 \mathrm{kcal})^{\mathrm{b}}$ & $0.89 \pm 0.05$ & $1.07 \pm 0.08$ & $0.99 \pm 0.05$ & $1.30 \pm 0.08$ & $1.25 \pm 0.08$ & $1.27 \pm 0.06$ & $<0.001^{c}$ \\
\hline Folate $(\mu \mathrm{g} / 1000 \mathrm{kcal})^{\mathrm{b}}$ & $87.1 \pm 10.3$ & $95.8 \pm 6.3$ & $93.0 \pm 6.4$ & $128.1 \pm 9.6$ & $110.1 \pm 6.9$ & $119.7 \pm 6.3$ & $<0.001^{c}$ \\
\hline Vitamin B12 (mg/ $1000 \mathrm{kcal})^{\mathrm{b}}$ & $3.46 \pm 0.96$ & $2.26 \pm 0.29$ & $2.96 \pm 0.55$ & $3.27 \pm 0.62$ & $2.87 \pm 0.44$ & $3.04 \pm 0.39$ & $0.257^{c}$ \\
\hline Niacin $(\mathrm{mg} / 1000 \mathrm{kcal})^{\mathrm{b}}$ & $9.28 \pm 0.53$ & $9.13 \pm 0.61$ & $9.15 \pm 0.42$ & $11.67 \pm 0.68$ & $10.81 \pm 0.58$ & $11.24 \pm 0.46$ & $0.001^{c}$ \\
\hline Vitamin C (mg/ $1000 \mathrm{kcal})^{\mathrm{b}}$ & $46.2 \pm 7.6$ & $54.0 \pm 5.4$ & $52.0 \pm 4.9$ & $67.4 \pm 6.6$ & $57.2 \pm 5.5$ & $61.2 \pm 4.2$ & $0.025^{c}$ \\
\hline Dietary Inflammatory Index^ & $6.11 \pm 0.43$ & $5.73 \pm 0.39$ & $5.84 \pm 0.31$ & $4.44 \pm 0.35$ & $4.49 \pm 0.35$ & $4.48 \pm 0.25$ & $<0.001^{\mathrm{c}}$ \\
\hline Physical Activity" & $9.07 \pm 0.18$ & $9.07 \pm 0.21$ & $8.95 \pm 0.14$ & $9.06 \pm 0.20$ & $8.78 \pm 0.18$ & $9.03 \pm 0.14$ & 0.437 \\
\hline
\end{tabular}


${ }^{a}$ Dietary intake as \% of total energy intake; ${ }^{b}$ dietary intake in gram or milligram per $1000 \mathrm{kcal}$ of total energy intake; 'wilcoxon signed ranks t-test for non-normally distributed data. *p value of paired t-test comparing baseline diet and weight maintenance diet in the whole group. 'Dietary inflammatory index: The sum of dietary inflammatory scores of each nutrient as calculated by Tabung et al. [26]; "physical activity was calculated using the Baecke questionnaire for habitual physical activity [27]. Data on dietary intake during the weight maintenance period are the average of dietary records obtained during the weight stable (WS) and the follow up (FU) periods; dietary intakes during WS and FU are provided in Supplementary Table 3.2; no significant differences were found between LCD and VLCD groups (independent t-test) before and during weight maintenance; LCD: low calorie diet group; VLCD: very low calorie diet group, MUFA: mono-unsaturated fatty acid; PUFA: poly-unsaturated fatty acid.

Table 3.3. Correlations between the dietary macronutrient content, the dietary inflammatory index and its components, and weight regain.

\begin{tabular}{|c|c|c|c|c|}
\hline & \multicolumn{2}{|c|}{ Uncorrected Bivariate Correlation } & \multicolumn{2}{|c|}{$\begin{array}{c}\text { Partial Correlation } \\
\text { (corrected for physical activity }\end{array}$} \\
\hline & $r$ & $\mathrm{p}$ & $\mathbf{r}$ & $\boldsymbol{p}$ \\
\hline Dietary Inflammatory Index^ ${ }^{\wedge}$ & $0.304^{b}$ & $0.032^{*}$ & 0.287 & $0.045^{*}$ \\
\hline Energy ${ }^{\sharp} \wedge \wedge$ & $0.363^{\mathrm{a}}$ & $0.018^{*}$ & 0.344 & $0.027^{*}$ \\
\hline Protein $\wedge \wedge$ & $-0.204^{b}$ & 0.196 & -0.212 & 0.183 \\
\hline Carbohydrate $\wedge \wedge$ & $0.157^{\mathrm{a}}$ & 0.322 & 0.169 & 0.292 \\
\hline Sugars & 0.043 & 0.786 & 0.058 & 0.721 \\
\hline Fat $\wedge \wedge$ & $-0.054^{a}$ & 0.735 & -0.106 & 0.510 \\
\hline Saturated fat $\wedge \wedge$ & $-0.035^{a}$ & 0.824 & -0.068 & 0.674 \\
\hline Trans fat $\wedge \wedge$ & $-0.060^{\mathrm{b}}$ & 0.704 & -0.090 & 0.577 \\
\hline MUFA^^ & $-0.018^{\mathrm{a}}$ & 0.909 & -0.059 & 0.714 \\
\hline PUFA $\wedge \wedge$ & $-0.043^{\mathrm{a}}$ & 0.789 & -0.070 & 0.663 \\
\hline Omega 3 fatty acids $\wedge \wedge$ & $-0.095^{a}$ & 0.551 & -0.123 & 0.443 \\
\hline Omega 6 fatty acids $\wedge \wedge$ & $-0.027^{a}$ & 0.868 & -0.065 & 0.684 \\
\hline Cholesterol $\wedge \wedge$ & $-0.052^{\mathrm{a}}$ & 0.743 & -0.060 & 0.711 \\
\hline Fiber $\wedge \wedge$ & $-0.240^{\mathrm{a}}$ & 0.094 & -0.170 & 0.242 \\
\hline Alcohol^^ & $0.103^{b}$ & 0.517 & 0.124 & 0.442 \\
\hline Magnesium $\wedge \wedge$ & $-0.328^{a}$ & $0.034^{*}$ & -0.279 & 0.077 \\
\hline $\operatorname{Iron} \wedge \wedge$ & $-0.017^{b}$ & 0.916 & -0.092 & 0.566 \\
\hline Selenium $\wedge \wedge$ & $-0.280^{\mathrm{a}}$ & 0.072 & -0.277 & 0.080 \\
\hline $\operatorname{Zinc} \wedge \wedge$ & $-0.289^{a}$ & 0.064 & -0.253 & 0.111 \\
\hline Vitamin $A \wedge \wedge$ & $0.002^{b}$ & 0.990 & -0.072 & 0.655 \\
\hline Vitamin $D^{\wedge} \wedge$ & $-0.026^{b}$ & 0.873 & 0.025 & 0.878 \\
\hline Vitamin $E^{\wedge} \wedge$ & $-0.170^{b}$ & 0.283 & -0.273 & 0.084 \\
\hline Thiamin $\wedge \wedge$ & $-0.199^{b}$ & 0.207 & -0.138 & 0.388 \\
\hline Riboflavin $\wedge \wedge$ & $-0.387^{a}$ & $0.011^{*}$ & -0.378 & $0.015^{*}$ \\
\hline Vitamin $B 6 \wedge \wedge$ & $-0.229^{a}$ & 0.144 & -0.206 & 0.197 \\
\hline Folate $\wedge \wedge$ & $-0.313^{b}$ & $0.044^{*}$ & -0.290 & 0.066 \\
\hline Vitamin $B 12 \wedge \wedge$ & $-0.125^{b}$ & 0.429 & -0.069 & 0.667 \\
\hline Niacin $\wedge \wedge$ & $-0.130^{\mathrm{a}}$ & 0.413 & -0.118 & 0.463 \\
\hline Vitamin $C \wedge \wedge$ & $-0.230^{b}$ & 0.142 & -0.232 & 0.144 \\
\hline
\end{tabular}

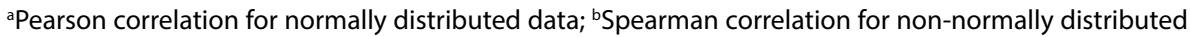
data; ${ }^{*} p<0.05$ (2-tailed); All nutrient intakes were expressed as the total amount corrected for energy intake per day. "Energy intake was expressed in kcal/day; Data on dietary intake after weight loss is a combination on dietary intake during weight stable and follow up period; $\wedge$ Dietary inflammatory index: The sum of dietary inflammatory scores of each nutrient as calculated by Tabung et al [26]; 
$\wedge \wedge$ Components of the dietary inflammatory index; MUFA: mono-unsaturated fatty acid; PUFA: polyunsaturated fatty acid. Data on dietary macronutrient and DII were collected during weight maintenance period (average of D2 and D3), while weight regain was calculated as while weight regain is the different between follow up (M4) and weight stable (M3).

\section{DISCUSSION}

This experimental study evaluated the association of dietary intake with weight regain during a period of intended weight maintenance after successful weight loss. Subjects reduced their energy intake following a weight loss period, with no significant differences between the groups that had attained their weight loss within five or 12 weeks. The macronutrient composition of the weight maintenance diet was not associated with weight regain. In contrast, we showed that the dietary inflammatory index was positively correlated with weight regain, confirming that inflammation may play a role in the regulation of body weight after weight loss. Intake of several individual micronutrients with anti-inflammatory properties, such as magnesium, folate and riboflavin, were found to be negatively correlated with weight regain.

During the weight stable period, all subjects received dietary counseling to promote a healthy eating pattern based on the recommendations of the Netherlands nutrition centre [24]. According to this guideline, individuals should increase consumption of fruits, vegetables, whole grain cereals, and fatty fish. Those types of food provide a significant amount of dietary vitamins (such as thiamin, riboflavin and folate), minerals (such as magnesium and zinc), fiber and omega-3 fatty acids, which are considered as anti-inflammatory nutrients $[20,28,29]$. Reduction of the consumption of saturated fat and trans fat is also recommended, which will lower the dietary inflammatory index as well [20]. By adhering to these dietary guidelines, subjects should benefit from having a diet with lower dietary inflammatory index. Except for omega-3 fatty acid intake, intake of all the above nutrients showed significant changes in the recommended direction during the weight maintenance period.

Energy intake during the weight maintenance period, but not dietary macronutrient composition, was correlated with weight regain. This finding is in line with Sacks et al. [15] who showed that the long-term maintenance of weight loss depended on the reduced calorie intake irrespective of diet composition. However, this was different from data from the DiOGenes trial $[10,11]$ and other smaller scale intervention studies $[12,13,14]$, which showed that increased protein intake helps to maintain weight loss. In the present study, the only dietary advice given during the WM period was to follow the Dutch national recommendations, and thus, experimental manipulation of the diet composition was minor, resulting in a wide variation of dietary compositions in a relatively limited number of subjects, making it difficult to measure effects of individual macronutrients. 
In this study, we found significant associations between the dietary inflammatory index and several of its components and weight regain. Based on our previous findings showing that weight regain was associated with continued weightloss-induced adipocyte stress and inflammation $[17,18]$, the hypothesis of this study was that a diet with a higher inflammatory index might also be associated with weight regain. The current results, indeed, seem to support this hypothesis. This is also supported by another study which showed that higher levels of inflammation markers in the systemic circulation (insulin, IL-6 and leukocyte number) and a higher adipose tissue inflammation were associated with resistance towards weight loss and proneness to weight regain [30]. The association between the dietary inflammatory index and obesity was previously reported in a cross-sectional study of adults [31]. This was confirmed by a large cohort study which showed that dietary inflammatory index can be used as a predictor of weight gain over eight years of follow-up, as well as of predisposition to the early development of obesity [32]. To our knowledge, this is the first study to show the effect of the dietary inflammatory index on weight regain in a weight loss trial. Overall, these results point to an important role of inflammation in the modulation of body weight, the development of obesity and the tendency for body weight regain after weight loss.

The dietary inflammatory index was based on a compilation of effects of specific nutrients and bioactive components that are derived from dietary histories. This calculation was proposed by Shivappa et al. [20] and modified by Tabung et al. [26], The positive effects of pro-inflammatory nutrients such as vitamin B12, carbohydrate, cholesterol, energy, total fat, iron, protein, saturated fat and trans fat were added up, and then the negative effects of anti-inflammatory nutrients such as vitamin B6, fiber, folic acid, Mg, MUFA, niacin, omega-3 fatty acid, omega- 6 fatty acid, PUFA, riboflavin, selenium, thiamin, vitamin A, vitamin C, vitamin D and vitamin E were subtracted. One limitation of our study is that we could not include all 45 components of the dietary inflammatory index that were proposed by Shivappa et al. [20]. This has also been the case in other studies, where the number of included dietary components ranged between 17 and 44 [21,22,26,32].

The components of dietary inflammatory index might also have an individual impact on weight regain. Therefore, correlation analyses were done separately based on each component. We showed that the intake of several micronutrients with anti-inflammatory properties, such as magnesium, riboflavin and folate was negatively correlated with weight regain. However, from those three micronutrients, only riboflavin intake remained significantly correlated with weight regain after correction for physical activity. Regular physical activity has been shown to have antiinflammatory properties [33].

There are no prior data on the association between dietary magnesium, folate and riboflavin and the protection against weight regain in overweight and obese individuals. We suggest that this effect is due to the anti-inflammatory properties of 
those micronutrients. Magnesium is suggested as a protective factor against oxidative stress, since hypomagnesemia was accompanied by a greater degree of oxidative stress in humans [34]. Folate has been associated with a reduction of inflammatory signals in overweight individuals [35]. Additionally, a low folate concentration was correlated with increasing risk of obesity [36]. These results suggest that there may be a potential role for magnesium and folate intake in body weight regulation via their effect on inflammation.

A role for riboflavin in the regulation of body weight has not yet been established or understood. It was previously shown that dietary riboflavin was protective against obesity [36]. In contrast, a population-based ecological study showed that a higher consumption of riboflavin per capita was associated with increased risk for obesity [37]. In vitro, induction of riboflavin in adipocytes was able to reduce proinflammatory factors such as tumor necrosis factor alpha, interleukin-6, MCDP-1 and HMGB1, while at the same time increasing anti-inflammatory markers such as adiponectin and interleukin 10. In addition, riboflavin supplementation in vitro was able to prevent macrophage infiltration in adipose tissue [38]. Riboflavin deficiency was associated with higher cellular stress in adipocytes, as shown by increased obesity-related apoptosis, reactive oxygen species and inflammation markers [39]. A high dietary intake of riboflavin might therefore be hypothesized to reduce weight loss-induced adipose tissue stress and inflammation and thus prevent weight regain.

This study has several strengths and limitations. To evaluate the association between dietary intake and weight regain after weight loss, this study applied an adequate study design with rigorous and strict weight loss regimes as well as a wellmanaged monitoring system. Compared to other long-term lifestyle-based weight loss studies, the drop-out rate of the subjects in this study was low. Limitations of this study include the small number of participants and the data collection on dietary intake for which we relied on three days of self-reported dietary records, which are known to be biased by underreporting. Underreporting of total energy intake and specific nutrients, such as saturated fat and sugar, will influence the calculation of the DII. However, this may be less important for the correlation analyses, if underreporting is comparable in all participants. Another limitation of the study is that the DII was formulated based on a limited number of items, and thus, the effect of other items in the DII will be underestimated in this study. The DII explained only $\sim 9 \%$ of the variation in weight regain in our study. However, very strong associations are not to be expected given the complexity of body weight regulation. Several other factors, including a reduction in basal and activity-related energy expenditure, a higher level of physical activity, changes in hunger- and satiety-associated hormones, and an increase in fat cell stress in response to fat mass reduction have also been suggested to play a role $[7,8,23]$. Moreover, a causal relationship between DII and weight regain cannot be derived from this study. To confirm these results, further studies are needed to evaluate the effect of diets with lower inflammatory index on weight regain in an experimental design. 
In summary, we found no evidence for a role of macronutrient composition of diet after a weight loss intervention for the prevention of weight regain in this study. On the other hand, the inflammatory properties of the diet during the weight maintenance period may play a role in weight regain after a diet-induced weight loss program in overweight and obese adults. Further research should investigate whether tailoring diet with the aim to reduce the dietary inflammatory index is a potential approach to improve weight maintenance.

\section{Funding agencies}

Netherlands Organisation for Scientific Research TOP, grant number: 200500001.

\section{Disclosure}

The authors declare no conflict of interest.

\section{Author Contribution}

HFLM: Harry Freitag Luglio Muhammad; RGV : Roel G Vink; NJTR : Nadia JT Roumans; LAJA: Laura AJ Arkenbosch; ECM : Edwin C Mariman; MAvB : Marleen A van Baak; "MAvB and ECM conceived and designed the experiments; NJTR, LAJA, RGV performed the experiments; HFLM analyzed the data; HFLM, MAvB and ECM wrote the paper. All authors read and approved the manuscript".

\section{REFERENCES}

1. GBD 2015 Obesity Collaborators, Afshin A, Forouzanfar $\mathrm{MH}$, et al. Health Effects of Overweight and Obesity in 195 Countries over 25 Years. N Engl J Med 2017, 377, 13-27.

2. Tremmel M, Gerdtham UG, Nilsson P, et al. Economic Burden of Obesity: A Systematic Literature Review. Int J Environ Res Public Health 2017, 14, 435.

3. Ross R. The challenge of obesity treatment: avoiding weight regain. CMAJ 2009, 180, 997.

4. Weiss EC, Galuska DA, Kettel-Khan L, et al. Weight Regain in U.S. Adults Who Experienced Substantial Weight Loss, 1999-2002. Am J Prev Med 2007, 33, 34-40.

5. Turk MW, Yang K, Hravnak M, et al. Randomized clinical trials of weight-loss maintenance: A review. J Cardiovasc Nurs 2009, 24, 58-80.

6. Kraschnewski JL, Boan J, Esposito J, et al. Long-term weight loss maintenance in the United States. Int J Obes 2010, 34, 1644-1654.

7. Greenway FL. Physiological adaptations to weight loss and factors favouring weight regain. Int J Obes 2015, 39, 1188-1196.

8. Mariman ECM. Human biology of weight maintenance after weight loss. J. Nutrigenet. Nutrigenomics 2012, 5, 13-25.

9. Elfhag $K$, Rössner S. Who succeeds in maintaining weight loss? A conceptual review of factors associated with weight loss maintenance and weight regain. Obes Rev 2005, 6, 67-85. 
10. Aller EEJG, Larsen TM, Claus $\mathrm{H}$, et al. Weight loss maintenance in overweight subjects on ad libitum diets with high or low protein content and glycemic index: the DIOGENES trial 12-month results. Int J Obes (Lond) 2014, 38, 1511-1517.

11. Larsen TM, Dalskov SM, van Baak M, et al. Diets with high or low protein content and glycemic index for weight-loss maintenance. N Engl J Med 2010, 363, 2102-2113.

12. Claessens M, van Baak MA, Monsheimer S, et al. The effect of a low-fat, high-protein or high-carbohydrate ad libitum diet on weight loss maintenance and metabolic risk factors. Int J Obes 2009, 33, 296-304.

13. Westerterp-Plantenga MS, Lejeune MPGM, Nijs I, et al. High protein intake sustains weight maintenance after body weight loss in humans. Int J Obes 2004, 28, 57-64.

14. Hursel R, Westerterp-Plantenga MS. Green tea catechin plus caffeine supplementation to a high-protein diet has no additional effect on body weight maintenance after weight loss. Am J Clin Nutr 2009, 89, 822-830.

15. Sacks FM, Bray GA, Carey VJ, et al. Comparison of Weight-Loss Diets with Different Compositions of Fat, Protein, and Carbohydrates. N Engl J Med 2009, 360, 859-873.

16. Kjølbæk L, Sørensen LB, Søndertoft NB, et al. Protein supplements after weight loss do not improve weight maintenance compared with recommended dietary protein intake despite beneficial effects on appetite sensation and energy expenditure: a randomized, controlled, double-blinded trial. Am J Clin Nutr 2017, 106, 684-697.

17. Roumans NJT, Vink RG, Fazelzadeh P, et al. A role for leukocyte integrins and extracellular matrix remodeling of adipose tissue in the risk of weight regain after weight loss. Am J Clin Nutr 2017, 105, 1054-1062.

18. Roumans NJT, Camps SG, Renes J, et al. Weight loss-induced stress in subcutaneous adipose tissue is related to weight regain. Br J Nutr 2016, 115, 913-920.

19. Cavicchia PP, Steck SE, Hurley TG, et al. A New Dietary Inflammatory Index Predicts Interval Changes in Serum High-Sensitivity C-Reactive Protein. J Nutr 2009, 139, 2365-2372.

20. Shivappa N, Steck SE, Hurley TG, et al. Designing and developing a literature-derived, population-based dietary inflammatory index. Public Health Nutr 2014, 17, 1689-1696.

21. Shivappa N, Steck SE, Hurley TG, et al. A population-based dietary inflammatory index predicts levels of C-reactive protein in the Seasonal Variation of Blood Cholesterol Study (SEASONS). Public Health Nutr 2014, 17, 1825-1833.

22. Shivappa N, Hébert JR, Rietzschel ER, et al. Associations between dietary inflammatory index and inflammatory markers in the Asklepios Study. Br J Nutr 2015, 113, 665-671.

23. Vink RG, Roumans NJT, Arkenbosch LAJ, et al. The effect of rate of weight loss on longterm weight regain in adults with overweight and obesity. Obesity 2016, 24, 321-327.

24. Netherlands Nutrition Center. Richtlijnen voedselkeuze. Available online: http://www. voedingscentrum.nl/ professionals/schijf-van-vijf/Richtlijnen.aspx (accessed on Aug 19, 2015).

25. Willett W, Stampfer MJ. Total energy intake: implications for epidemiologic analyses. Am J Epidemiol 1986, 124, 17-27. 
26. Tabung FK, Smith-Warner SA, Chavarro JE, et al. An Empirical Dietary Inflammatory Pattern Score Enhances Prediction of Circulating Inflammatory Biomarkers in Adults. $J$ Nutr 2017, 147, 1567-1577.

27. Baecke JAH, Burema J, Frijters JER. A short questionnaire for the measurement of habitual physical activity in epidemiological studies. Am J Clin Nutr 1982, 36, 936-942.

28. Vicente AR, Manganaris GA, Sozzi GO, et al. Nutritional Quality of Fruits and Vegetables. In Postharvest Handling; 2009; pp. 57-106 ISBN 9780123741127.

29. Gebauer SK, Psota TL, Harri WS, et al. n-3 Fatty acid dietary recommendations and food sources to achieve essentiality and cardiovascular benefits. Am J Clin Nutr 2006, 83(6 Suppl), 1526S-1535S.

30. Kong LC, Wuillemin P-H, Bastard J-P. et al. Insulin resistance and inflammation predict kinetic body weight changes in response to dietary weight loss and maintenance in overweight and obese subjects by using a Bayesian network approach. Am J Clin Nutr 2013, 98, 1385-1394.

31. Ruiz-Canela M, Zazpe I, Shivappa N, et al. Dietary inflammatory index and anthropometric measures of obesity in a population sample at high cardiovascular risk from the PREDIMED (PREvención con Dleta MEDiterránea) trial. Br J Nutr 2015, 113, 984-995.

32. Ramallal R, Toledo E, Martínez JA, et al. Inflammatory Potential of Diet, Weight Gain, and Incidence of Overweight/Obesity: The SUN Cohort. Obesity 2017, 25, 997-1005.

33. Gleeson M, Bishop NC, Stensel DJ, et al. The anti-inflammatory effects of exercise: mechanisms and implications for the prevention and treatment of disease. Nat Rev Immunol 2011, 11, 607-615.

34. Morais JBS, Severo JS, Santos LR, et al. Role of Magnesium in Oxidative Stress in Individuals with Obesity. Biol Trace Elem Res 2017, 176, 20-26.

35. Solini A, Santini E, Ferrannini E. Effect of short-term folic acid supplementation on insulin sensitivity and inflammatory markers in overweight subjects. Int J Obes 2006, 30, 11971202.

36. Gunanti IR, Marks GC, Al-Mamun A, et al. Low serum vitamin B-12 and folate concentrations and low thiamin and riboflavin intakes are inversely associated with greater adiposity in mexican american children. J Nutr 2014, 144, 2027-2033.

37. Zhou S-S, Li D, Zhou Y-M, et al. B-vitamin consumption and the prevalence of diabetes and obesity among the US adults: population based ecological study. BMC Public Health 2010, 10, 746.

38. Mazur-Bialy Al, Pocheć E. Riboflavin reduces pro-inflammatory activation of adipocytemacrophage co-culture. Potential application of vitamin B2 enrichment for attenuation of insulin resistance and metabolic syndrome development. Molecules 2016, 21(12), 1724.

39. Mazur-Bialy Al, Pocheć E. Vitamin B2 deficiency enhances the pro-inflammatory activity of adipocyte, consequences for insulin resistance and metabolic syndrome development. Life Sci 2017, 178, 9-16. 
Supplementary Table 3.1. Anthropometric data throughout the weight loss intervention.

\begin{tabular}{|c|c|c|c|c|c|c|c|c|}
\hline & $\begin{array}{l}\text { Baseline } \\
\text { (M1) }\end{array}$ & & $\begin{array}{l}\text { Weight Loss } \\
\text { Period (M2) }\end{array}$ & & $\begin{array}{l}\text { Weight Stab } \\
\text { Period (M3) }\end{array}$ & & $\begin{array}{l}\text { Follow Up } \\
\text { Period (M4) }\end{array}$ & \\
\hline & $\begin{array}{l}\text { LCD } \\
(n=29)\end{array}$ & $\begin{array}{l}\text { VLCD } \\
(n=28)\end{array}$ & $\operatorname{LCD}(n=29)$ & $\operatorname{VLCD}(n=28)$ & $\operatorname{LCD}(n=29)$ & $\operatorname{VLCD}(n=28)$ & $\operatorname{LCD}(n=28)$ & $\operatorname{VLCD}(n=27)$ \\
\hline Age (years) & $51.8 \pm 1.9$ & $50.7 \pm 1.5$ & & & & & & \\
\hline Weight (kg) & $92.4 \pm 1.9$ & $92.6 \pm 1.8$ & $84.2 \pm 1.9$ & $83.6 \pm 1.6$ & $84.0 \pm 1.9$ & $83.3 \pm 1.7$ & $88.4 \pm 2.0$ & $88.1 \pm 1.9$ \\
\hline BMI (kg/m2) & $31.3 \pm 0.5$ & $31.0 \pm 0.4$ & $28.6 \pm 0.5$ & $28.0 \pm 0.4$ & $28.5 \pm 0.5$ & $27.9 \pm 0.4$ & $30.0 \pm 0.5$ & $29.2 \pm 0.5$ \\
\hline Fat free mass (\%) & $60.1 \pm 1.8$ & $60.3 \pm 1.5$ & $65.5 \pm 2.1$ & $65.0 \pm 1.8$ & $66.2 \pm 2.1$ & $66.2 \pm 1.8$ & $63.5 \pm 2.0$ & $63.9 \pm 1.8$ \\
\hline Fat mass $(\mathrm{kg})$ & $36.6 \pm 1.7$ & $36.2 \pm 1.2$ & $29.0 \pm 1.9$ & $28.8 \pm 1.4$ & $28.3 \pm 2.0$ & $27.5 \pm 1.3$ & $32.2 \pm 2.0$ & $31.3 \pm 1.5$ \\
\hline Fat free mass (kg) & $55.4 \pm 2.2$ & $55.9 \pm 2.2$ & $54.9 \pm 2.1$ & $54.3 \pm 2.2$ & $55.2 \pm 2.2$ & $55.1 \pm 2.3$ & $56.0 \pm 2.3$ & $56.1 \pm 2.3$ \\
\hline Waist circumference (cm) & $102.6 \pm 2.0$ & $101.9 \pm 1.5$ & $95.3 \pm 1.8$ & $94.2 \pm 1.4$ & $94.3 \pm 2.0$ & $95.0 \pm 1.3$ & $98.3 \pm 1.9$ & $97.9 \pm 1.6$ \\
\hline Hip circumference (cm) & $110.8 \pm 1.3$ & $111.1 \pm 1.1$ & $105.8 \pm 1.4$ & $105.2 \pm 1.0$ & $104.6 \pm 1.4$ & $104.9 \pm 0.9$ & $106.7 \pm 1.8$ & $105.7 \pm 1.3$ \\
\hline
\end{tabular}

No significant differences were found between LCD and VLCD at any time point. 
Supplementary Table 3.2. Data on dietary intake, dietary inflammatory index, and physical activity at D2 and D3.

\begin{tabular}{|c|c|c|c|c|c|c|}
\hline & \multicolumn{3}{|c|}{$\begin{array}{l}\text { Weight Stable } \\
\text { (D2) }\end{array}$} & \multicolumn{3}{|c|}{$\begin{array}{l}\text { Follow Up } \\
\text { (D3) }\end{array}$} \\
\hline & LCD & VLCD & All & LCD & VLCD & All \\
\hline Energy intake (kcal/day) & $1666 \pm 89$ & $1614 \pm 91$ & $1641 \pm 64$ & $1773 \pm 147$ & $1827 \pm 100$ & $1800 \pm 88$ \\
\hline Protein (\%) ${ }^{a}$ & $21.9 \pm 1.0$ & $20.5 \pm 0.8$ & $21.2 \pm 0.6$ & $18.2 \pm 1.0$ & $19.4 \pm 0.8$ & $18.8 \pm 0.6^{\# \#}$ \\
\hline Carbohydrate (\%) ${ }^{\mathrm{a}}$ & $46.6 \pm 1.6$ & $47.2 \pm 0.9$ & $46.9 \pm 0.9$ & $48.5 \pm 1.4$ & $45.3 \pm 1.6$ & $46.9 \pm 1.1$ \\
\hline Sugars (\%) ${ }^{\mathrm{a}}$ & $22.1 \pm 1.5$ & $19.3 \pm 1.2$ & $20.8 \pm 1.0$ & $12.9 \pm 1.1$ & $11.06 \pm 0.77$ & $11.97 \pm 0.69$ \\
\hline Fat $(\%)^{\mathrm{a}}$ & $30.2 \pm 1.3$ & $31.0 \pm 1.0$ & $30.7 \pm 0.8$ & $30.9 \pm 1.2$ & $33.2 \pm 1.5$ & $32.1 \pm 0.9$ \\
\hline Saturated fat $(\mathrm{g} / 1000 \mathrm{kcal})^{\mathrm{b}}$ & $11.6 \pm 0.6$ & $11.9 \pm 0.5$ & $11.7 \pm 0.4$ & $11.9 \pm 0.8$ & $13.7 \pm 0.8$ & $12.8 \pm 0.6$ \\
\hline Trans fat $(\mathrm{g} / 1000 \mathrm{kcal})^{\mathrm{b}}$ & $0.87 \pm 0.15$ & $0.90 \pm 0.07$ & $0.89 \pm 0.09$ & $0.79 \pm 0.09$ & $1.00 \pm 0.10$ & $0.89 \pm 0.068$ \\
\hline MUFA (mg/ $1000 \mathrm{kcal})^{\mathrm{b}}$ & $12.2 \pm 0.8$ & $11.7 \pm 0.5$ & $11.9 \pm 0.5$ & $11.9 \pm 0.5$ & $12.8 \pm 0.61$ & $12.3 \pm 0.4$ \\
\hline PUFA (mg/ $1000 \mathrm{kcal})^{\mathrm{b}}$ & $6.36 \pm 0.37$ & $7.40 \pm 0.45$ & $6.85 \pm 0.30$ & $7.15 \pm 0.45$ & $6.66 \pm 0.54$ & $6.91 \pm 0.35$ \\
\hline Omega 3 fatty acids $(\mathrm{mg} / 1000 \mathrm{kcal})^{\mathrm{b}}$ & $0.88 \pm 0.08$ & $0.83 \pm 0.07$ & $0.86 \pm 0.05$ & $0.91 \pm 0.14$ & $0.85 \pm 0.10$ & $0.88 \pm 0.08$ \\
\hline Omega 6 fatty acids $(\mathrm{mg} / 1000 \mathrm{kcal})^{\mathrm{b}}$ & $4.98 \pm 0.30$ & $5.79 \pm 0.44$ & $5.36 \pm 0.26$ & $5.36 \pm 0.37$ & $5.27 \pm 0.45$ & $5.31 \pm 0.29$ \\
\hline Cholesterol $(\mathrm{mg} / 1000 \mathrm{kcal})^{\mathrm{b}}$ & $116.6 \pm 12.1$ & $96.5 \pm 9.1$ & $107.2 \pm 7.8$ & $98.72 \pm 10.01$ & $115.5 \pm 12.9$ & $107.1 \pm 8.2$ \\
\hline Fiber $(\mathrm{g} / 1000 \mathrm{kcal})^{\mathrm{b}}$ & $13.82 \pm 0.70$ & $15.09 \pm 0.93$ & $14.42 \pm 0.57$ & $12.79 \pm 0.86$ & $12.40 \pm 0.59$ & $12.59 \pm 0.52^{\#}$ \\
\hline Alcohol $(\mathrm{g} / 1000 \mathrm{kcal})^{\mathrm{b}}$ & $1.93 \pm 0.66$ & $1.76 \pm 0.75$ & $1.85 \pm 0.49$ & $3.26 \pm 0.92$ & $3.02 \pm 0.93$ & $3.14 \pm 0.65$ \\
\hline Magnesium (mg/ $1000 \mathrm{kcal})^{\mathrm{b}}$ & $194.9 \pm 7.1$ & $188.3 \pm 7.1$ & $191.8 \pm 5.0$ & $181.7 \pm 10.7$ & $177.9 \pm 6.7$ & $179.8 \pm 6.2$ \\
\hline Iron $(\mathrm{mg} / 1000 \mathrm{kcal})^{\mathrm{b}}$ & $7.17 \pm 0.32$ & $7.10 \pm 0.26$ & $7.14 \pm 0.21$ & $7.31 \pm 0.55$ & $6.89 \pm 0.21$ & $7.10 \pm 0.29$ \\
\hline Selenium (mg/ $1000 \mathrm{kcal})^{\mathrm{b}}$ & $35.2 \pm 2.6$ & $28.6 \pm 2.4$ & $32.1 \pm 1.8$ & $28.3 \pm 2.3$ & $28.9 \pm 2.8$ & $28.6 \pm 1.8$ \\
\hline Zinc (mg/ $1000 \mathrm{kcal})^{\mathrm{b}}$ & $6.19 \pm 0.23$ & $6.17 \pm 0.36$ & $6.18 \pm 0.21$ & $5.45 \pm 0.43$ & $5.56 \pm 0.30$ & $5.50 \pm 0.26^{\#}$ \\
\hline Vitamin A $(\mu \mathrm{g} / 1000 \mathrm{kcal})^{\mathrm{b}}$ & $355.5 \pm 29.6$ & $626.0 \pm 134.2$ & $483.1 \pm 67.2$ & $403.2 \pm 44.1$ & $451.0 \pm 58.3$ & $427.1 \pm 36.3$ \\
\hline Vitamin D (mg/ $1000 \mathrm{kcal})^{\mathrm{b}}$ & $1.88 \pm 0.19$ & $2.09 \pm 0.18$ & $1.98 \pm 0.13$ & $2.08 \pm 0.27$ & $2.19 \pm 0.50$ & $2.13 \pm 0.28$ \\
\hline Vitamin $E(\mathrm{mg} / 1000 \mathrm{kcal})^{\mathrm{b}}$ & $6.45 \pm 0.45$ & $6.52 \pm 0.59$ & $6.49 \pm 0.36$ & $7.17 \pm 0.58$ & $6.60 \pm 0.60$ & $6.89 \pm 0.42$ \\
\hline Thiamin $(\mathrm{mg} / 1000 \mathrm{kcal})^{\mathrm{b}}$ & $0.82 \pm 0.05$ & $0.80 \pm 0.06$ & $0.81 \pm 0.04$ & $0.85 \pm 0.08$ & $0.67 \pm 0.05$ & $0.76 \pm 0.05$ \\
\hline Riboflavin (mg/ $1000 \mathrm{kcal})^{\mathrm{b}}$ & $1.06 \pm 0.07$ & $0.97 \pm 0.07$ & $1.02 \pm 0.05$ & $0.91 \pm 0.09$ & $0.88 \pm 0.10$ & $0.89 \pm 0.07$ \\
\hline Vitamin B6 (mg/ $1000 \mathrm{kcal})^{\mathrm{b}}$ & $1.36 \pm 0.09$ & $1.41 \pm 0.10$ & $1.38 \pm 0.07$ & $1.25 \pm 0.10$ & $1.07 \pm 0.08$ & $1.16 \pm 0.07^{\# \#}$ \\
\hline Folate $(\mu \mathrm{g} / 1000 \mathrm{kcal})^{\mathrm{b}}$ & $129.4 \pm 9.6$ & $115.9 \pm 9.7$ & $123.03 \pm 6.8$ & $121.4 \pm 15.19$ & $106.6 \pm 5.1$ & $114.0 \pm 7.99$ \\
\hline Vitamin B12 (mg/ $1000 \mathrm{kcal})^{\mathrm{b}}$ & $3.57 \pm 0.77$ & $3.06 \pm 0.73$ & $3.33 \pm 0.53$ & $2.94 \pm 0.64$ & $2.80 \pm 0.34$ & $2.86 \pm 0.36$ \\
\hline Niacin $(\mathrm{mg} / 1000 \mathrm{kcal})^{\mathrm{b}}$ & $11.92 \pm 0.76$ & $10.99 \pm 0.67$ & $11.48 \pm 0.51$ & $10.84 \pm 0.92$ & $10.30 \pm 0.69$ & $10.57 \pm 0.57$ \\
\hline Vitamin C (mg/ $1000 \mathrm{kcal})^{\mathrm{b}}$ & $76.2 \pm 8.1$ & $57.2 \pm 6.5$ & $67.2 \pm 5.4$ & $52.5 \pm 7.0$ & $57.4 \pm 6.3$ & $54.9 \pm 4.7$ \\
\hline Dietary Inflammatory Index^ & $4.37 \pm 0.36$ & $4.10 \pm 0.44$ & $4.24 \pm 0.28$ & $4.60 \pm 0.54$ & $5.14 \pm 0.35$ & $4.87 \pm 0.32$ \\
\hline Physical Activity & $9.21 \pm 0.22$ & $8.97 \pm 0.18$ & $9.06 \pm 0.14$ & $8.95 \pm 0.20$ & $8.60 \pm 0.21$ & $8.80 \pm 0.14^{\# \#}$ \\
\hline
\end{tabular}

${ }^{a}$ Dietary intake as $\%$ of total energy intake; ${ }^{b}$ Dietary intake in gram or milligram per $1000 \mathrm{kcal}$ of total energy intake; $\wedge$ Dietary inflammatory index: The sum of dietary inflammatory scores of each nutrient as calculated by Tabung et al [26]; $P$ value ${ }^{\#}<0.05, " \#<0.01$ and ${ }^{\# \#}<0.001$ for difference between D2 and D3 (paired t-test or Wilcoxon test). No significant differences were found between LCD and VLCD groups (independent t-test) at any time point. LCD: low calorie diet group ; VLCD: very low calorie diet group, MUFA: mono-unsaturated fatty acid; PUFA: poly-unsaturated fatty acid. 
BETWEEN INFLAMMATORY PROPERTIES OF DIET AND GENETIC VARIATION IN BODYWEIGHT REGULATION 


\section{CHAPTER 4}

\section{Low Calorie Low Inflammatory Diet is Beneficial to Reduce hs-CRP during a Weight Loss Intervention among Individuals with Obesity}

Harry Freitag Luglio Muhammad ${ }^{1,2}$,

Edwin C. Mariman², Marleen A. van Baak²

${ }^{1}$ Department of Nutrition and Health, Universitas Gadjah Mada, Yogyakarta, 55281, Indonesia

${ }^{2}$ Department of Human Biology, NUTRIM School of Nutrition and Translational Research in Metabolism, Maastricht Medical Centre+, 6200 MD Maastricht, The Netherlands 


\section{ABSTRACT}

Obesity is associated with increased systemic inflammation. The objective of this study was to investigate the effect of a low calorie low inflammatory diet (LCID) on inflammation markers, body weight and metabolic syndrome parameters in obese adults. We hypothesize that LCID can provide a beneficial effect on inflammation markers in addition to a reduction of body weight and metabolic syndrome parameters. This was a randomized controlled trial conducted for 8 weeks in 61 male and female Indonesian adults with obesity (51 completers). Subjects were randomly divided into 2 groups: a low-calorie diet (LCD) and a LCID group. Markers of inflammation (hs-CRP, TNF-alpha, and IL-6), anthropometric variables and metabolic syndrome parameters (blood pressure, lipid profile, and fasting glucose) were measured before and at the end of the intervention. At the end of the intervention, there was a significant increase of plasma TNF-alpha $(p<0.001)$ and IL-6 concentrations ( $p=0.015)$, but no significant changes in hs-CRP level $(p=0.707)$ in the whole group. Subjects in the LCID group had a lower hs-CRP $(p=0.029)$, compared to those in the LCD group, but no difference was seen in TNF-alpha $(p=0.319)$ and IL- 6 $(p=0.628)$. Subjects in both groups had a significant reduction in body weight, body fat, lipid profile and blood pressure (all $p<0.05$ ) with no differences between groups (all $p>0.05$ ). This study showed that the LCID had beneficial effects on hs-CRP during a weight loss intervention compared to the LCD but not on TNF-alpha, and IL-6, and this effect was independent of changes in body composition. Compared to LCD, LCID did not influence difference in the changes of body weight, body composition and metabolic syndrome parameters markers.

Keywords: inflammation, diet, obesity, weight loss, CRP. 


\section{INTRODUCTION}

Obesity affects millions of adults worldwide and this condition is associated with increased risk for non-communicable diseases, such as type 2 diabetes mellitus and cardiovascular diseases [1]. Inflammation has been suggested as an important mediator between obesity and the development of cardiovascular diseases [2,3]. Obesity is associated with increased systemic and adipose tissue inflammation [4]. Hypertrophic adipose tissue shows elevated immune cell infiltration and higher production of pro-inflammatory cytokines [4]. The role of inflammation in the development of diabetes mellitus, hypertension, and dyslipidemia has been investigated in the past few decades [3] and studies suggest that inflammation leads to insulin resistance, disruption of the renin-angiotensin system, and damage of the arterial wall [3]. The insulin resistance then leads to increased production of hepatic lipoproteins leading to dyslipidemia.

In individuals with obesity, weight loss interventions are associated with a reduction of the clinical signature of cardiovascular diseases and diabetes mellitus (such as elevated blood pressure, triglycerides, low-density lipoprotein cholesterol, fasting glucose and HbA1c) [5] as well as of premature mortality [6]. Weight loss was also associated with a reduction in circulating inflammation markers, such as hs-CRP (high sensitivity C-reactive protein), in several studies [7-9]. However, other studies found no reduction in hs-CRP after weight loss $[10,11]$ and adipose tissue inflammatory pathways have been reported to be up-regulated during calorie restriction and these pathways were only gradually down-regulated during the follow-up period [12,13]. In addition to hs-CRP, previous investigations showed a controversy whether other inflammatory markers such as plasma TNF-alpha and IL-6 concentrations were increased or unchanged at the end of a weight loss program $[14,15,16]$.

One of the factors affecting the inflammatory status is diet composition [17]. Several tools to assess the inflammatory properties of the diet have been developed such as the dietary inflammatory index (DII) [18], the dietary inflammation score [19] and the food-based index of dietary inflammatory potential [20]. The score on these indices has been shown to be associated with systemic inflammation in populationbased studies [19-22].

The main objective of this study was to investigate the effect of weight loss on different inflammatory markers and whether this effect is modifiable by diet in adults with obesity. Thus, we developed a Low Calorie Low Inflammatory Diet (LCID), a diet with the aim to induce a calorie deficit as well as to reduce inflammation during a weight loss program. The diet was inspired by Mediterranean diet principle which previously was shown to reduce inflammation [23]. We hypothesize that LCID can provide a beneficial effect on inflammation markers in addition to a reduction of body weight and metabolic syndrome parameters. If the composition of the energyrestricted diet is indeed able to have a (further) beneficial effect on the inflammatory status, this might lead to an improved standard for dietary counseling for weight loss. 


\section{MATERIALS AND METHODS}

\section{Study Subjects}

This was a randomized controlled trial in Indonesian male and female obese adults. The intervention was conducted in Yogyakarta, Indonesia. The inclusion criteria for this study were adults between 21 and 56 years old and body mass index (BMI) higher than $27.5 \mathrm{~kg} / \mathrm{m}^{2}$. The cut off point is lower in Asian population because the health risk is greater than those non-Asian population with the same BMI [24]. The exclusion criteria were current chronic diseases such as type 2 diabetes mellitus and heart diseases, elevated blood pressure (systolic $>140 \mathrm{~mm} \mathrm{Hg}$ and/or diastolic > $90 \mathrm{mmHg}$ ) and blood glucose concentrations (higher than $11.1 \mathrm{mmol} / \mathrm{L}$ for random and $6.94 \mathrm{mmol} / \mathrm{L}$ for fasting glucose), pregnancy, breastfeeding, smoking, long-term consumption of certain drugs (such as metformin, allopurinol and simvastatin), being on a weight loss diet or using weight loss supplements, drugs or herbal preparations. This study followed the ethical guidelines of the 1975 Declaration of Helsinki. Registered under Medical and Health Research Ethics Committee, Faculty of Medicine, Public Health and Nursing, Universitas Gadjah Mada, Indonesia identifier number KE/0560/05/2017.

Subjects were recruited by announcements via flyers, a webpage, and social media in October 2017. A total of 195 individuals applied to become participants via short messages, phone, and email. Of those 195,77 subjects had a BMI above 27.5 $\mathrm{kg} / \mathrm{m} 2$. Those subjects were then invited to the university for measurements of blood glucose and blood pressure. 61 subjects were eligible and willing to participate in the study after having the protocol explained, including the changes in dietary intake and an exercise routine at the university 2 times a week. The minimum number of subjects in each group was calculated based on $\beta$ value $10 \%, \alpha$ value 0.05 , expected mean difference in $\mathrm{hs}-\mathrm{CRP}=1.3 \mathrm{mg} / \mathrm{L}$ and standard deviation $=1.9 \mathrm{mg} / \mathrm{L}$ (moderate change) [25]. Result from the calculation was a total of 23 subjects in each group.

Eligible subjects were randomized into 2 groups, the low-calorie diet group (LCD) and the low calorie low inflammatory diet group (LCID). The randomization was done using an online randomization tool (https://www.randomizer.org) stratified for sex. Subjects were blinded to the type of dietary group while researchers and nutritionists were not blinded. The intervention included dietary counseling and an exercise program. The duration of the intervention was 8 weeks.

\section{Dietary Recommendations}

The dietary recommendations for weight loss in this study were given by trained nutritionists. The counseling sessions were done at the beginning of the study, and every 2 weeks thereafter. Subjects were asked to stay on the LCD and LCID regime until post-test assessments were done. 
The dietary recommendations given by nutritionists were based on two components: 1) explanation of the principles of the diet and 2) prescribing a one-day meal plan that could be followed by the participant. Subjects were allowed to change their meal plan by exchange with other meals with similar caloric and macronutrient contents. They were provided with a list of foods and their portion size with a similar calorie and macronutrient content. If subjects had problems following the meal plan that had been provided, the nutritionists could help them arrange the closest meal plan that the subject could achieve. The recommended one-day meal plan was divided into 5 meals per day: breakfast, lunch, dinner and 2 snacks (morning and afternoon).

Subjects in this study were divided into two groups: LCD and LCID. The recommendation for total energy intake was the same in both groups, i.e. $1500 \mathrm{kcal}$ per day. Subjects in both groups also had the same distribution of calories over their daily meals. However, subjects in the LCD and the LCID group followed different dietary principles. Subjects in the LCD group only had to adhere to the reduction in energy intake, subjects in the LCID group were also given advice on how to lower the inflammatory properties of their diet. For instance, consuming white meat or soy products instead of red meat as the source of protein; always eat fruit in between meals as snacks, avoid sugary food such as cake and other party products. Details about the difference in dietary advice between the low-calorie diet and low calorie low inflammatory diet groups can be found in Table 4.1.

Table 4.1. The dietary recommendations in the LCD and LCID groups.

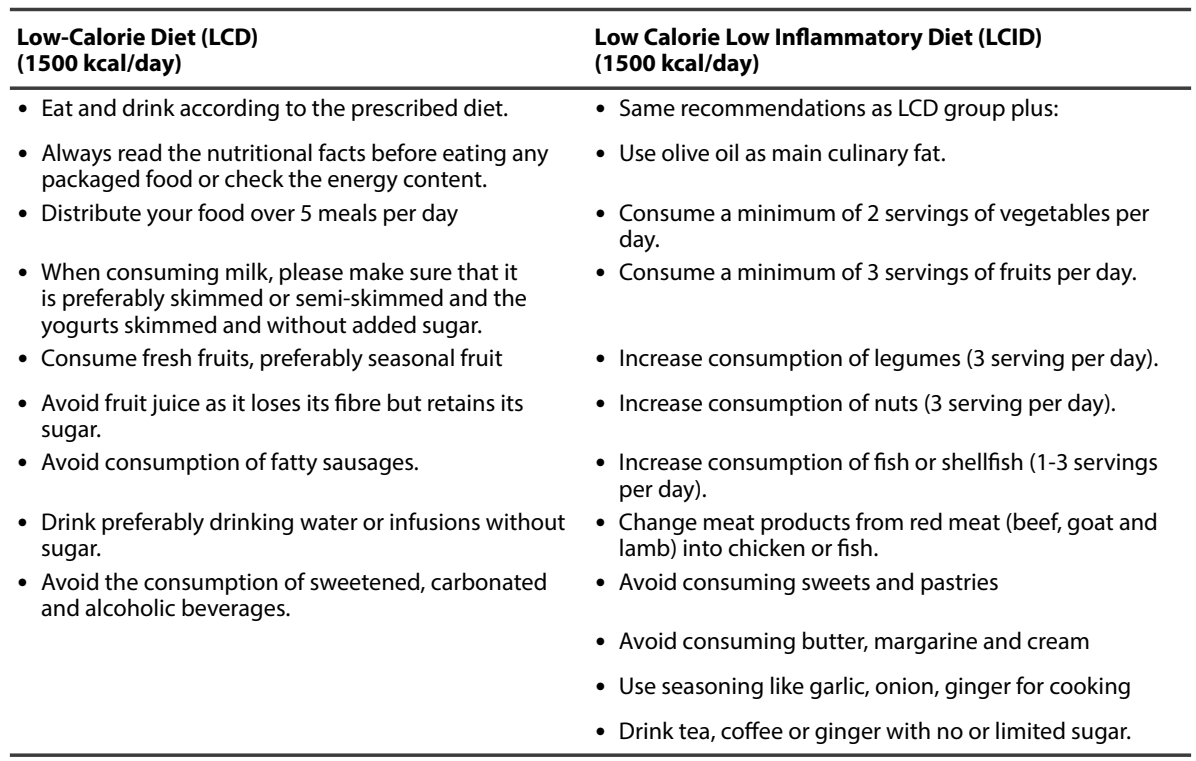


The LCID regime was based on the principles of the Mediterranean diet (https://dietamediterranea.com/nutricion-saludable-ejercicio-fisico/) because this type of diet was previously shown to be associated with a reduction of inflammatory markers compared with a typical western diet [23]. The compliance with this dietary recommendation was assessed by the Mediterranean Diet score [26] as well as from the intake of its food components (vegetables, fruits, white meat, red meat, legumes and fish/seafood).

\section{Exercise}

The exercise was an integral part of this intervention study. Subjects in the LCD and LCID groups followed the same exercise regime. This included one session of aerobic exercise and one session of dumbbell exercise every week. The dumbbell combinedresistance exercise was a combination of aerobic and strength exercise where subjects used dumbbells or their own weight. The duration of each exercise session was 60 minutes, which was composed of 15 minutes of warming-up, 30 minutes of core exercise and 15 minutes of cooling down. All the exercise sessions were done in a group setting with an instructor leading the group exercises. In total, subjects undertook 16 sessions of exercise. The exercise program was the same in both groups. Subjects in the LCD and LCID groups exercised in different group sessions with a different schedule. The aim of this separation was to prevent information exchange between subjects in the two groups.

\section{Anthropometric Measurements}

Anthropometric measurements were done to evaluate the effect of diet on changes in adiposity. The anthropometric measures included body weight $(\mathrm{kg})$, body mass index (BMI) $\left(\mathrm{kg} / \mathrm{m}^{2}\right)$, total body fat (\%), visceral fat (\%), subcutaneous fat (\%), muscle mass $(\%)$, waist circumference $(\mathrm{cm})$, hip circumference $(\mathrm{cm})$, and waist-to-hip ratio (WHR). Body weight, percent body fat, total body fat, visceral fat, subcutaneous fat, and muscle mass were measured using a bioelectrical impedance body composition monitor and scale (0.01 kg precision; Omron Karada Scan HBF-375, Osaka, Japan). Height was measured using a wall-mounted tape $(0.1 \mathrm{~cm}$ precision, GEA medical, Jakarta, Indonesia). Waist and hip circumference were measured using a non-elastic tape $(0.1 \mathrm{~cm}$ precision). All anthropometric measurements were done by trained personnel using calibrated instruments at baseline and at the end of the intervention.

\section{Assessment of dietary intake and Mediterranean Diet (MD) score}

Dietary intake was assessed before the intervention (week 0 ) and at the end of the intervention (week 9). The dietary intake at week 0 and week 9 was assessed using a semi-quantitative food frequency questionnaire (SQ-FFQ). Together with the SQ$F F Q$, a separate questionnaire was used to assess the Mediterranean Diet (MD) 
score [26]. The SQ-FFQ that was used in this study has been validated [27] and used before in the same location in a similar study population [28]. The analysis of the SQ-FFQ data was based on the food data base of Indonesian foods and that of the United States Department of Agriculture [29]. Data collection for the SQ-FFQ was done by a face-to-face interview with trained nutritionists. The SQ-FFQ contains data on the amount of foods consumed and the frequency. Data on foods intake were transformed into the amount of consumed foods per day. Furthermore, analysis of individual nutrient intakes was done for each food and then compiled into total daily nutrient intake. The intake of energy, protein, fat, saturated fat, trans fat, cholesterol, monounsaturated fatty acid, polyunsaturated fatty acid, omega 3 fatty acid, omega 6 fatty acid, carbohydrate, fibre, alcohol, iron, magnesium, selenium, zinc, vitamin A, thiamin, riboflavin, niacin, vitamin B6, folate, vitamin B12, vitamin C, vitamin $D$, vitamin $E$, beta carotene, tea and caffeine was estimated because their association with inflammation [18].

The MD score was assessed according to Martínez-González et al [26]. The score was calculated based on 14 questions regarding foods and drinks that are encouraged or avoided in a Mediterranean diet: 1 ) The usage of olive oil as main culinary fat; 2) daily consumption of olive oil; 3) daily consumption of vegetables; 4) daily consumption of fruit; 5) daily consumption of red meat and other meat products; 6) daily consumption of butter, margarine or cream; 7) daily consumption of carbonated beverages; 8) weekly consumption of wine; 9) weekly consumption of legumes; 10) weekly consumption of fish or seafood; 11) weekly consumption of commercial sweets and pastries; 12) weekly consumption of nuts; 13) preferred consumption of white meat instead of red meat; 14) weekly consumption of sofrito (tomato sauce). A higher MD score represents higher adherence towards the Mediterranean diet principle.

Physical activity was assessed using the global physical activity questionnaire (GPAQ) [30]. This questionnaire contains information on the intensity and duration of several activities including work/job, transportation, house-related work and maintenance, recreation, exercise, and leisure-time physical activity. Each activity has a unique MET (metabolic equivalent of task) score, which represents the amount of energy used for a certain type of activity as multiple of resting metabolic rate. In order to obtain an overall picture of the individual's physical activity, all activities that have been reported in GPAQ are transformed into MET-minutes/week. The GPAQ was developed, validated for the Indonesian population and used before [30].

\section{Assessment of markers of the metabolic syndrome}

Blood pressure was measured using an Omron HEM 7120 Automatic Blood Pressure device (Omron, Japan). This measurement was done after at least 10 minutes rest from recent activity and the subjects were asked to sit in a comfortable sitting position with their left arm fully exposed and resting on a supportive surface at heart level. 
Blood pressures were measured three times on the left arm using an appropriate cuff size. For analysis, the average value of those three measurements was used.

Plasma concentrations of metabolic and inflammation markers were measured in blood samples which were collected in the morning after an 8-10 hours fast. A $5 \mathrm{~mL}$ blood sample was collected in a ethylenediaminetetraacetic acid (EDTA)containing tube. After collection, blood plasma was separated by centrifugation and stored at $-80 \mathrm{oC}$. Plasma concentrations of total cholesterol, high density lipoprotein cholesterol (HDL-c) and low-density lipoprotein cholesterol (LDL-C) were measured using the CHOD-PAP enzymatic photometric test. Plasma triglyceride concentration was measured using the glycerol phosphate oxidase (GPO) method. Fasting plasma glucose concentration was measured using the glucose hexokinase method (Diasys, Holzheim, Germany).

The presence of metabolic syndrome was established at baseline and at the end of the intervention based on the International Diabetes Federation guideline [31]. The parameter of metabolic syndrome includes central obesity (marked by waist circumference higher than $90 \mathrm{~cm}$ for men or $80 \mathrm{~cm}$ for women) and at least two of the following components: 1) raised triglycerides (higher than $1.7 \mathrm{mmol} / \mathrm{L}$ ); 2) reduced HDL-c (lower than $1.03 \mathrm{mmol} / \mathrm{L}$ for men or $1.29 \mathrm{mmol} / \mathrm{L}$ for women); 3) raised blood pressure (systolic higher than $130 \mathrm{mmHg}$ or diastolic higher than $85 \mathrm{mmHg}$ ); 4) raised fasting glucose (higher than $5.6 \mathrm{mmol} / \mathrm{L}$ ). Metabolic syndrome score was calculated by adding one of those components (waist circumference, triglyceride, $\mathrm{HDL}-\mathrm{C}$, blood pressure and fasting glucose) that higher than cut off value in sex-specific manner.

\section{Assessment of inflammation markers}

Fasting plasma concentrations of hs-CRP, TNF-alpha and IL- 6 were measured at baseline and at the end of the weight loss intervention. Hs-CRP, TNF-alpha and IL-6 were measured using enzyme immunoassays (DRG, USA and FineTest, China).

\section{Statistical Analysis}

JASP software (Version 0.8.3.1, The University of Amsterdam) was used for statistical analysis in this study. The anthropometric measures, metabolic syndrome components, inflammation markers, dietary intake, and physical activity were compared between subjects in the LCD and LCID group at baseline using an independent t-test. The difference in dietary intake (including total energy, nutrients intake, and Mediterranean diet score) between LCD and LCID, before and during intervention were analyzed using repeated measure ANOVA. The analysis was done on those with a complete dataset for each measurement. Main outcomes were the intervention (time) effect, the group effect and the time $x$ group interaction. Similar 
to dietary intake, the anthropometric measures, metabolic syndrome parameters and inflammation markers were compared between LCD and LCID group, before and at the end of the intervention using repeated measure ANOVA. Adjustment for sex and body fat changes was applied to the analysis of metabolic syndrome parameters, and inflammation markers. The relationships between dietary components during a weight loss program and inflammatory markers in the total group of subjects were examined using linear regression analysis. Statistical significance was obtained when the $p$-value was less than 0.05 . All statistical analyses were conducted 2-tailed.

\section{RESULTS}

This was a randomized controlled trial conducted among obese male and female adults in Indonesia. From 61 subjects who initially participated in this study, 30 subjects were assigned to the LCD group 31 subjects were assigned to the LCID group. Ten subjects dropped out ( 5 subjects in each group) during the intervention with the following reasons: 1 ) unable to follow the dietary regime and exercise due to personal reasons, 2) loss of interest and 3) loss of contact (Figure 4.1). There were no significant differences in anthropometric measures, metabolic syndrome parameters or inflammatory markers between the LCD and LCID group (Table 4.2; all p>0.05). Additionally, subjects in both groups had a comparable energy intake, and physical activity (Table 4.2; all p>0.05).

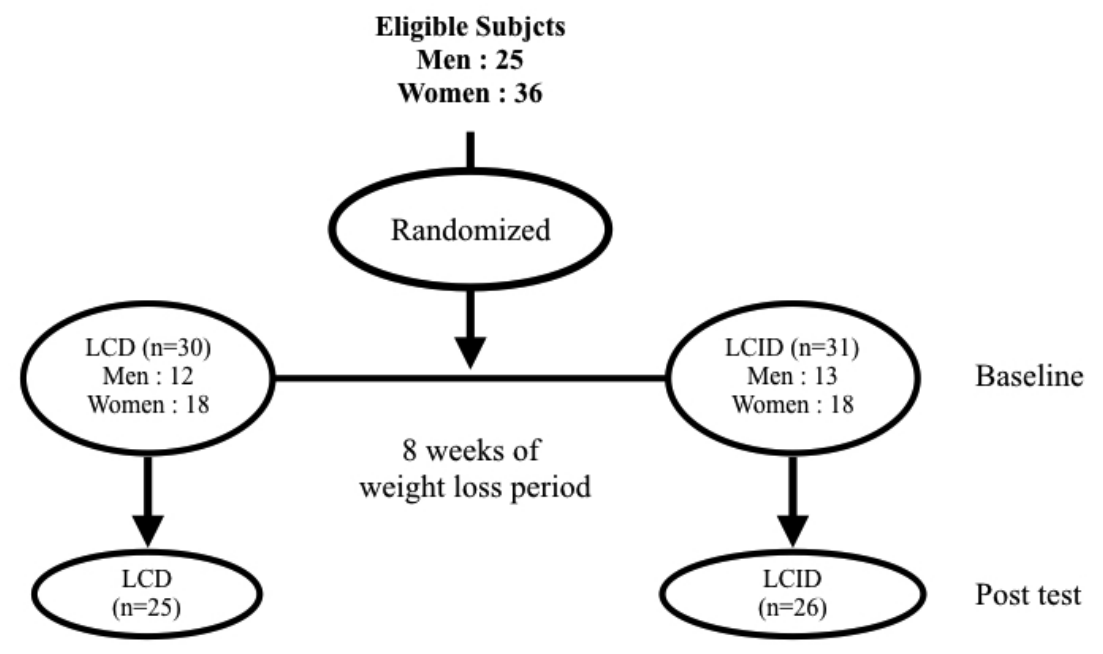

Figure 4.1. Study flow diagram. 
Table 4.2. Characteristics of subjects at baseline.

\begin{tabular}{|c|c|c|c|}
\hline & $\operatorname{LCD}(n=30)$ & $\operatorname{LCID}(n=31)$ & $p^{*}$ \\
\hline Male/female & $12 / 18$ & $13 / 18$ & \\
\hline Age (years) & $24.7 \pm 5.3$ & $24.0 \pm 5.9$ & 0.613 \\
\hline \multicolumn{4}{|l|}{ Anthropometric measures } \\
\hline Height (cm) & $161.6 \pm 10.1$ & $161.6 \pm 9.6$ & 0.994 \\
\hline Weight (kg) & $87.4 \pm 13.5$ & $87.3 \pm 16.8$ & 0.984 \\
\hline $\mathrm{BMI}\left(\mathrm{kg} / \mathrm{m}^{2}\right)$ & $33.5 \pm 4.1$ & $33.1 \pm 4.9$ & 0.731 \\
\hline Body fat (\%) & $35.9 \pm 4.9$ & $35.6 \pm 5.6$ & 0.826 \\
\hline Visceral fat (\%) & $16.2 \pm 16.2$ & $15.5 \pm 6.1$ & 0.644 \\
\hline Subcutaneous fat (\%) & $31.6 \pm 7.9$ & $31.1 \pm 8.6$ & 0.815 \\
\hline Muscle (\%) & $25.3 \pm 3.7$ & $25.5 \pm 4.1$ & 0.843 \\
\hline Waist circumference $(\mathrm{cm})$ & $96.5 \pm 9.8$ & $97.5 \pm 10.7$ & 0.711 \\
\hline Hip circumference $(\mathrm{cm})$ & $110.1 \pm 7.5$ & $109.3 \pm 10.5$ & 0.730 \\
\hline Waist-to-hip ratio & $0.88 \pm 0.07$ & $0.90 \pm 0.06$ & 0.233 \\
\hline Energy intake (kcal/day) & $2281 \pm 936$ & $2158 \pm 908$ & 0.605 \\
\hline Dietary inflammatory index score & $5.3 \pm 4.4$ & $5.0 \pm 4.4$ & 0.789 \\
\hline Physical activity (METs-min/weeks) & $1273 \pm 2946$ & $1845 \pm 2385$ & 0.407 \\
\hline \multicolumn{4}{|l|}{ Markers of the metabolic syndrome } \\
\hline Glucose (mmol/L) & $5.69 \pm 0.96$ & $5.74 \pm 1.3$ & 0.897 \\
\hline Triglycerides (mmol/L) & $1.47 \pm 0.71$ & $1.16 \pm 0.55$ & 0.066 \\
\hline Total cholesterol (mmol/L) & $4.85 \pm 0.92$ & $4.93 \pm 0.82$ & 0.713 \\
\hline $\mathrm{HDL}-\mathrm{c}(\mathrm{mmol} / \mathrm{L})$ & $1.71 \pm 0.31$ & $1.70 \pm 0.23$ & 0.857 \\
\hline LDL-c (mmol/L) & $4.60 \pm 1.06$ & $4.70 \pm 0.74$ & 0.655 \\
\hline Systolic blood pressure $(\mathrm{mmHg})$ & $112.5 \pm 11.6$ & $114.7 \pm 9.7$ & 0.422 \\
\hline Diastolic blood pressure $(\mathrm{mmHg})$ & $79.9 \pm 8.3$ & $80.9 \pm 7.1$ & 0.614 \\
\hline \multicolumn{4}{|l|}{ Inflammation markers } \\
\hline hs-CRP (mg/L) & $7.0 \pm 4.1$ & $6.6 \pm 3.1$ & 0.642 \\
\hline TNF-alpha (pg/mL) & $10.8 \pm 3.4$ & $11.1 \pm 3.2$ & 0.702 \\
\hline IL-6 (pg/mL) & $2.2 \pm 1.6$ & $3.5 \pm 2.8$ & 0.068 \\
\hline
\end{tabular}

*Independent t-test. Data are presented as mean \pm standard deviation. BMI: body mass index; hs-CRP: high sensitive C-reactive protein; HDL-c: high density lipoprotein cholesterol; IL-6: interleukin 6; LDL-c: low density lipoprotein cholesterol; TNF-alpha: tumor necrosis factor alpha; LCD: low calorie diet; LCID: low calorie low inflammatory diet

Dietary intake and physical activity of 47 out of 51 subjects were recorded before and at the end of the weight loss intervention (Table 4.3). Subjects in both groups reduced their dietary intake and there was no significant difference in total energy intake between groups $(p=0.901)$. The adherence to the low-calorie diet was not very strict in both groups, thus only a modest reduction in body weight was reported. We 
found no significant time $\mathrm{x}$ group interactions for macro and micronutrient intakes nor for physical activity during the intervention (all $p>0.05$ ). The MD score in both groups as well as intakes of MD score components (diet compositions) are shown in Supplementary Table 4.1. Subjects in the LCID as well as the LCD group had a small increment in the MD score $(p=0.034)$ during the intervention and no differences were seen between groups $(p=0.645)$. There was no difference in physical activity, including participation in the exercise program, between the LCD and LCID groups during the weight loss program $(p=0.585)$.

Table 4.3. Dietary intake and physical activity before and during the weight loss program.

\begin{tabular}{|c|c|c|c|c|c|c|c|}
\hline & \multicolumn{2}{|c|}{ Pre } & \multicolumn{2}{|c|}{ Post } & \multirow[b]{2}{*}{$p^{*}$} & \multirow[b]{2}{*}{$\mathrm{p}^{\wedge}$} & \multirow[b]{2}{*}{$p+$} \\
\hline & $\operatorname{LCD}(n=23)$ & $\operatorname{LCID}(n=24)$ & $\operatorname{LCD}(n=23)$ & $\operatorname{LCID}(n=24)$ & & & \\
\hline Energy (kcal) & $2233 \pm 203$ & $2143 \pm 200$ & $1946 \pm 130$ & $1817 \pm 146$ & 0.053 & 0.565 & 0.901 \\
\hline Protein (g/1000kcal) & $32.9 \pm 1.7$ & $32.2 \pm 1.6$ & $30.5 \pm 1.5$ & $33.3 \pm 1.4$ & 0.668 & 0.542 & 0.221 \\
\hline Fat (g/1000kcal) & $30.5 \pm 2.3$ & $28.4 \pm 2.2$ & $26.1 \pm 1.7$ & $27.5 \pm 1.8$ & 0.135 & 0.868 & 0.331 \\
\hline Saturated fat (g/1000kcal) & $12.6 \pm 1.0$ & $11.8 \pm 1.0$ & $10.5 \pm 0.7$ & $11.2 \pm 0.8$ & 0.143 & 0.978 & 0.417 \\
\hline Trans fat (g/1000kcal) & $0.10 \pm 0.02$ & $0.09 \pm 0.02$ & $0.06 \pm 0.02$ & $0.09 \pm 0.03$ & 0.088 & 0.661 & 0.088 \\
\hline Cholesterol (mg/1000kcal) & $104.9 \pm 12.8$ & $96.4 \pm 9.3$ & $87.8 \pm 11.8$ & $116.7 \pm 12.5$ & 0.881 & 0.428 & 0.078 \\
\hline MUFA (g/1000kcal) & $10.2 \pm 0.8$ & $9.5 \pm 0.7$ & $8.9 \pm 0.7$ & $9.4 \pm 0.7$ & 0.254 & 0.938 & 0.335 \\
\hline PUFA (g/1000kcal) & $5.1 \pm 0.4$ & $5.0 \pm 0.4$ & $4.4 \pm 0.4$ & $4.5 \pm 0.3$ & 0.057 & 0.917 & 0.641 \\
\hline Omega 3 fatty acid (g/1000kcal) & $0.14 \pm 0.02$ & $0.11 \pm 0.02$ & $0.14 \pm 0.02$ & $0.11 \pm 0.02$ & 0.995 & 0.245 & 0.774 \\
\hline Omega 6 fatty acid (g/1000kcal) & $0.40 \pm 0.07$ & $0.38 \pm 0.05$ & $0.30 \pm 0.05$ & $0.41 \pm 0.05$ & 0.485 & 0.418 & 0.228 \\
\hline Carbohydrate (g/1000kcal) & $146.5 \pm 5.7$ & $149.6 \pm 5.7$ & $159.8 \pm 3.9$ & $151.9 \pm 4.1$ & 0.073 & 0.656 & 0.203 \\
\hline Fiber (g/1000kcal) & $8.2 \pm 0.4$ & $8.9 \pm 0.6$ & $9.8 \pm 0.8$ & $9.7 \pm 0.6$ & 0.026 & 0.611 & 0.394 \\
\hline Alcohol (g/1000kcal) & $0.0 \pm 0.0$ & $0.6 \pm 0.6$ & $0.05 \pm 0.04$ & $0.01 \pm 0.01$ & 0.385 & 0.369 & 0.302 \\
\hline $\mathrm{Fe}(\mathrm{mg} / 1000 \mathrm{kcal})$ & $6.9 \pm 0.3$ & $6.8 \pm 0.4$ & $6.0 \pm 0.3$ & $6.7 \pm 0.4$ & 0.080 & 0.499 & 0.232 \\
\hline $\mathrm{Mg}(\mathrm{mg} / 1000 \mathrm{kcal})$ & $130.0 \pm 8.1$ & $141.0 \pm 10.0$ & $135.6 \pm 11.9$ & $141.4 \pm 10.4$ & 0.704 & 0.492 & 0.762 \\
\hline Se $(\mu \mathrm{g} / 1000 \mathrm{kcal})$ & $43.1 \pm 1.5$ & $40.9 \pm 1.3$ & $41.0 \pm 1.0$ & $43.3 \pm 1.6$ & 0.880 & 0.957 & 0.060 \\
\hline $\mathrm{Zn}$ (mg/1000kcal) & $4.0 \pm 0.2$ & $3.9 \pm 0.1$ & $3.8 \pm 0.2$ & $3.9 \pm 0.1$ & 0.556 & 0.994 & 0.344 \\
\hline Vitamin A (RE/1000kcal) & $242.6 \pm 29.5$ & $275.1 \pm 39.2$ & $254.3 \pm 32.5$ & $384.5 \pm 55.0$ & 0.109 & 0.071 & 0.194 \\
\hline Thiamin (mg/1000kcal) & $0.52 \pm 0.02$ & $0.52 \pm 0.02$ & $0.54 \pm 0.02$ & $0.53 \pm 0.02$ & 0.312 & 0.816 & 0.983 \\
\hline Riboflavin (mg/1000kcal) & $0.54 \pm 0.02$ & $0.52 \pm 0.02$ & $0.50 \pm 0.04$ & $0.61 \pm 0.04$ & 0.756 & 0.202 & 0.158 \\
\hline Niacin (mg/1000kcal) & $8.2 \pm 0.5$ & $8.0 \pm 0.4$ & $8.0 \pm 0.4$ & $8.9 \pm 0.5$ & 0.430 & 0.474 & 0.195 \\
\hline Vitamin B6 (mg/1000kcal) & $0.62 \pm 0.04$ & $0.63 \pm 0.04$ & $0.67 \pm 0.06$ & $0.75 \pm 0.05$ & 0.067 & 0.412 & 0.382 \\
\hline Folate $(\mu \mathrm{g} / 1000 \mathrm{kcal})$ & $126.6 \pm 12.9$ & $144.5 \pm 19.8$ & $130.3 \pm 18.5$ & $155.4 \pm 16.6$ & 0.596 & 0.289 & 0.785 \\
\hline Vitamin B12 ( $\mu \mathrm{g} / 1000 \mathrm{kcal})$ & $1.1 \pm 0.1$ & $1.0 \pm 0.1$ & $1.0 \pm 0.1$ & $1.1 \pm 1.0$ & 0.886 & 0.844 & 0.480 \\
\hline Vitamin C (mg/1000kcal) & $71.8 \pm 14.2$ & $77.5 \pm 11.0$ & $82.2 \pm 17.1$ & $84.4 \pm 12.1$ & 0.475 & 0.792 & 0.893 \\
\hline Vitamin D ( $\mu \mathrm{g} / 1000 \mathrm{kcal})$ & $0.8 \pm 0.2$ & $0.7 \pm 0.2$ & $0.9 \pm 0.2$ & $0.8 \pm 0.1$ & 0.151 & 0.547 & 0.480 \\
\hline Vitamin E (mg/1000kcal) & $1.1 \pm 0.2$ & $1.2 \pm 0.2$ & $1.4 \pm 0.3$ & $1.3 \pm 0.2$ & 0.364 & 0.984 & 0.804 \\
\hline Beta carotene $(\mu \mathrm{g} / 1000 \mathrm{kcal})$ & $1391.8 \pm 211.7$ & $1695.3 \pm 323.5$ & $1551.3 \pm 249.5$ & $2355.9 \pm 373.4$ & 0.113 & 0.108 & 0.325 \\
\hline Tea (g/1000kcal) & $0.90 \pm 0.20$ & $0.56 \pm 0.10$ & $0.59 \pm 0.16$ & $0.57 \pm 0.13$ & 0.137 & 0.308 & 0.202 \\
\hline Caffeine (g/1000kcal) & $0.030 \pm 0.010$ & $0.004 \pm 0.004$ & $0.004 \pm 0.004$ & $0.013 \pm 0.007$ & 0.001 & 0.056 & 0.056 \\
\hline Physical activity (METs-min) & $1579 \pm 688$ & $2002 \pm 516$ & $1831 \pm 321$ & $1724 \pm 248$ & 0.978 & 0.735 & 0.585 \\
\hline
\end{tabular}

Data are presented as mean \pm standard error of mean; METS-min: metabolic equivalent of tasks-minute; MUFA: monounsaturated fatty acid; PUFA: polyunsaturated fatty acid; LCD: low calorie diet; LCID: low calorie low inflammatory diet; Analysis were done using repeated-measure ANOVA *within subjects effects, $\wedge$ between subjects effects, +time x group interaction. 
At the end of the intervention, there was a significant increase of plasma TNFalpha $(p<0.001)$ and IL- 6 concentrations $(p=0.015)$, but no significant changes in hsCRP level $(p=0.707)$ in the whole group. After correction for sex and changes in body fat, subjects in the LCID group had a greater reduction in hs-CRP concentration than those in the LCD group ( $p=0.029$ ) (Figure 4.2). There were no significant differences in changes of TNF-alpha $(p=0.319)$ and IL- $6(p=0.628)$ between the LCD and LCID groups (Figure 4.2). We also found a significant reduction in body weight, body mass index, percent body fat, triglyceride, cholesterol, HDL-cholesterol and diastolic blood pressure, and an increase in muscle mass percentage in the total group (all $p<0.050$ ), but no differences between the diet groups (Table 4.4).

Table 4.4. Changes in anthropometric and metabolic syndrome parameters.

\begin{tabular}{|c|c|c|c|c|c|c|c|c|}
\hline \multirow[b]{2}{*}{ Variables } & \multicolumn{2}{|c|}{ Pre } & \multicolumn{2}{|c|}{ Post } & \multirow[b]{2}{*}{$p^{*}$} & \multirow[b]{2}{*}{$p^{\wedge}$} & \multirow[b]{2}{*}{$\boldsymbol{p}^{+}$} & \multirow[b]{2}{*}{$p^{\#}$} \\
\hline & $\operatorname{LCD}(n=25)$ & $\operatorname{LCID}(n=26)$ & $\operatorname{LCD}(n=25)$ & $\operatorname{LCID}(n=26)$ & & & & \\
\hline \multicolumn{9}{|l|}{ Anthropometric measures } \\
\hline Weight (kg) & $86.6 \pm 2.8$ & $85.0 \pm 2.9$ & $85.0 \pm 2.7$ & $83.9 \pm 3.0$ & $<0.01$ & 0.740 & 0.416 & $\mathrm{~N} / \mathrm{A}$ \\
\hline BMI $\left(\mathrm{kg} / \mathrm{m}^{2}\right)$ & $33.3 \pm 0.8$ & $33.0 \pm 1.1$ & $32.7 \pm 0.9$ & $32.5 \pm 1.2$ & $<0.01$ & 0.860 & 0.902 & $\mathrm{~N} / \mathrm{A}$ \\
\hline Body fat (\%) & $36.0 \pm 1.1$ & $36.0 \pm 1.0$ & $35.1 \pm 1.2$ & $35.4 \pm 1.1$ & $<0.01$ & 0.929 & 0.459 & $\mathrm{~N} / \mathrm{A}$ \\
\hline Visceral fat (\%) & $15.8 \pm 1.1$ & $15.3 \pm 1.3$ & $14.8 \pm 1.1$ & $14.8 \pm 1.3$ & $<0.01$ & 0.913 & 0.186 & $\mathrm{~N} / \mathrm{A}$ \\
\hline Subcutaneous fat (\%) & $32.0 \pm 1.7$ & $31.4 \pm 1.7$ & $31.2 \pm 1.8$ & $30.9 \pm 1.7$ & $<0.01$ & 0.849 & 0.283 & $\mathrm{~N} / \mathrm{A}$ \\
\hline Muscle (\%) & $25.2 \pm 0.8$ & $25.3 \pm 0.8$ & $25.5 \pm 0.9$ & $25.4 \pm 0.8$ & 0.049 & 0.990 & 0.627 & $\mathrm{~N} / \mathrm{A}$ \\
\hline Waist circumference (cm) & $96.5 \pm 2.0$ & $95.9 \pm 2.1$ & $96.1 \pm 1.5$ & $94.2 \pm 2.4$ & 0.298 & 0.653 & 0.517 & $\mathrm{~N} / \mathrm{A}$ \\
\hline Hip circumference $(\mathrm{cm})$ & $110.2 \pm 1.4$ & $108.4 \pm 2.1$ & $107.9 \pm 1.7$ & $107.7 \pm 2.0$ & 0.076 & 0.174 & 0.345 & $\mathrm{~N} / \mathrm{A}$ \\
\hline Waist-to-hip ratio & $0.89 \pm 0.01$ & $0.90 \pm 0.01$ & $0.90 \pm 0.02$ & $0.87 \pm 0.02$ & 0.504 & 0.511 & 0.206 & $\mathrm{~N} / \mathrm{A}$ \\
\hline \multicolumn{9}{|c|}{ Metabolic syndrome parameters } \\
\hline Glucose (mmol/L) & $5.7 \pm 0.2$ & $5.87 \pm 0.3$ & $5.9 \pm 0.2$ & $6.0 \pm 0.2$ & 0.120 & 0.770 & 0.992 & 0.917 \\
\hline Triglycerides $(\mathrm{mmol} / \mathrm{L})$ & $1.4 \pm 0.1$ & $1.1 \pm 0.1$ & $1.2 \pm 0.2$ & $1.0 \pm 0.1$ & 0.046 & 0.159 & 0.773 & 0.705 \\
\hline Cholesterol ( $\mathrm{mmol} / \mathrm{L})$ & $4.9 \pm 0.2$ & $4.9 \pm 0.2$ & $4.4 \pm 0.2$ & $4.6 \pm 0.2$ & $<0.01$ & 0.616 & 0.311 & 0.594 \\
\hline $\mathrm{HDL}-\mathrm{c}(\mathrm{mmol} / \mathrm{L})$ & $1.7 \pm 0.1$ & $1.7 \pm 0.1$ & $1.4 \pm 0.0$ & $1.6 \pm 0.1$ & $<0.01$ & 0.301 & 0.147 & 0.309 \\
\hline LDL-c $(\mathrm{mmol} / \mathrm{L})$ & $4.6 \pm 0.2$ & $4.7 \pm 0.1$ & $4.4 \pm 0.2$ & $4.4 \pm 0.2$ & 0.261 & 0.776 & 0.995 & 0.716 \\
\hline Systolic bp (mmHg) & $113.0 \pm 2.5$ & $112.8 \pm 2.0$ & $109.5 \pm 2.7$ & $110.1 \pm 2.7$ & 0.081 & 0.943 & 0.825 & 0.665 \\
\hline Diastolic bp (mmHg) & $80.0 \pm 1.8$ & $80.7 \pm 1.4$ & $77.5 \pm 1.9$ & $76.5 \pm 1.7$ & 0.008 & 0.933 & 0.509 & 0.609 \\
\hline Metabolic syndrome score & $1.9 \pm 0.2$ & $1.8 \pm 0.2$ & $2.2 \pm 0.2$ & $1.8 \pm 0.2$ & 0.226 & 0.249 & 0.226 & 0.169 \\
\hline
\end{tabular}

Data are presented as mean \pm standard error of mean; repeated measure ANOVA for * within subjects effects, ^ between subjects effects, + group x time interaction; \#group x time interaction with correction for sex and changes in body fat. BMI: body mass index; hs-CRP: high sensitive C-reactive protein; HDL-C: high density lipoprotein cholesterol; IL-6: interleukin 6; LDL-c: low density lipoprotein cholesterol; TNFalpha: tumor necrosis factor alpha.

To further evaluate the influence of the inflammatory properties of the diet on changes in inflammatory markers, linear regression analyses were done with correction for sex and changes in body fat. As shown in Supplementary Table 4.2, in all subjects of both groups intakes of protein, selenium, zinc, niacin, beta carotene and cholesterol were negatively correlated with changes in hs-CRP (all $p<0.05$ ). None 
of the nutrient intakes were correlated with changes of TNF-alpha. By contrast, intake of tea $(p=0.019)$ and caffeine $(p=0.028)$ were negatively correlated with changes in IL-6.
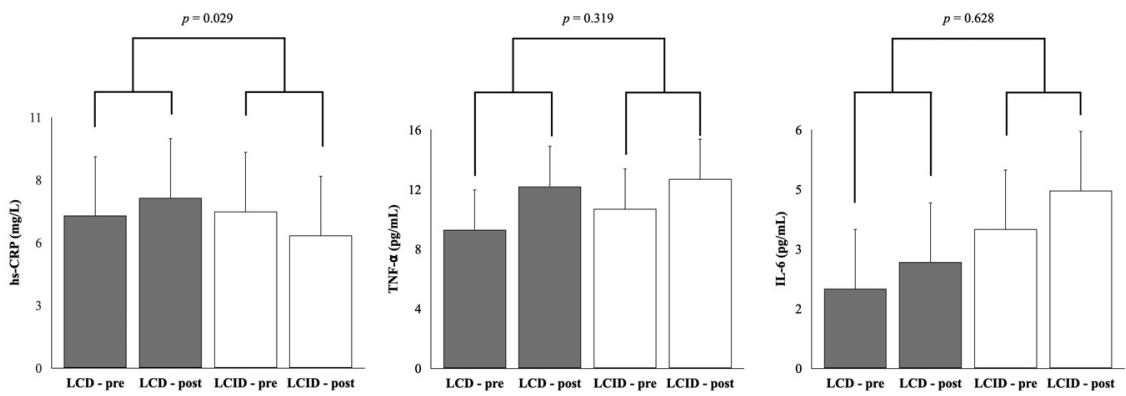

Figure 4.2. Inflammatory markers before and after intervention separated by intervention group. Data are presented as mean (standard deviation). Analysis was done using repeated measure ANOVA with correction for sex and changes in body fat. There was a significant increase of plasma TNF-alpha $(p<0.001)$ and IL- 6 concentrations ( $p=0.015)$, but no significant changes in hs-CRP level $(p=0.707)$ in the whole group. The $p$ value in the figure reflected differences in changes between dietary groups. LCD: low calorie diet; LCID: low calorie low inflammatory diet; hs-CRP: high sensitivity C-reactive protein;TNFalpha: tumor necrosis factor-alpha; IL-6: interleukin 6.

\section{DISCUSSION}

The general aim of this study was to investigate the effect of weight loss on inflammatory markers and to evaluate whether changes in systemic inflammation can be modified by diet. The hypothesis of this study was partly accepted. At the end of the intervention, we found increased plasma TNF-alpha and IL-6 concentrations, but no change in hs-CRP concentration in the total group. Interestingly, when comparing the diet effect, we showed that LCID group had a greater reduction in hs-CRP at the end of the intervention compared to those in the LCD group. No differences were seen in changes of TNF-alpha and IL-6 concentrations between groups. The weight loss intervention in this study induced significant reductions in body weight, body fat, and metabolic syndrome parameters such as plasma triglycerides and blood pressure, with no differences between groups.

In the scientific literature reports on the effects of weight loss on the inflammatory status of individuals with obesity are inconsistent. Some investigators found a reduction in hs-CRP after a weight loss intervention [7,8], others report unchanged hs-CRP concentrations [10,11] and unchanged [14] or increased plasma TNF-alpha and IL-6 concentrations $[15,16]$ have also been measured. In this study, we showed that a weight loss program using a low-calorie diet and exercise program was associated with an increase in plasma TNF-alpha and IL-6, but no change in hsCRP concentrations. Differences among studies may be due to the type of weight 
loss intervention (level of energy restriction, duration and total weight loss, with or without exercise). The finding that not all inflammatory markers respond in the same way is not surprising. hs-CRP is mainly derived from the liver, whereas adipose tissue more likely contributes to the changes in TNF-alpha and IL-6 concentration. Although all subjects participated in an exercise training program during the weight loss intervention, it does not seem very likely that the exercise bouts contributed to the increased plasma levels of IL-6, because the increased release of IL- 6 by the exercising skeletal muscles is quickly normalized after stopping the exercise [32]. The weight loss-induced increase in plasma TNF-alpha and IL-6 is in line with other reports showing that inflammatory gene expression pathways are upregulated in adipose tissue during a weight loss program [12,13,33].

Another factor that may be responsible for the inconsistent findings with respect to weight loss-induced changes in inflammatory markers may be the diet composition. In our study, we showed that the hs-CRP concentration was on average not affected by the weight loss program in the total group. However, when the group was divided based on type of diet, we showed that hs-CRP was lower in the LCID group compared to the LCD group. No group difference was found for the changes in TNF-alpha and IL-6. It can be speculated that the weight loss-induced increase in inflammatory status of the adipose tissue is not sensitive to changes in the inflammatory properties of the diet, whereas the liver remains responsive to the diet composition under the conditions of energy restriction. However, more evidence should be obtained to further support this suggestion.

To our knowledge, this is the first study to evaluate the effect of dietary counseling with a combination of an attempt to lower energy intake as well as to lower inflammatory properties of the diet during a weight loss intervention. The notion to reduce inflammation by means of a dietary intervention has been applied in studies in Australia (AUSMED Heart Trial) [34,35] and in the United States (IMAGINE study) [36]. In comparison to other studies which aimed to lower inflammation through modification of diet, the strength of our study was that all other factors such as gender distribution, age, recommended energy intake, and training program were controlled by design which leaves only the effect of lowering the inflammatory property of the diet as the independent variable.

The analysis of inflammation markers was done at the end of the weight loss program whilst subjects were still in the energy deficit state. It was previously reported by Vink et al [13] that during a weight-loss period, there was an increase in gene expressions related to inflammation followed by a reduction in those gene expressions during a weight stable period. Thus, it is argued that because the timing of this analysis was done at the end of the weight-loss period with participants still in negative energy balance, subjects had increased inflammation markers. This is marked by higher TNF-alpha and IL-6 than the baseline. 
A limitation of this study was that it could not show significant differences in changes in dietary intake between the LCID and LCD groups. This might be due to inadequacy of SQ-FFQ and MD score to capture small differences in dietary intake in combination with the small sample size. Not all principles of the Mediterranean diet, such as increased consumption of dairy, potatoes, olives, and wine, could be applied in the Indonesian population. Differences in dietary intake between the groups may have been small, because the intake of several components that contribute to the MD score were already high or low at baseline in this population. For instance, consumption of wine is low-to-none and because alcohol consumption is prohibited among Moslems it will not increase during the intervention. Additionally, consumption of red meat was already low at baseline among subjects, because legumes (tempe or tofu) and chicken meat were the preferred sources of protein, leaving little room for a further reduction. Some subjects experienced difficulty in complying with the diet on a daily basis because of several factors including appetite, work/job, social events, food availability and economic condition. The Indonesian population usually consumes rice as the source of carbohydrates instead of potatoes, pasta and bread. Indonesians are also less likely to consume dairy products such as milk and cheese, especially during adulthood. Nevertheless our results showed a difference in response of hs-CRP with weight loss between the groups. Replication of this result in other populations is required before an anti-inflammatory weight loss diet can be propagated.

In summary, we found that reducing the inflammatory properties of the diet during a weight loss program can help to reduce systemic inflammation, as marked by hs-CRP level, in adults with obesity. On the other hand, such a diet does not prevent the increment of adipose tissue inflammation, as marked by TNF-alpha and IL-6 concentrations, due to energy restriction. This may suggest that the liver is responsive to diet composition during a period of energy restriction, whereas adipose tissue is not. To confirm this finding, follow-up studies should be done.

\section{Conflict of Interest Statement}

There is no financial and personal relationship with other people or organizations that could inappropriately influence this work.

\section{Statement of Authorship}

Conceptualization, H.F.L.M., M.A.v.B. and E.C.M, Methodology, H.F.L.M., M.A.v.B. and E.C.M, Investigation, H.F.L.M., Resources, H.F.L.M. Data Curation, H.F.L.M., M.A.v.B. and E.C.M.; Writing - Original Draft Preparation, H.F.L.M., M.A.v.B. and E.C.M.; Writing - Review \& Editing, H.F.L.M., M.A.v.B. and E.C.M.; Supervision, M.A.v.B. and E.C.M; Project Administration, H.F.L.M.; Funding Acquisition, H.F.L.M. Harry Freitag Luglio Muhammad (H.F.L.M.), Marleen A. van Baak (M.A.v.B.) and Edwin C. Mariman (E.C.M.) 


\section{Trial Registration}

Registered under Medical and Health Research Ethics Committee, Faculty of Medicine, Public Health and Nursing, Universitas Gadjah Mada, Indonesia identifier number KE/0560/05/2017, website : http://komisietik.fk.ugm.ac.id

\section{Funding sources}

This study was funded by internal grant from Universitas Gadjah Mada, Indonesia

\section{Acknowledgements}

We thank to Satwika Arya Pratama, S.Gz and Maya Nurfitriani Hartono, S.Gz for help with nutritional counseling and preparation of exercise sessions. We also thank Dr. Nuria Rosique Esteban for her help during the development of the dietary recommendation protocol.

\section{REFERENCES}

1. GBD 2015 Obesity Collaborators, Afshin A, Forouzanfar MH, Reitsma MB, Sur P, Estep K, et al. Health Effects of Overweight and Obesity in 195 Countries over 25 Years. N Engl J Med 2017, 377(1), 13-27.

2. Wang Z, Nakayama T. Inflammation, a link between obesity and cardiovascular disease. Mediators Inflamm 2010, 2010, 535918.

3. Lopez-Candales A, Hernández Burgos PM, Hernandez-Suarez DF, et al. Linking Chronic Inflammation with Cardiovascular Disease: From Normal Aging to the Metabolic Syndrome. J Nat Sci 2017, 3(4), e341.

4. Han JM, Levings MK. Immune regulation in obesity-associated adipose inflammation. J Immunol 2013, 191(2), 527-532.

5. Zomer E, Gurusamy K, Leach R, et al. Interventions that cause weight loss and the impact on cardiovascular risk factors: a systematic review and meta-analysis. Obes Rev 2016, 17(10), 1001-1011.

6. Ma C, Avenell A, Bolland $\mathrm{M}$, et al. Effects of weight loss interventions for adults who are obese on mortality, cardiovascular disease, and cancer: systematic review and metaanalysis. BMJ 2017, 359, j4849.

7. Nicklas JM, Sacks FM, Smith SR, et al. Effect of dietary composition of weight loss diets on high-sensitivity c-reactive protein: the Randomized POUNDS LOST trial. Obesity 2013, 21(4), 681-689.

8. Gögebakan $\mathrm{O}$, Kohl A, Osterhoff MA, et al. Effects of weight loss and long-term weight maintenance with diets varying in protein and glycemic index on cardiovascular risk factors: the diet, obesity, and genes (DiOGenes) study: a randomized, controlled trial. Circulation 2011, 124(25), 2829-2838.

9. Selvin E, Paynter NP, Erlinger TP. The effect of weight loss on C-reactive protein: a systematic review. Arch Intern Med 2007, 167(1), 31-39. 
10. Mediano MF, Neves FA, Cunha AC, et al. Changes in body weight, C-reactive protein, and total adiponectin in non-obese women after 12 months of a small-volume, home-based exercise program. Clinics (Sao Paulo) 2013, 68(8), 1121-1127.

11. Belza A, Toubro S, Stender S, et al. Effect of diet-induced energy deficit and body fat reduction on high-sensitive CRP and other inflammatory markers in obese subjects. Int $J$ Obes 2009, 33(4), 456-464.

12. Capel F, Viguerie $\mathrm{N}$, Vega $\mathrm{N}$, et al. Contribution of energy restriction and macronutrient composition to changes in adipose tissue gene expression during dietary weight-loss programs in obese women. J Clin Endocrinol Metab 2008, 93(11), 4315-4322.

13. Vink RG, Roumans NJ, Fazelzadeh P, et al. Adipose tissue gene expression is differentially regulated with different rates of weight loss in overweight and obese humans. Int J Obes 2017, 41(2), 309-316.

14. Snel M, van Diepen JA, Stijnen T, et al. Immediate and long-term effects of addition of exercise to a 16-week very low calorie diet on low-grade inflammation in obese, insulindependent type 2 diabetic patients. Food Chem Toxicol 2011, 49(12), 3104-3111.

15. Vink RG, Roumans NJ, Čajlaković $M$, et al. Diet-induced weight loss decreases adipose tissue oxygen tension with parallel changes in adipose tissue phenotype and insulin sensitivity in overweight humans. Int J Obes 2017, 41(5), 722-728.

16. Siklova-Vitkova M, Klimcakova E, Polak J, et al. Adipose tissue secretion and expression of adipocyte-produced and stromavascular fraction-produced adipokines vary during multiple phases of weight-reducing dietary intervention in obese women. J Clin Endocrinol Metab 2012, 97(7), E1176-E1181.

17. Cavicchia PP, Steck SE, Hurley TG, et al. A new dietary inflammatory index predicts interval changes in serum high-sensitivity C-reactive protein. J Nutr 2009, 139(12), 2365-2372.

18. Shivappa N, Steck SE, Hurley TG, et al. Designing and developing a literature-derived, population-based dietary inflammatory index. Public Health Nutr 2014, 17(8), 1689-1696.

19. Byrd DA, Judd SE, Flanders WD, et al. Development and Validation of Novel Dietary and Lifestyle Inflammation Scores. J Nutr 2019, 149(12), 2206-2218.

20. Na W, Yu TY, Sohn C. Development of a food-based index of dietary inflammatory potential for Koreans and its relationship with metabolic syndrome. Nutr Res Pract 2019, 13(2), 150-158.

21. Shivappa N, Steck SE, Hurley TG, et al. A population-based dietary inflammatory index predicts levels of C-reactive protein in the Seasonal Variation of Blood Cholesterol Study (SEASONS). Public Health Nutr 2014, 17(8), 1825-1833.

22. Shivappa N, Hébert JR, Rietzschel ER, et al. Associations between dietary inflammatory index and inflammatory markers in the Asklepios Study. Br J Nutr 2015, 113(4), 665-671.

23. Sureda A, Bibiloni MDM, Julibert $A$, et al. Adherence to the Mediterranean Diet and Inflammatory Markers. Nutrients 2018, 10(1), 62.

24. WHO Expert Consultation. Appropriate body-mass index for Asian populations and its implications for policy and intervention strategies. Lancet 2004, 363(9403), 157-163. 
25. Camhi SM, Stefanick ML, Ridker PM, et al. Changes in C-reactive protein from low-fat diet and/or physical activity in men and women with and without metabolic syndrome. Metabolism 2010, 59(1), 54-61.

26. Martínez-González MA, García-Arellano A, Toledo E, et al. A 14-item Mediterranean diet assessment tool and obesity indexes among high-risk subjects: the PREDIMED trial. PLoS One 2012, 7(8), e43134.

27. Steinemann N, Grize L, Ziesemer K, et al. Relative validation of a food frequency questionnaire to estimate food intake in an adult population. Food Nutr Res 2017, 61(1), 1305193.

28. Luglio HF, Sulistyoningrum DC, Huriyati E, et al. The Gene-Lifestyle Interaction on Leptin Sensitivity and Lipid Metabolism in Adults: A Population Based Study. Nutrients 2017, 9(7), 716.

29. United States Department of Agriculture. https://ndb.nal.usda.gov/ndb/search/list (Accessed at December 2017).

30. $\mathrm{Ng} \mathrm{N}$, Hakimi M, Van Minh $\mathrm{H}$, et al. Prevalence of physical inactivity in nine rural INDEPTH Health and Demographic Surveillance Systems in five Asian countries. Glob Health Action 2009, 2.

31. International Diabetes Foundation. IDF Consensus Worldwide Definition of the Metabolic Syndrome. 2006. Belgium: IDF.

32. Pedersen BK, Febbraio MA. Muscles, exercise and obesity: skeletal muscle as a secretory organ. Nat Rev Endocrinol 2012, 8(8), 457-65.

33. van Baak MA, Mariman ECM. Mechanisms of weight regain after weight loss - the role of adipose tissue. Nat Rev Endocrinol 2019, 15(5), 274-287.

34. Mayr HL, Tierney AC, Kucianski T, et al. Australian patients with coronary heart disease achieve high adherence to 6-month Mediterranean diet intervention: preliminary results of the AUSMED Heart Trial. Nutrition 2019, 61, 21-31.

35. Mayr HL, Thomas CJ, Tierney AC, et al. Randomization to 6-month Mediterranean diet compared with a low-fat diet leads to improvement in Dietary Inflammatory Index scores in patients with coronary heart disease: the AUSMED Heart Trial. Nutr Res 2018, 55, 94107.

36. Turner-McGrievy GM, Wirth MD, Shivappa N, et al. Impact of a 12-month Inflammation Management Intervention on the Dietary Inflammatory Index, inflammation, and lipids. Clin Nutr ESPEN 2019, 30, 42-51. 
Supplementary Table 4.1. The Mediterranean Diet score and daily intake of food components

\begin{tabular}{|c|c|c|c|c|c|c|c|}
\hline & \multicolumn{2}{|c|}{ Pre } & \multicolumn{2}{|c|}{ Post } & \multirow[b]{2}{*}{$\mathrm{p}^{*}$} & \multirow[b]{2}{*}{$p^{\wedge}$} & \multirow[b]{2}{*}{$p+$} \\
\hline & $\operatorname{LCD}(n=23)$ & $\operatorname{LCID}(n=24)$ & $\operatorname{LCD}(n=23)$ & $\operatorname{LCID}(n=24)$ & & & \\
\hline Mediterranean diet score & $5.2 \pm 1.8$ & $5.4 \pm 1.2$ & $5.8 \pm 1.4$ & $6.1 \pm 1.6$ & 0.034 & 0.440 & 0.654 \\
\hline Vegetables (g/day) & $126.0 \pm 18.1$ & $118.1 \pm 14.4$ & $121.8 \pm 13.3$ & $145.6 \pm 22.9$ & 0.447 & 0.790 & 0.210 \\
\hline Fruits (g/day) & $136.3 \pm 22.1$ & $188.6 \pm 36.2$ & $202.7 \pm 31.6$ & $247.7 \pm 38.6$ & 0.024 & 0.206 & 0.863 \\
\hline Legumes (g/day) & $112.5 \pm 15.0$ & $96.7 \pm 12.7$ & $56.1 \pm 6.6$ & $65.8 \pm 14.7$ & 0.001 & 0.771 & 0.263 \\
\hline Fish and seafood (g/day) & $16.3 \pm 2.8$ & $14.7 \pm 3.5$ & $22.2 \pm 7.6$ & $15.1 \pm 3.1$ & 0.535 & 0.353 & 0.585 \\
\hline White meat (g/day) & $38.1 \pm 11.0$ & $32.6 \pm 4.0$ & $32.6 \pm 4.8$ & $44.3 \pm 7.6$ & 0.670 & 0.720 & 0.165 \\
\hline Red meat (g/day) & $21.8 \pm 3.9$ & $11.8 \pm 2.5$ & $13.7 \pm 3.9$ & $8.5 \pm 1.7$ & 0.021 & 0.054 & 0.461 \\
\hline
\end{tabular}

Data are presented as mean \pm standard deviation; LCD: low calorie diet; LCID: low calorie low inflammatory diet; repeated measure ANOVA for *within subject effects, ^ ${ }^{*}$ between subjects effects, + group $\mathrm{x}$ time interaction.

Supplementary Table 4.2. Correlation between dietary components during weight loss program on changes in inflammation markers.

\begin{tabular}{|c|c|c|c|c|c|c|c|c|c|c|c|c|}
\hline \multirow[b]{2}{*}{$\begin{array}{l}\text { Dietary intake during weight } \\
\text { loss intervention }\end{array}$} & \multirow[b]{2}{*}{$B^{*}$} & \multicolumn{2}{|c|}{$\begin{array}{l}\text { Changes of } \\
\text { hs-CRP }\end{array}$} & \multirow[b]{2}{*}{$\mathrm{P}$} & \multicolumn{4}{|c|}{ Changes of TNF-alpha } & \multirow[b]{2}{*}{$B^{*}$} & \multicolumn{2}{|c|}{ Changes of IL- 6} & \multirow[b]{2}{*}{$P$} \\
\hline & & $P$ & $\mathrm{~B} \wedge^{\wedge}$ & & $B^{*}$ & $P$ & $\mathrm{~B} \wedge^{\wedge}$ & $\mathrm{P}$ & & $P$ & $\mathrm{~B} \wedge^{\wedge}$ & \\
\hline Energy (kcal) & 0.090 & 0.546 & 0.111 & 0.523 & -0.276 & 0.067 & -0.091 & 0.590 & 0.068 & 0.671 & 0.075 & 0.683 \\
\hline Protein (g/1000kcal) & -0.296 & 0.043 & -0.363 & 0.030 & 0.193 & 0.203 & 0.012 & 0.941 & -0.151 & 0.345 & -0.104 & 0.555 \\
\hline Fat (g/1000kcal) & -0.003 & 0.982 & 0.001 & 0.993 & 0.142 & 0.351 & 0.121 & 0.422 & -0.012 & 0.939 & -0.010 & 0.955 \\
\hline Carbohydrate (g/1000kcal) & 0.065 & 0.663 & 0.083 & 0.599 & -0.091 & 0.553 & -0.028 & 0.855 & 0.093 & 0.561 & 0.074 & 0.664 \\
\hline Fiber (g/1000kcal) & -0.076 & 0.610 & -0.046 & 0.802 & 0.158 & 0.300 & -0.002 & 0.989 & -0.061 & 0.703 & -0.064 & 0.743 \\
\hline $\mathrm{Fe}$ (mg/1000kcal) & -0.227 & 0.124 & -0.233 & 0.183 & 0.164 & 0.283 & 0.090 & 0.609 & -0.109 & 0.498 & -0.126 & 0.487 \\
\hline $\mathrm{Mg}$ (mg/1000kcal) & -0.214 & 0.148 & -0.226 & 0.215 & 0.110 & 0.471 & -0.023 & 0.989 & -0.141 & 0.378 & -0.182 & 0.328 \\
\hline Se $(\mu \mathrm{g} / 1000 \mathrm{kcal})$ & -0.399 & 0.005 & -0.435 & 0.006 & -0.026 & 0.865 & -0.093 & 0.553 & 0.214 & 0.179 & 0.290 & 0.104 \\
\hline Zn (mg/1000kcal) & -0.241 & 0.102 & -0.332 & 0.048 & 0.235 & 0.120 & 0.045 & 0.786 & -0.128 & 0.426 & -0.045 & 0.806 \\
\hline Vitamin A (RE/1000kcal) & -0.229 & 0.121 & -0.259 & 0.117 & 0.044 & 0.773 & -0.060 & 0.710 & -0.050 & 0.758 & -0.021 & 0.905 \\
\hline Thiamin (mg/1000kcal) & -0.025 & 0.868 & -0.006 & 0.974 & 0.210 & 0.165 & 0.122 & 0.473 & -0.143 & 0.374 & -0.166 & 0.375 \\
\hline Riboflavin (mg/1000kcal) & -0.305 & 0.037 & -0.326 & 0.054 & 0.035 & 0.818 & -0.087 & 0.601 & -0.217 & 0.174 & -0.242 & 0.163 \\
\hline Niacin (mg/1000kcal) & -0.316 & 0.031 & -0.378 & 0.020 & 0.152 & 0.319 & 0.034 & 0.833 & 0.072 & 0.654 & 0.158 & 0.381 \\
\hline Vitamin B6 (mg/1000kcal) & -0.210 & 0.157 & -0.280 & 0.119 & 0.215 & 0.155 & 0.030 & 0.865 & -0.097 & 0.548 & -0.057 & 0.770 \\
\hline Folate ( $\mu \mathrm{g} / 1000 \mathrm{kcal})$ & -0.291 & 0.047 & -0.322 & 0.071 & 0.095 & 0.533 & -0.020 & 0.910 & -0.103 & 0.521 & -0.138 & 0.463 \\
\hline Vitamin B12 ( $\mu \mathrm{g} / 1000 \mathrm{kcal})$ & -0.297 & 0.043 & -0.300 & 0.073 & -0.060 & 0.696 & -0.134 & 0.414 & -0.120 & 0.455 & -0.120 & 0.492 \\
\hline Vitamin C (mg/1000kcal) & -0.164 & 0.270 & -0.152 & 0.375 & 0.156 & 0.305 & 0.023 & 0.890 & -0.116 & 0.472 & -0.119 & 0.507 \\
\hline Vitamin D ( $\mu \mathrm{g} / 1000 \mathrm{kcal})$ & -0.283 & 0.054 & -0.268 & 0.114 & 0.001 & 0.996 & -0.024 & 0.884 & -0.044 & 0.786 & -0.096 & 0.617 \\
\hline
\end{tabular}


CHAPTER 4

Low Calorie Low Inflammatory Diet is Beneficial to Reduce hs-CRP during a Weight Loss Intervention among Individuals with Obesity

\begin{tabular}{|c|c|c|c|c|c|c|c|c|c|c|c|c|}
\hline \multirow[b]{2}{*}{$\begin{array}{l}\text { Dietary intake during weight } \\
\text { loss intervention }\end{array}$} & \multirow[b]{2}{*}{$\mathrm{B}^{*}$} & \multicolumn{2}{|c|}{$\begin{array}{l}\text { Changes of } \\
\text { hs-CRP }\end{array}$} & \multirow[b]{2}{*}{$\mathrm{P}$} & \multicolumn{4}{|c|}{ Changes of TNF-alpha } & \multirow[b]{2}{*}{$B^{*}$} & \multicolumn{2}{|c|}{ Changes of IL-6 } & \multirow[b]{2}{*}{$\mathrm{P}$} \\
\hline & & $P$ & $\mathrm{~B} \wedge^{\wedge}$ & & $B^{*}$ & $P$ & $\mathrm{~B} \wedge^{\wedge}$ & $P$ & & $P$ & $\mathrm{~B} \wedge^{\wedge}$ & \\
\hline Vitamin E (mg/1000kcal) & -0.252 & 0.088 & -0.254 & 0.158 & 0.032 & 0.833 & -0.067 & 0.703 & -0.035 & 0.830 & -0.073 & 0.705 \\
\hline Saturated fat (g/1000kcal) & 0.068 & 0.650 & 0.053 & 0.737 & 0.083 & 0.588 & 0.084 & 0.580 & 0.068 & 0.671 & 0.082 & 0.647 \\
\hline MUFA (g/1000kcal) & -0.010 & 0.948 & 0.002 & 0.990 & 0.134 & 0.381 & 0.145 & 0.337 & 0.032 & 0.845 & 0.023 & 0.891 \\
\hline PUFA (g/1000kcal) & -0.070 & 0.639 & -0.020 & 0.905 & 0.107 & 0.484 & 0.115 & 0.472 & -0.128 & 0.425 & -0.171 & 0.320 \\
\hline Trans fat (g/1000kcal) & -0.169 & 0.255 & -0.196 & 0.211 & 0.058 & 0.707 & -0.058 & 0.703 & -0.013 & 0.936 & 0.048 & 0.780 \\
\hline Cholesterol (mg/1000kcal) & -0.468 & $<0.001$ & -0.602 & $<0.001$ & 0.050 & 0.743 & 0.001 & 0.994 & 0.104 & 0.517 & 0.127 & 0.539 \\
\hline Omega 3 fatty acid (g/1000kcal) & -0.277 & 0.059 & -0.270 & 0.099 & -0.070 & 0.647 & -0.149 & 0.349 & -0.080 & 0.619 & -0.052 & 0.766 \\
\hline Omega 6 fatty acid (g/1000kcal) & -0.132 & 0.375 & -0.224 & 0.163 & 0.165 & 0.279 & -0.117 & 0.451 & -0.042 & 0.792 & 0.076 & 0.655 \\
\hline Alcohol (g/1000kcal) & 0.042 & 0.780 & -0.082 & 0.608 & 0.297 & 0.048 & -0.158 & 0.302 & -0.209 & 0.190 & -0.105 & 0.541 \\
\hline Tea (g/1000kcal) & -0.089 & 0.550 & -0.051 & 0.745 & -0.062 & 0.685 & 0.045 & 0.772 & -0.337 & 0.031 & -0.383 & 0.019 \\
\hline Caffeine (g/1000kcal) & -0.083 & 0.580 & -0.062 & 0.694 & -0.080 & 0.600 & 0.070 & 0.647 & -0.338 & 0.031 & -0.360 & 0.028 \\
\hline Beta carotene $(\mu \mathrm{g} / 1000 \mathrm{kcal})$ & -0.249 & 0.091 & -0.348 & 0.032 & 0.123 & 0.421 & -0.090 & 0.573 & -0.044 & 0.784 & 0.001 & 0.995 \\
\hline
\end{tabular}

Linear regression test ${ }^{*}$ without correction and $\wedge$ with correction for sex and changes in body fat, $B=$ standardized coefficient, $p=$ significance level. 


\section{CHAPTER 5}

\section{The Effect of a Low Calorie Low Inflammatory Diet on}

Relative Telomere Length and Mitochondrial DNA Copy Number among Obese Indonesian Adults

Harry Freitag Luglio Muhammad'; Marleen van Baak²;

Edwin Mariman²; Sukma Oktavianthi ; Safarina G. Malik ${ }^{3}$

${ }^{1}$ Department of Nutrition and Health, Faculty of Medicine, Public Health and Nursing, Universitas Gadjah Mada, Indonesia.

${ }^{2}$ NUTRIM, School of Nutrition and Translational Research in Metabolism, Maastricht Medical Centre+, Maastricht, The Netherlands.

${ }^{3}$ Eijkman Institute for Molecular Biology, Indonesia 


\section{ABSTRACT}

We developed a low calorie low inflammatory diet (LCID) which has been previously reported to reduce the pro-inflammatory marker high sensitive C-reactive protein (hsCRP). It was previously reported by other study that higher inflammation is associated with reduction of mitochondrial DNA copy number (mtDNA-CN) and relative telomere length (RTL) which in turn could increase susceptibility of degenerative diseases. The objective of this study was to evaluate the effect of LCID on mtDNA-CN and RTL. This is a randomized controlled trial among Indonesian adults with obesity. Participants were divided into 2 groups: low-calorie diet (LCD) and low calorie low inflammatory diet (LCID). Participants in both groups undertook 2 times a week a supervised exercise program. The length of the weight loss program was 8 weeks, and participants were followed for 8 weeks of the weight maintenance period. 61 participants initially started the program, 51 finished the weight loss period, and 35 finished the maintenance period. The mtDNA-CN and RTL were evaluated at baseline and after the weight loss program. The mtDNA-CN was unchanged $(p=0.960)$ after weight loss while RTL was shown to be increased ( $p=0.002)$. Changes in RTL were higher in LCID than those in the LCD group $(p=0.036)$, while mtDNA-CN showed no difference. Weight changes after weight loss and maintenance period were not associated with mtDNA-CN or RTL (all $p>0.05$ ). We concluded that a weight loss program was associated with the elongation of telomere length among adults with obesity. Those in LCID responded with significantly longer telomeres as compared to LCD despite a similar degree of weight loss.

Keywords: telomere, mitochondrial DNA, obesity, weight loss, inflammation. 


\section{introduction}

Obesity affects millions of adults worldwide and this state of over-nutrition is associated with increased risk for non-communicable diseases (NCDs) [1,2]. One of the mechanisms, which may explain the interaction between obesity and the development of NCDs, is inflammation [3-7]. Inflammation plays a role in the regulation of several molecular signatures such as mitochondrial function and telomere length. Increased inflammation is associated with the reduction of mitochondrial DNA copy number (mtDNA-CN), an indicator for mitochondrial biogenesis and function [8]. Evidence of mitochondrial involvement in the pathogenesis of obesity through mitochondrial dysfunctions leading to oxidative stress has been reported [9]. In addition, increased inflammation is also associated with the shortening of telomere length. In humans, concentrations of inflammatory proteins such as high-sensitive C-reactive protein (hs-CRP), interleukin 6 (IL-6) and tumor necrosis factor-alpha (TNFalpha) were reported to be negatively associated with relative telomere length (RTL) $[10,11]$. Telomere shortening may predispose individuals to age-related diseases and increased mortality [12].

Studies in the past decades suggested that mIDNA-CN and RTL are molecular markers for aging [13]. Interestingly, it also has been shown that mtDNA-CN and RTL are related to an individual's body weight. A recent prospective study reported that reductions in mIDNA-CN and RTL were associated with weight gain [14]. This finding is supported by cross-sectional studies which show an inverse correlation between mtDNA-CN and adiposity in Korean [15] and Italian populations [16]. The RTL was also inversely associated with adiposity measures such as body mass index and waist circumference in a large epidemiological study in the United States [12]. The tendency of a negative correlation between obesity and RTL was then confirmed by a meta-analysis of data from 39 studies [17].

MtDNA-CN and RTL were previously reported to be affected by lifestyle factors, such as diet and physical activity. Among individuals with overweight, intervention with a low-fructose and low-sodium diet for 8 weeks was associated with an increment of mtDNA-CN [18]. In patients with chronic kidney disease, conducting a resistance exercise program for 12 weeks was associated with an improvement of mtDNA-CN [19]. The role of dietary components in regulating RTL has been reported in epidemiological studies. Consumption of sugar-sweetened beverages and meat was associated with the shortening of RTL while consumption of antioxidant-rich plants was associated with RTL maintenance [20].

From the literature, it can be concluded that there were association between mtDNA-CN, RTL and systemic inflammation due to increased adiposity. It was previously reported that mtDNA-CN and RTL are associated with weight gain, and those parameters are influenced by diet and physical activity. However, the majority of reports on the role of dietary components on changes in mtDNA-CN and RTL among 
adults are based on observational studies. Therefore, conducting an intervention study is important to evaluate whether diet and exercise had an influence on mtDNACN and RTL.

\section{METHODS}

\section{Participants and study group}

This is a secondary analysis of a clinical trial conducted among Indonesian men and women with obesity. The intervention was conducted in Yogyakarta, Indonesia. The inclusion criteria in this rial (Chapter 4) were adults between 21 and 56 years old and body mass index (BMI) higher than $27.5 \mathrm{~kg} / \mathrm{m}^{2}$. The exclusion criteria were current chronic diseases such as type 2 diabetes mellitus and heart diseases, elevated blood pressure and blood glucose concentrations, pregnancy, breastfeeding, smoking, longterm consumption of certain drugs (such as metformin, allopurinol and simvastatin), being on a weight loss diet or using weight loss supplements, drugs or herbal formula. Ethical clearance was obtained from the Medical and Health Research Ethics Committee, Faculty of Medicine, Public Health and Nursing, Universitas Gadjah Mada, Indonesia (KE/0560/05/2017). This study followed the ethical guidelines of the 1975 Declaration of Helsinki.

Participants were recruited by announcements via fliers, a webpage, and social media. A total of 195 individuals applied to become participants via short messages, phone, and email. Of those 195, 77 participants had a BMI above $27.5 \mathrm{~kg} /$ $\mathrm{m}^{2}$. Those participants were then invited to the university (Universitas Gadjah Mada, Yogyakarta, Indonesia) for measurements of blood glucose and blood pressure. Those with high blood glucose (fasting higher than $6.94 \mathrm{mmol} / \mathrm{L}$ or random higher than $11.1 \mathrm{mmol} / \mathrm{L}$ ) or elevated blood pressure (higher than $140 / 90 \mathrm{mmHg}$ ) were not included in the study. 61 participants were eligible and willing to participate in the study after being informed of the study protocol, including the changes in dietary intake and an exercise routine at the university 2 times a week.

After stratification for sex, the participants were randomized (https://www. randomizer.org) into 2 groups, the low-calorie diet group (LCD) and the low calorie low inflammatory diet group (LCID). The intervention in this study included dietary counseling and an exercise program. The exercise consisted of 15 minutes warmingup, 30 minutes core exercise and 15 minutes cool down. A combination of aerobic and dumbbell exercises with low-to-medium exercise intensity and an estimated total calorie expenditure of $300 \mathrm{kcal}$ was used. The exercise program was the same in both groups. The duration of the intervention was 8 weeks (Figure 5.1). Details about the weight loss program were published elsewhere (Chapter 4). 


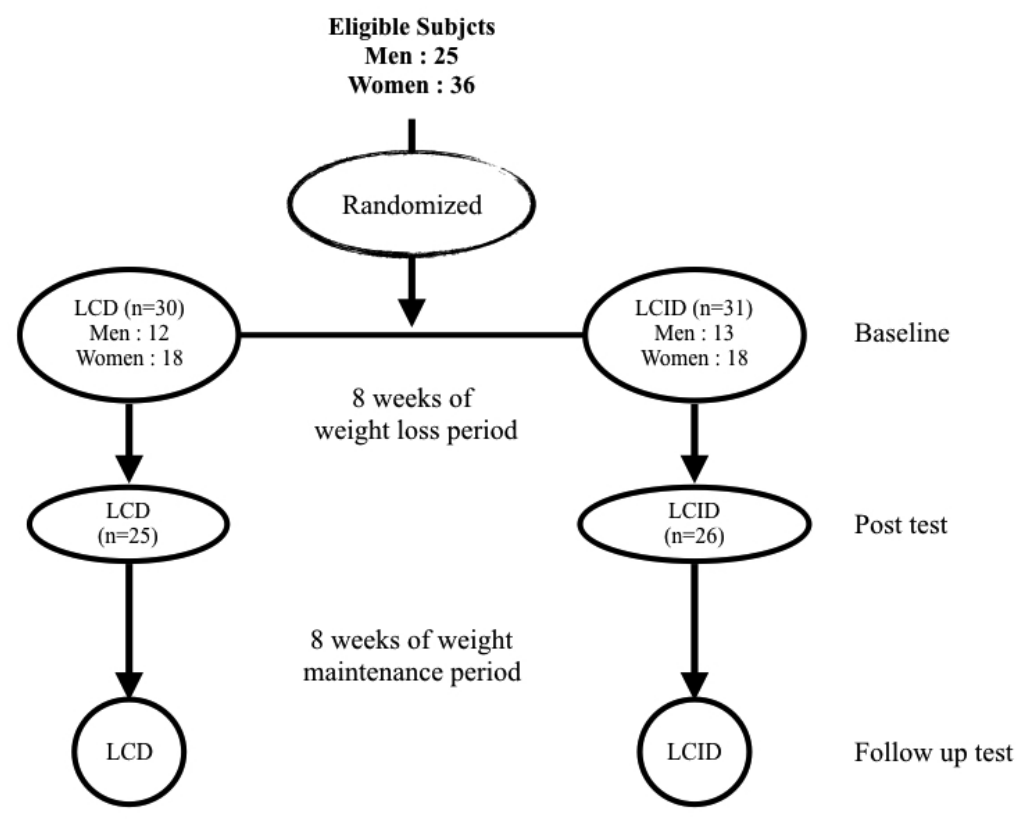

Figure 5.1. Study design

The dietary counseling was done to reduce energy intake and participants in both groups had similar $1500 \mathrm{kcal}$ energy intake a day. While those in LCD only focused on reducing calorie intake, those with LCID had additional dietary recommendations to reduce inflammation. This is achieved by adapting Mediterranean diet principles to the low-calorie diet regime [21]. In our initial publication, we showed that LCD and LCID had a similar weight loss but those in the LCID group had a greater reduction in hs-CRP (Chapter 4).

\section{Measurements}

Measurements (anthropometrics and blood sampling) were performed at baseline, after the weight-loss period (week 9), and after the weight maintenance period (week 16). In this study, the anthropometric measures included body weight (kg) and body mass index (BMI) $\left(\mathrm{kg} / \mathrm{m}^{2}\right)$. Body weight was measured using a bioelectrical impedance body composition monitor and scale $(0.01 \mathrm{~kg}$ precision; Omron, Osaka, Japan). Height was measured using a wall-mounted tape measure $(0.1 \mathrm{~cm}$ precision, GEA medical, Jakarta, Indonesia). BMI was calculated by dividing body weight with squared height (in $\mathrm{m}$ ). WC was measured at the midpoint between the lower margin of the least palpable rib and the top of the iliac crest using a non-elastic tape $(0.1 \mathrm{~cm}$ precision).

Blood samples were collected in the morning after an 8-10 hours fast. From each subject, a $5 \mathrm{~mL}$ blood sample was collected in ethylenediaminetetraacetic 
acid (EDTA)-containing tubes. After collection, blood plasma and buffy coat were separated by centrifugation and stored at $-80^{\circ} \mathrm{C}$. Genomic DNA was extracted from peripheral blood mononuclear cells (PBMC) using FavorPrep Blood Genomic DNA Extraction Mini Kit (Favorgen, Taiwan) for quantification of MtDNA-CN and RTL. The inflammation markers hs-CRP, leptin, TNF-alpha, and IL-6 were measured in plasma using enzyme-linked immunosorbent assay according to the manufacturer's protocol (DRG, New Jersey, USA; Finetest, Wuhan, China).

\section{Quantification of MtDNA-CN and RTL}

MtDNA-CN and RTL were determined by quantitative real-time PCR (qPCR) assay, using SYBR Select MasterMix detection (Applied Biosystem, Foster City, USA) in the 7500 Real-Time PCR System (Applied Biosystem), as previously described [22]. Briefly, the mtDNA-CN measurement was done by using primers for mitochondrial tRNAleu (MT-TL1) and nuclear-encoded $\beta$-2 microglobulin (B2M) genes, following the protocol from Venegas, et al. [23], while for telomere repeats, the measurement was conducted following the protocol by O'Callaghan et al. [24]. Copy number of MT-TL1 gene and telomere repeats were normalized by the single copy $B 2 M$ as a reference gene. MtDNA-CN and RTL were calculated based on the efficiency-corrected method as implemented in the " $q P C R$ " package in R-Project for Statistical Computing version 3.4.3 (www.r-project.org), according to the five-parameter sigmoidal models fitted to the raw fluorescence data $[25,26]$.

\section{Statistical analyses}

Statistical analysis was done using JASP software version 0.8.3.1 (University of Amsterdam). Changes of mtDNA-CN and RTL over the weight-loss period within groups were analyzed using the Wilcoxon signed-rank test. The between groups differences between mtDNA-CN and RTL at baseline and their changes with weight loss were evaluated using the Mann Whitney test and the ANCOVA test. The ANCOVA test was also used to evaluate the difference in changes in anthropometric measures, inflammation markers, mtDNA-CN, and RTL between weight gainers and weight losers. The analysis was done on those with a complete dataset for each measurement. The correlation of mIDNA-CN and RTL with body weight and inflammation markers was analyzed using the Spearman correlation test and linear regression test with correction for age, sex, and changes in body weight (for nonanthropometric analysis). A P-value of less than 0.05 was considered as statistically significant. This analysis was done in whole group and in the separate intervention groups (LCID vs LCD). 


\section{RESULTS}

Details about changes in dietary intake, inflammation markers, and anthropometric measures have been reported elsewhere (Chapter 4). Of 51 participants who finished the weight loss program, 35 participants were followed after 8 weeks (during weight maintenance) (Figure 5.2). We found no differences in body weight changes between LCD and LCID during the weight-loss period $(p=0.443)$ and during the weight maintenance period $(p=0.634)$.

We also evaluated the differences in changes of mtDNA-CN and RTL during the different dietary interventions, LCID and LCD. The changes in mIDNA-CN and RTL in both groups are shown in Figure 5.3. There was no difference in mtDNA-CN and RTL at baseline between LCD and LCID ( $p=0.154, p=0.605$, respectively). We found a significant increment of RTL ( $p<0.001)$, but no changes in mtDNA-CN $(p=0.641)$ in the total group with weight loss program. When comparing between-group changes using an ANCOVA test with correction for age, sex, height and initial weight (Table 5.2), the result showed that those in the LCID group had a higher increment in RTL as compared to those in the LCD group ( $p=0.036)$, but no difference was seen in mtDNA$\mathrm{CN}(\mathrm{p}=0.336)$.

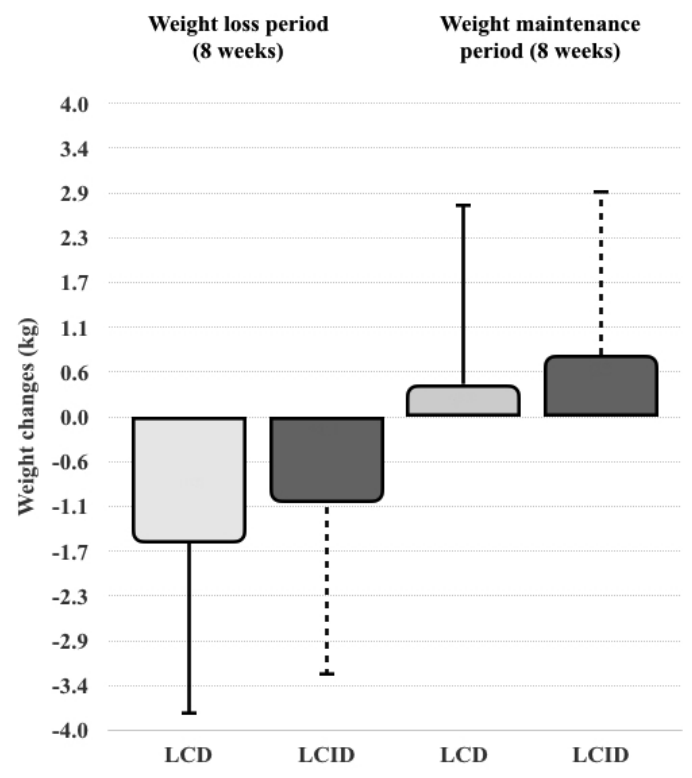

Figure 5.2. Body weight changes during weight loss period and during weight maintenance period. Data were presented as mean (standard deviation). 
A

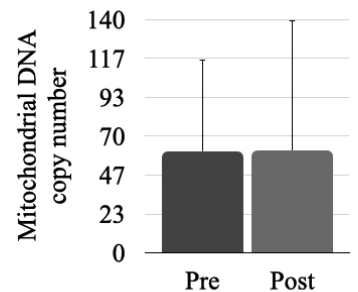

$\mathrm{C}$

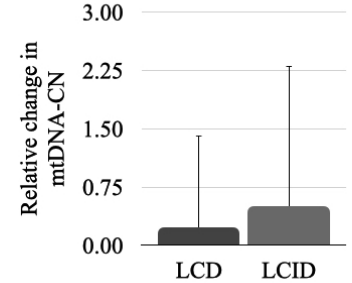

B

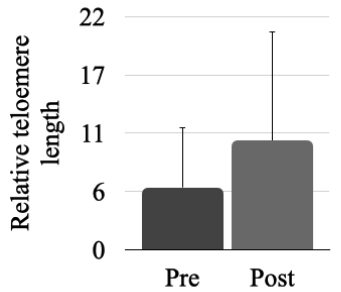

$\mathrm{D}$

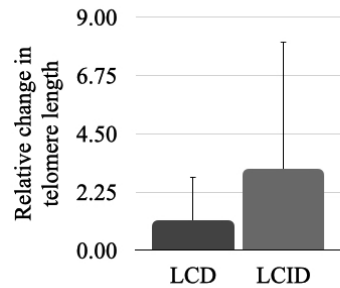

Figure 5.3. The mtDNA-CN and RTL before and after the weight loss period ( $A$ and $B$, respectively). The difference in relative changes of mtDNA-CN and RTL between $L C D$ and $L C I D$ ( $C$ and $D$, respectively).

The correlations between mtDNA-CN and RTL with inflammation markers were analyzed at baseline and after the weight loss program. At baseline mtDNA$\mathrm{CN}$ and RTL showed negative correlations with leptin and IL-6 (all $p<0.05$ ) in the total group of participants, but no correlations with hs-CRP and TNF-alpha (Table 5.1). In separate group analyses, only those in the LCID group showed the negative correlations, consistent with the total group of participants.

Table 5.1. Correlation of inflammation markers with mitochondrial DNA copy number and relative telomere length at baseline.

\begin{tabular}{lcccc}
\hline & \multicolumn{2}{c}{ Mitochondrial DNA copy number } & \multicolumn{2}{c}{ Relative telomere length } \\
\cline { 2 - 5 } & \multicolumn{2}{c}{ All $(\mathrm{n}=47)$} & \multicolumn{2}{c}{ All $(\mathrm{n}=47)$} \\
\cline { 2 - 5 } Baseline values & $\mathbf{R}^{*}$ & $\boldsymbol{P}$ & $\mathbf{R}^{*}$ & $\boldsymbol{p}$ \\
\hline hs-CRP $(\mathrm{mg} / \mathrm{L})$ & -0.113 & 0.456 & -0.126 & 0.404 \\
\hline TNF-alpha $(\mathrm{pg} / \mathrm{mL})$ & -0.018 & 0.909 & 0.020 & 0.894 \\
Leptin $(\mathrm{ng} / \mathrm{mL})$ & $-\mathbf{0 . 4 1 6}$ & $\mathbf{0 . 0 0 9}$ & $\mathbf{- 0 . 3 3 0}$ & $\mathbf{0 . 0 4 3}$ \\
\hline IL-6 $(\mathrm{pg} / \mathrm{mL})$ & $-\mathbf{0 . 3 5 2}$ & $\mathbf{0 . 0 3 0}$ & $\mathbf{- 0 . 4 9 5}$ & $\mathbf{0 . 0 0 2}$ \\
\hline Body weight $(\mathrm{kg})$ & 0.011 & 0.943 & -0.061 & 0.685 \\
\hline
\end{tabular}

*Spearman correlation test.

The correlation between changes in inflammation markers and changes in mtDNA-CN and RTL was also analyzed (Table 5.2). Among all participants, we found that changes in TNF-alpha were negatively correlated with percent changes 
of mtDNA-CN ( $p=0.013)$ while changes in other inflammation markers were not correlated with percent changes of mtDNA-CN (all $p>0.05$ ). We found that changes in RTL were not correlated with any inflammation marker in this study (hs-CRP, leptin, TNF-alpha and IL-6, $p>0.05$ ). To evaluate the influence of dietary intervention, further analysis was done by analyzing the correlation between changes in mtDNA-CN and RTL and changes in inflammation markers in the dietary groups separately. Among participants in the LCID group, the change in mtDNA-CN was negatively correlated with changes of TNF-alpha ( $p=0.014)$ and IL-6 ( $p=0.053$, borderline significant) after correction for age, sex, and body weight change. In this group, the change of RTL was negatively correlated with change in TNF-alpha $(p=0.029)$, but the association was no longer evident after correction for confounding factors. By contrast, among participants in the LCD group the change in IL- 6 was positively correlated with the change in mtDNA-CN ( $p=0.026)$. In this group, the change in RTL was not correlated with changes of inflammation markers (all $p>0.050$ ).

Table 5.2. Correlation between changes in inflammation markers with relative changes in mtDNA-CN and RTL (n=47).

\begin{tabular}{|c|c|c|c|c|c|c|c|c|c|c|c|c|}
\hline \multirow{2}{*}{$\begin{array}{l}\text { Correlation with mtD- } \\
\text { NA-CN change }\end{array}$} & \multicolumn{4}{|c|}{ All participants $(n=47)$} & \multicolumn{4}{|c|}{$\operatorname{LCD}(n=23)$} & \multicolumn{4}{|c|}{$\operatorname{LCID}(n=24)$} \\
\hline & $\mathrm{R}$ & $p$ & B & $p$ & $\mathrm{R}$ & $p$ & B & $p$ & $\mathrm{R}$ & $p$ & B & $p$ \\
\hline Change hs-CRP (mg/L) & 0.053 & 0.724 & $-0.040^{*}$ & 0.799 & 0.158 & 0.469 & $-0.174^{*}$ & 0.465 & 0.021 & 0.921 & $-0.035^{*}$ & 0.884 \\
\hline TNF-alpha (pg/mL) & -0.101 & 0.507 & $-0.466^{*}$ & 0.013 & 0.238 & 0.287 & $-0.201 *$ & 0.545 & -0.387 & 0.068 & $-0.615^{*}$ & 0.014 \\
\hline Leptin (ng/mL) & 0.212 & 0.208 & $0.236^{*}$ & 0.272 & -0.040 & 0.876 & $-0.221^{*}$ & 0.405 & 0.359 & 0.131 & $0.324^{*}$ & 0.398 \\
\hline IL-6 (pg/mL) & 0.130 & 0.431 & $-0.028^{*}$ & 0.872 & 0.469 & 0.043 & $0.525^{*}$ & 0.026 & -0.215 & 0.362 & $-0.463^{*}$ & 0.053 \\
\hline Weight loss (kg) & 0.049 & 0.750 & $-0.048 \wedge$ & 0.761 & -0.053 & 0.821 & $-0.303 \wedge$ & 0.216 & 0.137 & 0.533 & $0.094 \wedge$ & 0.675 \\
\hline \multirow[t]{2}{*}{ Correlation with RTL } & \multicolumn{4}{|c|}{ All participants $(n=47)$} & \multicolumn{4}{|c|}{$\operatorname{LCD}(n=23)$} & \multicolumn{4}{|c|}{ LCID $(n=24)$} \\
\hline & $\mathrm{R}$ & $p$ & B & $p$ & $\mathrm{R}$ & $p$ & B & $p$ & $\mathrm{R}$ & $p$ & B & $p$ \\
\hline hs-CRP (mg/L) & -0.003 & 0.982 & $-0.143^{*}$ & 0.368 & 0.223 & 0.304 & $0.252^{*}$ & 0.296 & -0.103 & 0.629 & $-0.241^{*}$ & 0.315 \\
\hline TNF-alpha (pg/mL) & -0.118 & 0.439 & $-0.103^{*}$ & 0.608 & 0.294 & 0.185 & $-0.276^{*}$ & 0.413 & -0.455 & 0.029 & $-0.065^{*}$ & 0.817 \\
\hline Leptin (ng/mL) & 0.064 & 0.706 & $0.340^{*}$ & 0.113 & 0.015 & 0.954 & $-0.303^{*}$ & 0.253 & 0.029 & 0.906 & $0.455^{*}$ & 0.239 \\
\hline IL-6 (pg/mL) & -0.081 & 0.623 & $-0.111^{*}$ & 0.521 & 0.082 & 0.739 & $0.038^{*}$ & 0.885 & -0.280 & 0.232 & $-0.255^{*}$ & 0.323 \\
\hline Weight loss (kg) & -0.032 & 0.835 & $0.117 \wedge$ & 0.467 & -0.064 & 0.782 & $-0.152^{\wedge}$ & 0.536 & -0.013 & 0.954 & $0.166^{\wedge}$ & 0.469 \\
\hline
\end{tabular}

Linear regression analysis with * correction for age, sex and body weight changes or $\wedge$ correction for age and sex; $B$ : standardized value for linear regression test with correction for confounding factors; R: Spearman test; $\mathrm{p}$ : significant value with 2-tailed analysis. 
Participants were separated based on their weight loser/gainer status (Table 5.3). Weight gainers and weight losers were defined by differences in weight changes from baseline (week 0) to weight maintenance period (week 16). Participants were weight losers when the net weight difference was negative while participants were weight gainer when net weight difference was 0 or positive. In this study, we showed that weight losers had higher body height $(p=0.045)$, greater weight loss $(p<0.001)$, and greater TNF-alpha increment $(p<0.001)$ during the weight-loss period. In addition, we showed no difference in changes of mtDNA-CN $(p=0.587)$ and RTL $(p=0.194)$ between weight gainer and weight loser.

Table 5.3. Differences in anthropometric, inflammation, mtDNA-CN and RTL changes during weight loss between those who gained weight and those who lose weight after 8 weeks of follow up.

\begin{tabular}{|c|c|c|c|c|c|c|}
\hline & \multicolumn{2}{|c|}{$\begin{array}{c}\text { Weight loser } \\
(n=19)\end{array}$} & \multicolumn{2}{|c|}{$\begin{array}{c}\text { Weight gainer } \\
(n=16)\end{array}$} & \multirow[b]{2}{*}{$p^{*}$} & \multirow[b]{2}{*}{$p^{\wedge}$} \\
\hline & Mean & SD & Mean & SD & & \\
\hline Age (years) & 25.1 & 5.4 & 24.1 & 5.1 & 0.468 & - \\
\hline Height (cm) & 163.3 & 8.8 & 156.9 & 9.7 & 0.045 & - \\
\hline \multicolumn{7}{|c|}{ Anthropometric changes during weight loss } \\
\hline Body weight (kg) & -3.02 & 1.94 & -0.21 & 1.53 & $<0.001$ & $<0.001$ \\
\hline Body fat (\%) & -1.06 & 1.52 & -0.43 & 0.61 & 0.163 & 0.547 \\
\hline Vis Fat (\%) & -1.31 & 0.94 & -0.27 & 0.65 & 0.002 & 0.009 \\
\hline $\mathrm{BMI}(\mathrm{kg} / \mathrm{m} 2)$ & -1.13 & 0.70 & -0.07 & 0.61 & $<0.001$ & $<0.001$ \\
\hline Subcutaneous fat (\%) & -1.11 & 0.92 & -0.34 & 0.54 & 0.012 & 0.044 \\
\hline Muscle (\%) & 0.42 & 0.72 & 0.23 & 0.30 & 0.468 & 0.916 \\
\hline Waist circumference $(\mathrm{cm})$ & -0.36 & 5.97 & 0.17 & 6.53 & 0.914 & 0.285 \\
\hline Hip circumference (cm) & -4.73 & 6.14 & 0.22 & 3.92 & 0.023 & 0.090 \\
\hline WHR & 0.04 & 0.07 & 0.00 & 0.08 & 0.301 & 0.752 \\
\hline \multicolumn{7}{|c|}{ Inflammation changes during weight loss } \\
\hline hs-CRP (mg/L) & -0.06 & 2.97 & -0.00 & 2.40 & 0.987 & 0.940 \\
\hline TNF-alpha (pg/mL) & 3.54 & 1.67 & 1.05 & 2.15 & 0.002 & $<0.001$ \\
\hline Leptin (ng/mL) & -4.28 & 3.71 & -0.72 & 5.56 & 0.044 & 0.051 \\
\hline IL-6 (pg/mL) & 1.24 & 1.93 & 0.40 & 1.44 & 0.589 & 0.259 \\
\hline \multicolumn{7}{|c|}{ mtDNA-CN and RTL changes during weight loss } \\
\hline mtDNA-CN (relative changes) & 0.20 & 1.28 & 0.43 & 1.40 & 0.343 & 0.587 \\
\hline RTL (relative changes) & 0.99 & 1.73 & 1.95 & 3.20 & 0.325 & 0.194 \\
\hline
\end{tabular}

*Mann Withney test; ^ANCOVA test with correction for age, sex, height and initial body weight. This analysis compares characteristic differences between weight losers and weight gainers. Participants were weight loser when the net weight difference from baseline to follow-up was negative while participants were weight gainer when the net weight difference was 0 or positive. MtDNA-CN: mitochondrial DNA copy number; RTL: relative telomere length. 


\section{DISCUSSIONS}

Participants in both diet groups (LCD and LCID) had an increase in RTL but not in mtDNA-CN after the weight loss program. The increment in RTL was higher among participants in the LCID group than in the LCD group. However, changes in RTL were not associated with changes in any of the pro-inflammatory markers analyzed, while changes in mtDNA-CN were negatively correlated with changes of TNF-alpha. There was no association between changes in mIDNA-CN and RTL and weight regain status.

To our knowledge, there are few studies investigating the effect of a weight loss program on telomere length [27]. A study in adolescents with obesity showed that a weight loss program with modification of diet and physical activity was associated with elongation of telomere length [28]. The effect of energy restriction among adults was conflicting, where one study showed a lengthening effect in adult men with obesity [29], but no effect was seen in postmenopausal women with overweight/ obesity [30]. By contrast, a correlation between weight loss and increasing telomere length was reported among adults after intragastric balloon therapy [31].

In this study, we showed an effect of a low-calorie diet on the elongation of telomere length in men and women with obesity, and by reducing the inflammation properties of the diet we were able to optimize the effect on telomere length. The reduction of the inflammatory properties of diet was obtained by adapting the principle of the Mediterranean diet in combination with the low-calorie diet prescription. It was previously reported that adherence to the Mediterranean diet principle was positively associated with longer telomere length [32]. The effect of Mediterranean diet principles on telomere length might be due to the combined effect of bioactive nutrients and phytochemicals contained in the recommended foods [33]. The effect of reducing inflammation on RTL in the LCID group is expected and in line with other studies. To our knowledge, this study is the first intervention study to evaluate the influence of Mediterranean diet principles in combination with a low-calorie diet on changes in telomere length. The majority of studies on the interaction between the Mediterranean diet and telomere length was based on an observational study [33].

Different from telomere length, this study showed that the weight loss program was not associated with changes in mtDNA-CN, and there were no differences in changes in mIDNA-CN between the LCD and LCID groups. As it was previously reported that mIDNA-CN was negatively associated with adiposity [1416], we expected that weight loss in this study could increase mtDNA-CN. However, a weight loss program among individuals with obesity through diet or gastric banding was also not associated with changes of adipocyte mtDNA-CN [34]. It was suggested that other aspects of mitochondrial examination such as structure, function or size might provide a better insight on mitochondrial health rather than the mtDNA-CN $[34,35]$. 
Findings from this study support the notion that inflammation is inversely associated with mtDNA-CN and RTL. At baseline IL- 6 and leptin were negatively correlated RTL. However, this study could not provide evidence that changes in RTL were associated with changes in the pro-inflammatory markers analyzed (hs-CRP, TNF-alpha or IL-6). The RTL improvement might be influenced by other inflammation markers such as IL-2 [36], which were not analysed in this study. In addition, this study was conducted in a relatively small number of subjects which make it hard to reach a significant value. Several mechanisms have been proposed on the interaction between inflammation and telomere length. First, inflammation is associated with a reduction of telomerase expression, the enzyme that is involved in the lengthening of telomeres. Second, inflammation also directly induces telomeric DNA damage mediated by reactive oxygen species [37].

Similar to RTL, IL-6 and leptin were inversely correlated with mtDNA-CN at baseline. Additionally, we showed that an increase in TNF-alpha after the intervention was associated with a reduction of mtDNA-CN. These findings suggest that more inflammation is associated with a reduction of mtDNA-CN among individuals with obesity. However, because of the nature of this study, we cannot draw conclusions about a causal relationship between inflammation and mtDNA-CN.

There are several limitations to this study. Because of the limitation of specimen collection due to ethical reasons, the mtDNA-CN and RTL in this study were analyzed from circulating leukocytes and not from adipose tissue, which would probably be more relevant in a weight loss study. It was previously reported that the association between inflammation, mtDNA-CN and RTL varied between tissues $[38,39]$. It was also reported that inflammation was positively correlated with adipocyte mtDNA-CN but negatively with monocyte mtDNA-CN [38]. Additionally, RTL from leukocytes is only significantly correlated with muscle RTL, but not with RTL of other tissues [39]. Another limitation in this study is that the number of participants was rather limited, thus further study with larger sample size is necessary to confirm the findings.

In conclusion, this study reported the effect of a weight loss intervention on changes in mtDNA-CN and RTL in PBMCs. We showed that reducing calorie intake and increasing physical activity among individuals with obesity was beneficial to increase RTL but had no effect on mtDNA-CN. Modification of diet to reduce inflammation had an additional benefit in improving RTL. 


\section{Acknowledgements}

We thank to Satwika Arya Pratama, S.Gz and Maya Nurfitriani Hartono, S.Gz for help with nutritional counseling and preparation of exercise sessions. We thank to Lidwina Priliani for help with statistical evaluation of RT PCR data. We also thank Dr. Nuria Rosique Esteban for her help during the development of the dietary recommendation protocol.

\section{Statement of Authorship}

Conceptualization, H.F.L.M., M.A.v.B. and E.C.M, Methodology, H.F.L.M., M.A.v.B. and E.C.M, Investigation, H.F.L.M., S.O., S.G.M., Resources, H.F.L.M., S.O and S.G.M, Data Curation, H.F.L.M., S.O., S.G.M., M.A.v.B. and E.C.M.; Writing - Original Draft Preparation, H.F.L.M., S.O., M.A.v.B. and E.C.M.; Writing - Review \& Editing, H.F.L.M., M.A.v.B., S.O., S.G.M., and E.C.M.; Supervision, S.G.M., M.A.v.B. and E.C.M; Project Administration, H.F.L.M.; Funding Acquisition, H.F.L.M. Harry Freitag Luglio Muhammad (H.F.L.M.), Edwin C. Mariman (E.C.M.), Marleen A. van Baak (M.A.v.B.), Safarina G. Malik (S.G.M) and Sukma Oktavianthi (S.O.).

\section{Conflict of Interest}

There is no financial and personal relationship with other people or organizations that could inappropriately influence this work.

\section{Funding Sources}

This study was funded by internal grant from Universitas Gadjah Mada, Indonesia.

\section{REFERENCES}

1. GBD 2015 Obesity Collaborators, et al. Health Effects of Overweight and Obesity in 195 Countries over 25 Years. N Engl J Med 2017, 377, 13-27.

2. Tremmel M, Gerdtham UG, Nilsson PM, et al. Economic Burden of Obesity: A Systematic Literature Review. Int J Environ Res Public Health 2017, 14(4), 435.

3. Monteiro R, Azevedo I. Chronic inflammation in obesity and the metabolic syndrome. Mediators Inflamm 2010, 2010:289645.

4. Han JM, Levings MK. Immune regulation in obesity-associated adipose inflammation. $J$ Immunol 2013, 191(2), 527-532.

5. Lumeng CN, Bodzin JL, Saltiel AR. Obesity induces a phenotypic switch in adipose tissue macrophage polarization. J Clin Invest 2007, 117, 175-184. 
6. Morris DL, Singer K, Lumeng CN. Adipose tissue macrophages: phenotypic plasticity and diversity in lean and obese states. Curr Opin Clin Nutr Metab Care 2011, 14, 341-346.

7. Tsoupras A, Lordan R, Zabetakis I. Inflammation, not Cholesterol, Is a Cause of Chronic Disease. Nutrients 2018, 10(5), E604.

8. Wu IC, Lin CC, Liu CS, et al. Interrelations Between Mitochondrial DNA Copy Number and Inflammation in Older Adults. J Gerontol A Biol Sci Med Sci 2017, 72(7), 937-944.

9. Bhatti JS, Bhatti GK, Reddy PH. Mitochondrial dysfunction and oxidative stress in metabolic disorders - A step towards mitochondria based therapeutic strategies. Biochim Biophys Acta Mol Basis Dis 2017, 1863(5), 1066-1077.

10. Wong JY, De Vivo I, Lin X, et al. The relationship between inflammatory biomarkers and telomere length in an occupational prospective cohort study. PLoS One 2014, 9(1), e87348.

11. Yang $M$, Jiang $P$, Jin C, et al. Longer Telomere Length and its Association with Lower Levels of C-Peptide. Front Endocrinol (Lausanne) 2017, 8, 244.

12. Batsis JA, Mackenzie TA, Vasquez $E$, et al. Association of adiposity, telomere length and mortality: data from the NHANES 1999-2002. Int J Obes 2018, 42(2), 198-204.

13. Zole E, Ranka R. Mitochondrial DNA copy number and telomere length in peripheral blood mononuclear cells in comparison with whole blood in three different age groups. Arch Gerontol Geriatr 2019, 83, 131-137.

14. Meng S, Wu S, Liang L, et al. Leukocyte mitochondrial DNA copy number, anthropometric indices, and weight change in US women. Oncotarget 2016, 7(37), 60676-60686.

15. Lee JY, Lee DC, Im JA, et al. Mitochondrial DNA copy number in peripheral blood is independently associated with visceral fat accumulation in healthy young adults. Int $J$ Endocrinol 2014, 2014, 586017.

16. Ding J, Sidore C, Butler TJ, et al. Assessing Mitochondrial DNA Variation and Copy Number in Lymphocytes of $\sim 2,000$ Sardinians Using Tailored Sequencing Analysis Tools. PLoS Genet 2015, 11(7), e1005306.

17. Mundstock E, Sarria EE, Zatti H, et al. Effect of obesity on telomere length: Systematic review and meta-analysis. Obesity 2015, 23(11), 2165-2174.

18. Hernández-Ríos R, Hernández-Estrada $S$, Cruz-Robles $D$, et al. Low fructose and low salt diets increase mitochondrial DNA in white blood cells of overweight subjects. Exp Clin Endocrinol Diabetes 2013, 121(9), 535-538.

19. Balakrishnan VS, Rao M, Menon V, et al. Resistance training increases muscle mitochondrial biogenesis in patients with chronic kidney disease. Clin J Am Soc Nephrol, 2010, 5(6), 996-1002.

20. Freitas-Simoes TM, Ros E, Sala-Vila A. Telomere length as a biomarker of accelerated aging: is it influenced by dietary intake? Curr Opin Clin Nutr Metab Care 2018, 21(6): 430-436.

21. Sureda A, Bibiloni MDM, Julibert $A$, et al. Adherence to the Mediterranean Diet and Inflammatory Markers. Nutrients 2018, 10(1), pii: E62. 
22. Oktavianthi S, Fauzi M, Trianty L, et al. Placental Mitochondrial DNA Copy Number is Associated with Reduced Birth Weight in Women with Placental Malaria. Placenta 2019, 80, 1-3.

23. Venegas V, Wang J, Dimmock D, et al. Real-time quantitative PCR analysis of mitochondrial DNA content. Curr. Protoc. Hum. Genet. Editor. Board Jonathan Haines Al. Chapter 19 (2011) Unit 19.7.

24. O'Callaghan $\mathrm{N}$, Dhillon $\mathrm{V}$, Thomas $\mathrm{P}$, et al. A quantitative real-time PCR method for absolute telomere length. BioTechniques 2008, 44, 807-809.

25. Ritz C, Spiess AN. qpcR: an R package for sigmoidal model selection in quantitative realtime polymerase chain reaction analysis. Bioinformatics 2008, 24, 1549-1551.

26. Kloke JD, McKean JW. Rfit: rank-based estimation for linear models, $R$ J. 2012; 4: 57-64.

27. Welendorf C, Nicoletti CF, Pinhel MAS, et al. Obesity, weight loss, and influence on telomere length: New insights for personalized nutrition. Nutrition 2019, 66, 115-121.

28. Garcia-Calzon S, Moleres A, Marcos A, et al. Telomere Length as a Biomarker for Adiposity Changes after a Multidisciplinary Intervention in Overweight/Obese Adolescents: The EVASYON Study. PLOS ONE 2014, 9(2), e89828.

29. O'Callaghan NJ, Clifton PM, Noakes M, et al. Weight loss in obese men is associated with increased telomere length and decreased abasic sites in rectal mucosa. Rejuvenation Res 2009, 12(3), 169-176.

30. Mason C, Risques RA, Xiao L, et al. Independent and combined effects of dietary weight loss and exercise on leukocyte telomere length in postmenopausal women. Obesity (Silver Spring) 2013, 21, E549-554.

31. Carulli L, Anzivino C, Baldelli E, et al. Telomere length elongation after weight loss intervention in obese adults. Mol Genet Metab 2016, 1182, 138-142.

32. Crous-Bou M, Fung TT, Prescott J, et al. Mediterranean diet and telomere length in Nurses' Health Study: population based cohort study. BMJ 2014, 349, g6674.

33. Davinelli S, Trichopoulou A, Corbi G, et al. The potential nutrigeroprotective role of Mediterranean diet and its functional components on telomere length dynamics. Ageing Res Rev 2019, 49, 1-10.

34. Kaaman M, Sparks LM, van Harmelen V, et al. Strong association between mitochondrial DNA copy number and lipogenesis in human white adipose tissue. Diabetologia 2007, 50(12), 2526-2533.

35. Breininger SP, Malcomson FC, Afshar S, et al. Effects of obesity and weight loss on mitochondrial structure and function and implications for colorectal cancer risk. Proc Nutr Soc 2019, 78(3), 426-437.

36. Kawauchi K, Ihjima K, Yamada O. IL-2 Increases Human Telomerase Reverse Transcriptase Activity Transcriptionally and Posttranslationally through Phosphatidylinositol 3'-Kinase/ Akt, Heat Shock Protein 90, and Mammalian Target of Rapamycin in Transformed NK Cells. J Immunol 2005, 174(9): 5261-5269. 
37. Kordinas V, loannidis A, Chatzipanagiotou S. The Telomere/Telomerase System in Chronic Inflammatory Diseases. Cause or Effect? Genes (Basel) 2016, 7(9), 60.

38. Skuratovskaia D, Zatolokin $P$, Vulf $M$, et al. Interrelation of chemerin and TNF- $\alpha$ with mtDNA copy number in adipose tissues and blood cells in obese patients with and without type 2 diabetes. BMC Med Genomics 2019, 12(Suppl 2), 40.

39. Dlouha D, Maluskova J, Kralova-Lesna I, et al. Comparison of the relative telomere length measured in leukocytes and eleven different human tissues. Physiol Res 2014, 63 Suppl 3, S343-S350. 


\section{CHAPTER 6}

\section{Interactions between SNPs at Pro-inflammatory Genes, Adiposity and C-reactive Protein and Their Association with Colorectal Cancer Risk}

Harry Freitag Luglio Muhammad ${ }^{1,2,3}$, Marleen van Baak ${ }^{1}$, Edwin Mariman ${ }^{1}$, Fiona C Malcomson ${ }^{3}$, John C. Mathers ${ }^{3}$

${ }^{1}$ NUTRIM, School of Translational Research in Nutrition and Metabolism, Maastricht Medical Centre+, Maastricht, The Netherlands.

${ }^{2}$ Department of Nutrition, Faculty of Medicine, Public Health and Nursing, Universitas Gadjah Mada, Yogyakarta, Indonesia

${ }^{3}$ Human Nutrition Research Centre, Centre for Healthier Lives, Population Health Sciences Institute, Newcastle University, Newcastle upon Tyne, NE2 4HH, United Kingdom. 


\section{ABSTRACT}

Obesity is associated with increased colorectal cancer (CRC) risk that is driven by increased inflammation. This study aimed to evaluate the interaction between variants in inflammation-related genes (CRP, TNFA, and IL6), adiposity, circulating concentration of high sensitive C-reactive protein (hs-CRP; a marker of systemic inflammation) and CRC risk. Participants undergoing endoscopy for bowel symptoms were recruited, adiposity and circulating hs-CRP concentration were measured. Four SNPs were analyzed including those in CRP (rs1800947, rs1205), TNFA (rs1800629) and IL6 (rs1800795). Individuals with a prior history of adenomatous polyps (therefore at higher risk of CRC), had higher hs-CRP concentrations ( $p=0.012$ ). Adiposity measures did not differ significantly between normal and higher-risk participants. Variation at TNFA ( $r$ 1800629) was associated with body mass index $(\mathrm{p}=0.007)$ and the presence of colorectal polyps $(p=0.002)$. We observed that variants in inflammatory genes may influence the relationships between adiposity and systemic inflammation but these influences appeared to be independent of the effect allele. Variation in TNFA was associated with adiposity and presence of colorectal polyps. In addition, SNPs at CRP, TNFA and IL6 influence the association of adiposity with systemic inflammation.

Keywords: obesity, inflammation, gene variation, CRP, colorectal polyp. 


\section{INTRODUCTION}

Obesity is associated with increased risk of several non-communicable diseases including cancers [1,2]. Several adiposity measures, including body mass index (BMI), visceral adiposity, and a body shape index (ABSI) predict colorectal cancer (CRC) risk [2-4]. Disturbances in hormones, insulin resistance, growth factors and systemic inflammation are plausible mechanisms through which obesity amplifies CRC risk [5,6]. In particular, excess adipose tissue is associated with increased leptin production, immune cell infiltration and higher production of pro-inflammatory cytokines [7]. This combination leads to a greater inflammatory state in adipose tissue as well as higher concentrations of circulating inflammatory markers in individuals with obesity $[8,9]$.

Low-grade systemic inflammation is induced by several factors including environmental exposures (diet, physical activity, pollutants) and genetics [10], and the obesity-inflammation relationship is influenced by variants in inflammationrelated genes. For example, Eiriksdottir et al. [11] reported that variants of the $C$ reactive protein $(C R P)$ gene modulate the relationship between $B M I$ and hs-CRP (a marker of systemic inflammation). Similar findings were reported in other studies $[12,13]$. Systemic inflammation is associated with increased risk of CRC [14] and single nucleotide polymorphisms (SNPs) at inflammatory genes including CRP ( $r$ 1800947, rs1205), TNFA (rs1800629), and IL6 (rs1800795) are associated with greater CRC risk [15-17].

However, the effects of variants in inflammation-related genes on the relationships between adiposity, inflammation and the development of CRC are less understood. Therefore, we focused on specific SNPs in CRP (rs1800947, rs1205), TNFA (rs1800629) and IL6 (rs1800795) known to affect circulating concentrations of the respective proteins [18-20], and for which meta-analyses have shown associations with increased risk of CRC and other cancers [15-17]. We aimed to investigate associations between each of these SNPs and i) measures of adiposity and ii) plasma concentrations of hs-CRP as a marker of systemic inflammation. We also examined whether those SNPs were associated with the risk of colorectal adenomatous polyps (a CRC precursor). Lastly, we evaluated the influence of the selected SNPs on the correlation between adiposity and hs-CRP.

\section{METHODS}

\section{Study design}

We used a cross-sectional study design involving adults living in the North East of England, United Kingdom, who participated in the Biomarkers Of Risk In Colorectal Cancer (BORICC) Study [21]. Adult (>18 years) participants who were listed to undergo endoscopy for diagnostic purposes were recruited from Wansbeck General Hospital, Northumberland, UK. The exclusion criteria of this study included: a familial predisposition to CRC; colorectal neoplasia and inflammatory disease. Ethical 
approval for the study was received from the Northumberland Local Research Ethics Committee (Project reference NLREC2/2001) and details of participant recruitment have been described elsewhere [21]. A total of 329 participants were recruited, comprising healthy individuals $(n=236$, at normal risk of CRC) and those with colorectal adenomatous polyps ( $n=93$, at higher risk of CRC).

\section{Markers of adiposity and inflammation}

Anthropometrics was assessed as body weight ( $\mathrm{kg}$ ), body mass index (BMI; kg/ $\mathrm{m}^{2}$ ), waist circumference (WC; $\mathrm{cm}$ ), hip circumference $(\mathrm{cm})$, and waist-to-hip ratio (WHR) by trained staff using standardized protocols. ABSI was calculated from WC, BMI and height measurements according to Krakauer and Krakauer (ABSI: WC/ $\left(\left(\mathrm{BMI}^{(2 / 3)} \times\right.\right.$ height $\left.\left.^{(1 / 2)}\right)\right)[22]$. Information on participant characteristics including medical history, drug history, smoking status, and supplement use were collected using a questionnaire. Plasma concentrations of hsCRP were measured using an enzyme linked immunosorbent assay.

\section{Assessment of genetic variants}

From plasma that had been stored at $-80^{\circ} \mathrm{C}, \mathrm{DNA}$ was extracted using the ThermoFisher Genomic DNA isolation kit (Waltham, MA, USA) following the manufacturer's instructions. The DNA was sent to LGC, Biosearch Technologies for analysis of genetic variants using KASP assays (LGC group) for the following 4 SNPs in inflammationrelated genes: CRP (+942G>C, rs1800947 and +1846C>T, rs1205), TNFA (-308 G>A, rs1800629) and IL6 (-174G>C, rs1800795).

The variation at TNFA rs1800629, IL6 (rs1800795) and CRP (rs1205) lies outside of the coding region whilst variation at CRP (rs1800947) is within the coding region. The G allele of TNFA (rs1800947), C allele of IL6 (rs1800795), G allele of CRP (rs1800947) and C allele of CRP (rs1800947), were considered as effect alleles because they have been associated with increased expression or concentration of the encoded proteins [23-27]. For further analyses, we used a dominant model (AA vs Aa+aa) comparing those who were homozygous for the effect allele with heterozygotes and those homozygous for the non-effect allele. To evaluate the cumulative effect of gene variants on risk of adenomatous polyps, we calculated a genetic risk score (GRS) for those with complete data for all four SNPs. Using the available literature (Table 6.2) [23-27], a score of 0 was allocated to those carrying 0 or 1 effect allele, and a score of 1 was allocated to those carrying two effect alleles (homozygote). The score for each gene was summed to yield a 'total score' ranging between 0 and 4 . 


\section{Data analysis}

Statistical analyses were performed using JASP software Version 0.8.3.1 (The University of Amsterdam). Differences in adiposity and hs-CRP concentration between those with and without adenomatous polyps were analyzed using the Mann-Whitney test. Calculation of Hardy-Weinberg equilibrium was performed using the online tool snpstat.com [28]. Differences in adiposity measures and in hs-CRP concentrations between genotypes were analyzed using the Mann-Whitney test and ANCOVA with adjustment for age, sex, medical history (including diabetes mellitus, any types of cancer, heart diseases, irritable bowel syndrome, fatty liver disease), drug history, smoking status, and presence of adenomatous polyps. Those factors were previously reported to be associated with inflammation [10]. The odds ratio (OR) for risk of adenomatous polyps, according to SNPs at inflammatory genes, was calculated using conditional logistic regression. Interactions between SNPs at inflammatory genes, adiposity measures, and hs-CRP concentrations for all participants combined were analyzed using linear regression. Within each specific genotype group, relationships between adiposity measures and hs-CRP concentration were investigated using linear regression with adjustment for age, sex, medical history, drug history, smoking status, and polyps group.

\section{RESULTS}

Participant characteristics are summarized in Table 6.1. From a total of 408 potential participants, we used data from 329 who had a complete dataset including genotype. Overall, there were similar numbers of males and females (169 and 160, respectively) who ranged in age from 17-83 years. Individuals with adenomatous polyps were more likely to be male and older compared with healthy individuals (without polyps). There were no significant differences in adiposity measures between those with, and those without, polyps. Participants with polyps had a higher WHR, but this association was no longer significant after adjustment for potential confounding factors. Systemic inflammation, assessed as circulating concentration of hs-CRP, was higher in participants with polyps $(\mathrm{p}=0.012)$. Participants with adenomatous polyps had higher GRS for inflammatory genes than those without adenomatous polyps $(p=0.002)$. 
Table 6.1. Characteristics of study participants.

\begin{tabular}{|c|c|c|c|c|c|c|c|c|c|}
\hline & & & & & Without & denomatous $p$ & olyp & & \\
\hline & All participants & With adeno & matous polyp & $(n=93)$ & & $(n=236)$ & & $p^{*}$ & $p^{\wedge}$ \\
\hline & & Men & Women & & Men & Women & & & \\
\hline & & & & $\boldsymbol{p}^{a}$ & & & $\boldsymbol{p}^{a}$ & & \\
\hline & & $(n=63)$ & $(n=30)$ & & $(n=106)$ & $(n=130)$ & & & \\
\hline Age (years) & $53.1 \pm 13.9$ & $60.6 \pm 11.7$ & $60.1 \pm 11.4$ & & $48.1 \pm 13.1$ & $51.9 \pm 13.9$ & & $<0.001$ & \\
\hline Height (m) & $1.69 \pm 0.10$ & $1.74 \pm 0.09$ & $1.59 \pm 0.06$ & $<0.001$ & $1.77 \pm 0.08$ & $16.2 \pm 0.07$ & $<0.001$ & 0.590 & 0.113 \\
\hline Weight (kg) & $82.2 \pm 19.1$ & $90.1 \pm 19.5$ & $72.9 \pm 17.2$ & $<0.001$ & $87.9 \pm 17.7$ & $75.7 \pm 17.4$ & $<0.001$ & 0.129 & 0.352 \\
\hline BMI $\left(\mathrm{kg} / \mathrm{m}^{2}\right)$ & $28.6 \pm 5.8$ & $29.6 \pm 6.1$ & $28.7 \pm 6.2$ & 0.424 & $27.9 \pm 4.6$ & $28.7 \pm 6.3$ & 0.890 & 0.182 & 0.103 \\
\hline WC $(\mathrm{cm})$ & $94.5 \pm 15.6$ & $102.1 \pm 14.0$ & $87.0 \pm 21.4$ & $<0.001$ & $98.3 \pm 13.2$ & $89.5 \pm 14.2$ & $<0.001$ & 0.050 & 0.821 \\
\hline $\mathrm{HC}(\mathrm{cm})$ & $104.4 \pm 13.0$ & $104.6 \pm 11.1$ & $99.8 \pm 22.6$ & 0.121 & $102.9 \pm 9.4$ & $106.6 \pm 13.3$ & 0.251 & 0.228 & 0.364 \\
\hline WHR & $0.90 \pm 0.09$ & $0.98 \pm 0.06$ & $0.87 \pm 0.07$ & $<0.001$ & $0.95 \pm 0.07$ & $0.84 \pm 0.07$ & $<0.001$ & $<0.001$ & 0.078 \\
\hline ABSI & $0.078 \pm 0.007$ & $0.081 \pm 0.007$ & $0.076 \pm 0.006$ & $<0.001$ & $0.080 \pm 0.005$ & $0.075 \pm 0.006$ & $<0.001$ & 0.010 & 0.404 \\
\hline $\begin{array}{l}\text { hs-CRP } \\
\text { (mg/L) }\end{array}$ & $3.90 \pm 5.06$ & $5.08 \pm 6.40$ & $5.31 \pm 5.4$ & 0.814 & $2.78 \pm 3.4$ & $3.62 \pm 4.98$ & 0.571 & 0.003 & 0.012 \\
\hline GRS & $2.3 \pm 0.87$ & $2.6 \pm 0.8$ & $2.8 \pm 0.6$ & 0.973 & $2.14 \pm 0.84$ & $2.19 \pm 9.2$ & 0.271 & $<0.001$ & 0.002 \\
\hline
\end{tabular}

Data are presented as mean \pm standard deviation; ${ }^{*}$ Chi-square test; *ANOVA test between those with and without polyp (combined men and women); ^ANCOVA test between those with and without polyp (combined men and women) adjusting for age, sex, current smoking status, supplement use, medical diagnosis, and inflammation affecting-drug use, ${ }^{a}$ ANCOVA test between men and women adjusting for age, current smoking status, supplement use, medical diagnosis, and inflammation affecting-drug use; ABSI: A body shape index; BMI: body mass index, GRS: genetic risk score, hs-CRP : high-sensitivity C-reactive protein, HC: hip circumference, WC: waist circumference, WHR: waist-to-hip ratio.

The distribution of variants in inflammation-related genes is shown in Table 6.2. In this study, not all genotypic data were available for all participants due to call rate. The call rates for genetic analyses were between 76\% (rs1205) and 96\% (rs1800947).

Table 6.2. Characteristics of genetic variants in study participants.

\begin{tabular}{|c|c|c|c|c|c|c|c|c|}
\hline Gene & SNP & Allele & $\begin{array}{l}\text { Amino acid } \\
\text { codon }\end{array}$ & SNP location & Effect & $\begin{array}{l}\% \text { call } \\
\text { rate }\end{array}$ & $p$ HWE & MAF \\
\hline TNFA & rs1800629 & $G>A$ & No & $\begin{array}{c}\text { Upstream Transcript } \\
\text { Variant }\end{array}$ & $\begin{array}{l}\text { G allele increase TNF-alpha } \\
\text { activity and plasma } \\
\text { concentration [23] }\end{array}$ & 78 & 0.027 & $A(0.15)$ \\
\hline IL6 & rs1800795 & $C>G$ & No & $\begin{array}{c}\text { Upstream Transcript } \\
\text { Variant }\end{array}$ & $\begin{array}{c}\text { C allele increases IL-6 } \\
\text { transcription IL-6 } \\
\text { concentration in blood } \\
{[24-26]}\end{array}$ & 85 & 0.001 & $C(0.41)$ \\
\hline CRP & rs1800947 & $G>C$ & $\begin{array}{l}\mathrm{L}[\mathrm{CTG}]>\mathrm{L} \\
{[\mathrm{CTC}]}\end{array}$ & Coding Sequence Variant & $\begin{array}{l}\text { G allele increases CRP } \\
\text { concentration [27] }\end{array}$ & 96 & 0.047 & $C(0.03)$ \\
\hline
\end{tabular}

HWE: Hardy-Weinberg equilibrium; MAF : minor allele frequency; CRP : C-reactive protein; TNFA : tumor necrosis factor alpha; IL6 : interleukin $6 ; \%$ call rate : \% successfully analyzed genotypes from all available DNA samples. 
Differences in markers of adiposity and in hs-CRP concentration between genotypes of each inflammation-related gene are summarized in Table 6.3. Those carrying the A allele of TNFA ( $r$ 1800629) had a lower body weight ( $p=0.023)$ and lower BMI ( $p=0.007$ ) compared with those carrying the $G$ allele. In contrast, for IL6 ( $r$ 1800795), those carrying the $G$ allele had higher body weight $(p=0.047)$. Circulating hs-CRP concentrations were lower in those with the A allele of TNFA ( $r$ 1800629) $(p=0.023)$ or the T allele of CRP ( $r s 1205)$ ( $p=0.007)$; however these findings were no longer statistically significant after adjusting for polyps status. There were no differences in markers of adiposity between CRP (rs1205) genotypes or between CRP (rs1800947) genotypes, and the latter did not influence hs-CRP concentration (all $\mathrm{p}>0.05)$.

Table 6.3. Differences in markers of adiposity and of hs-CRP concentration between genotypes for inflammation-related genes.

\begin{tabular}{|c|c|c|c|c|c|}
\hline & \multicolumn{5}{|c|}{ TNFA (rs 1800629) } \\
\hline & G/G ( $n=188)$ & $G / A+A / A(n=68)$ & Model $1 p^{*}$ & Model $2 p^{a}$ & Model $3 p^{b}$ \\
\hline Weight (kg) & $84.1 \pm 20.2$ & $79.0 \pm 16.7$ & 0.061 & 0.015 & 0.023 \\
\hline Waist circumference $(\mathrm{cm})$ & $95.6 \pm 17.0$ & $92.5 \pm 14.7$ & 0.187 & 0.079 & 0.086 \\
\hline Hip circumference $(\mathrm{cm})$ & $105.6 \pm 14.6$ & $103.3 \pm 10.5$ & 0.231 & 0.160 & 0.115 \\
\hline WHR & $0.90 \pm 0.09$ & $0.89 \pm 0.09$ & 0.387 & 0.129 & 0.224 \\
\hline \multirow[t]{3}{*}{ ABSI } & $0.078 \pm 0.007$ & $0.078 \pm 0.006$ & 0.783 & 0.845 & 0.837 \\
\hline & \multicolumn{5}{|c|}{ IL6 (rs 1800795) } \\
\hline & $C / C(n=60)$ & $G / C+G / G(n=219)$ & $\mathrm{p}^{*}$ & $\mathrm{p}^{\mathrm{a}}$ & $\mathrm{p}^{\mathrm{b}}$ \\
\hline Weight (kg) & $79.8 \pm 16.4$ & $82.7 \pm 19.6$ & 0.300 & 0.045 & 0.047 \\
\hline BMI $\left(\mathrm{kg} / \mathrm{m}^{2}\right)$ & $27.9 \pm 4.7$ & $28.8 \pm 6.0$ & 0.271 & 0.073 & 0.077 \\
\hline $\mathrm{Hs}-\mathrm{CRP}$ (mg/L) & $4.1 \pm 4.8$ & $3.8 \pm 5.2$ & 0.727 & 0.911 & 0.846 \\
\hline \multirow[t]{3}{*}{ ABSI } & $0.078 \pm 0.007$ & $0.078 \pm 0.007$ & 0.817 & 0.278 & 0.275 \\
\hline & \multicolumn{5}{|c|}{ CRP (rs1800947) } \\
\hline & G/G $(n=294)$ & $G / C+C / C(n=20)$ & $p^{*}$ & $p^{a}$ & $p^{b}$ \\
\hline Weight (kg) & $82.4 \pm 19.6$ & $81.3 \pm 15.9$ & 0.813 & 0.502 & 0.504 \\
\hline BMI $\left(\mathrm{kg} / \mathrm{m}^{2}\right)$ & $28.6 \pm 5.9$ & $27.9 \pm 5.4$ & 0.603 & 0.467 & 0.468 \\
\hline Waist circumference $(\mathrm{cm})$ & $94.6 \pm 16.0$ & $92.5 \pm 12.8$ & 0.575 & 0.589 & 0.590 \\
\hline Hip circumference $(\mathrm{cm})$ & $104.4 \pm 13.4$ & $103.8 \pm 12.0$ & 0.846 & 0.646 & 0.643 \\
\hline WHR & $0.91 \pm 0.09$ & $0.89 \pm 0.08$ & 0.513 & 0.774 & 0.778 \\
\hline $\mathrm{Hs}-\mathrm{CRP}(\mathrm{mg} / \mathrm{L})$ & $4.0 \pm 5.2$ & $2.4 \pm 2.0$ & 0.237 & 0.392 & 0.353 \\
\hline Hip circumference $(\mathrm{cm})$ & $104.7 \pm 11.4$ & $104.9 \pm 10.8$ & 0.849 & 0.978 & 0.998 \\
\hline WHR & $0.91 \pm 0.09$ & $0.89 \pm 0.09$ & 0.376 & 0.637 & 0.843 \\
\hline $\mathrm{Hs}-\mathrm{CRP}(\mathrm{mg} / \mathrm{L})$ & $4.9 \pm 6.5$ & $2.9 \pm 3.6$ & 0.007 & 0.037 & 0.074 \\
\hline$A B S I$ & $0.078 \pm 0.007$ & $0.078 \pm 0.007$ & 0.390 & 0.450 & 0.484 \\
\hline
\end{tabular}

Data are presented as mean \pm standard deviation, *Model 1 basic ANOVA, aodel 2: As for Model 1 adjusted for age, sex, medical history, drug history, supplement use, smoking status; ${ }^{\mathrm{b} M o d e l} 3$ : As for Model 2 plus adjustment for presence of adenomatous polyps; BMl: body mass index, hs-CRP : highsensitivity C-reactive protein, WHR: waist-to-hip ratio, ABSI: a body shape index 
Conditional logistic regression was used to evaluate the role of SNPs in inflammation-related genes on the risk of adenomatous polyps. We observed increased OR for the development of polyps among those who carried the GG genotype of TNFA (rs1800629) and CC genotype of CRP (rs1205). When corrected for confounding factors including age, sex, diagnoses of other diseases, antiinflammatory drug use, supplement use, smoking status, BMI and C-reactive protein, the effect of the GG genotype of TNFA (rs1800629) on risk of adenomatous polyps remained statistically significant $(p=0.002)$, while the effect of CC genotype of CRP (rs1205) diminished ( $p=0.255)$ (Table 6.4).

Table 6.4. Odds Ratio (OR) for risk of adenomatous polyp according to genotype of inflammationrelated genes.

\begin{tabular}{lccccccccc}
\hline & $\mathrm{N}$ & $\begin{array}{c}\text { Risk } \\
\text { geno- } \\
\text { type }\end{array}$ & Analysis & $\mathrm{OR}^{*}$ & $95 \% \mathrm{Cl}^{*}$ & $\mathrm{p}^{*}$ & $\mathrm{OR}^{*}$ & $95 \% \mathrm{Cl}^{*}$ & $\mathrm{p}^{*}$ \\
\hline TNFA (rs1800629) & 258 & GG & GG vs GA+AA & 4.46 & $1.82-10.90$ & $\mathbf{0 . 0 0 1}$ & 9.33 & $\begin{array}{c}2.33- \\
37.38\end{array}$ & $\mathbf{0 . 0 0 2}$ \\
\hline IL6 (rs1800795) & 282 & CC & CC vs GC+GG & 1.05 & $0.56-1.98$ & 0.885 & 0.77 & $0.34-1.76$ & 0.540 \\
CRP (rs1800947) & 317 & GG & GG vs GC+CC & 1.62 & $0.53-4.98$ & 0.401 & 0.75 & $0.14-2.60$ & 0.499 \\
\hline CRP (rs1205) & 254 & CC & CC vs CT+TT & 2.00 & $1.13-3.54$ & $\mathbf{0 . 0 1 7}$ & 1.53 & $0.74-3.17$ & 0.255 \\
\hline
\end{tabular}

aDominant model of risk allele, see Table 6.2. *Logistic regression analysis without adjustment; "Conditional logistic regression with adjustment for age, sex, medical diagnosis, anti-inflammatory drug use, supplement use, smoking status, body mass index and $\mathrm{C}$-reactive protein.; $\mathrm{OR}=$ adjusted odds ratio

The stratified analysis on the relationships between measures of adiposity and hs-CRP concentration based on variation in inflammation-related genes is summarized in Table 6.5. Among those with the GG genotype of TNFA (rs1800629), adiposity measures (body weight, BMI, waist and hip circumference) correlated positively with hs-CRP concentration ( $p<0.05$ ). This correlation was not seen among those with $G A+A A$ genotypes (all $p>0.05$ ). For IL-6, there were no relationships between adiposity markers and hs-CRP concentration among those with the $\mathrm{C} / \mathrm{C}$ genotype (rs1800795). In contrast, for those with the C/G + G/G genotype (rs1800795), body weight, BMI, waist and hip circumference were associated with hs-CRP concentration (all $\mathrm{p}<0.05$ ). Among those with $\mathrm{G} / \mathrm{G}$ genotype of CRP ( $\mathrm{rs1800947),} \mathrm{hs-CRP \text {was }}$ correlated with all adiposity measures while no interaction was seen among those with $\mathrm{G} / \mathrm{C}+\mathrm{C} / \mathrm{C}$ genotypes. With respect to the $C R P$ gene ( $\mathrm{rs} 1205)$, adiposity measures were associated with hs-CRP concentrations only in participants with the T/C + T/T genotypes with the $\mathrm{C} / \mathrm{C}$ genotype. Interestingly, for all genotypes individually, there was no relationship between ABSI and hs-CRP concentration (Table 6.5). 
Table 6.5. Influence of genotype for inflammation-related genes on the relationships between markers of adiposity and hs-CRP concentration.

\begin{tabular}{|c|c|c|c|c|c|c|c|c|}
\hline \multirow[b]{4}{*}{ TNFA (rs1800629) } & \multicolumn{8}{|c|}{ Correlation of adiposity markers with plasma concentration of hs-CRP } \\
\hline & \multicolumn{4}{|c|}{$\mathrm{G} / \mathrm{G}$} & \multicolumn{4}{|c|}{$\mathrm{G} / \mathrm{A}+\mathrm{A} / \mathrm{A}$} \\
\hline & \multicolumn{2}{|c|}{ Model 1} & \multicolumn{2}{|c|}{ Model 2} & \multicolumn{2}{|c|}{ Model 1} & \multicolumn{2}{|c|}{ Model 2} \\
\hline & $\mathrm{B}$ & $p$ & B & $p$ & B & $p$ & B & $p$ \\
\hline Body weight (kg) & 0.303 & 0.002 & 0.294 & 0.002 & 0.177 & 0.381 & 0.125 & 0.553 \\
\hline $\mathrm{BMI}\left(\mathrm{kg} / \mathrm{m}^{2}\right)$ & 0.258 & 0.003 & 0.244 & 0.004 & 0.176 & 0.315 & 0.150 & 0.397 \\
\hline Waist circumference $(\mathrm{cm})$ & 0.211 & 0.031 & 0.215 & 0.025 & 0.318 & 0.145 & 0.269 & 0.246 \\
\hline Hip circumference (cm) & 0.195 & 0.022 & 0.209 & 0.012 & 0.096 & 0.585 & 0.053 & 0.773 \\
\hline WHR & 0.057 & 0.664 & 0.037 & 0.776 & 0.462 & 0.061 & 0.421 & 0.100 \\
\hline \multirow[t]{2}{*}{ ABSI } & -0.016 & 0.887 & -0.001 & 0.995 & 0.163 & 0.485 & 0.104 & 0.668 \\
\hline & \multicolumn{4}{|c|}{$\mathrm{C} / \mathrm{C}$} & \multicolumn{4}{|c|}{$\mathrm{C} / \mathrm{G}+\mathrm{G} / \mathrm{G}$} \\
\hline IL6 (rs1800795) & B & $p$ & B & $p$ & B & $p$ & B & $p$ \\
\hline Body weight (kg) & 0.136 & 0.475 & 0.136 & 0.480 & 0.368 & $<0.001$ & 0.350 & $<0.001$ \\
\hline BMI $\left(\mathrm{kg} / \mathrm{m}^{2}\right)$ & 0.172 & 0.316 & 0.165 & 0.346 & 0.367 & $<0.001$ & 0.344 & $<0.001$ \\
\hline Waist circumference $(\mathrm{cm})$ & 0.280 & 0.189 & 0.287 & 0.178 & 0.313 & $<0.001$ & 0.307 & $<0.001$ \\
\hline Hip circumference $(\mathrm{cm})$ & 0.221 & 0.197 & 0.223 & 0.193 & 0.266 & $<0.001$ & 0.288 & $<0.001$ \\
\hline WHR & 0.178 & 0.500 & 0.187 & 0.480 & 0.189 & 0.098 & 0.124 & 0.277 \\
\hline \multirow[t]{2}{*}{ ABSI } & 0.201 & 0.302 & 0.239 & 0.241 & 0.012 & 0.908 & 0.003 & 0.972 \\
\hline & \multicolumn{4}{|c|}{$\mathrm{G} / \mathrm{G}$} & \multicolumn{4}{|c|}{$\mathrm{G} / \mathrm{C}+\mathrm{C} / \mathrm{C}$} \\
\hline CRP (rs1800947) & $\mathrm{B}$ & $p$ & B & $p$ & B & $p$ & B & $p$ \\
\hline Body weight (kg) & 0.327 & $<0.001$ & 0.316 & $<0.001$ & 0.035 & 0.946 & 0.052 & 0.940 \\
\hline BMI $\left(\mathrm{kg} / \mathrm{m}^{2}\right)$ & 0.329 & $<0.001$ & 0.316 & $<0.001$ & 0.024 & 0.967 & 0.017 & 0.982 \\
\hline Waist circumference $(\mathrm{cm})$ & 0.292 & $<0.001$ & 0.284 & $<0.001$ & -0.015 & 0.987 & 0.029 & 0.984 \\
\hline Hip circumference (cm) & 0.246 & $<0.001$ & 0.251 & $<0.001$ & -0.227 & 0.546 & -0.460 & 0.509 \\
\hline WHR & 0.193 & 0.050 & 0.164 & 0.097 & 0.696 & 0.322 & 1.307 & 0.253 \\
\hline \multirow[t]{2}{*}{ ABSI } & -0.016 & 0.835 & 0.003 & 0.966 & -0.260 & 0.599 & -0.259 & 0.683 \\
\hline & \multicolumn{4}{|c|}{$\mathrm{C} / \mathrm{C}$} & \multicolumn{4}{|c|}{$\mathrm{T} / \mathrm{C}+\mathrm{T} / \mathrm{T}$} \\
\hline CRP (rs1205) & $B$ & $\mathrm{p}$ & B & $p$ & B & $p$ & B & $p$ \\
\hline Body weight (kg) & 0.277 & 0.030 & 0.235 & 0.057 & 0.415 & $<0.001$ & 0.415 & $<0.001$ \\
\hline BMI $\left(\mathrm{kg} / \mathrm{m}^{2}\right)$ & 0.245 & 0.032 & 0.197 & 0.079 & 0.460 & $<0.001$ & 0.460 & $<0.001$ \\
\hline Waist circumference $(\mathrm{cm})$ & 0.264 & 0.041 & 0.206 & 0.099 & 0.485 & $<0.001$ & 0.486 & $<0.001$ \\
\hline Hip circumference (cm) & 0.288 & 0.009 & 0.254 & 0.017 & 0.411 & $<0.001$ & 0.414 & $<0.001$ \\
\hline WHR & 0.086 & 0.597 & 0.015 & 0.924 & 0.324 & 0.017 & 0.330 & 0.018 \\
\hline ABSI & -0.015 & 0.913 & -0.008 & 0.950 & 0.174 & 0.164 & 0.173 & 0.171 \\
\hline
\end{tabular}

Model 1: Linear regression adjusting for age, sex, medical diagnosis, drug, supplement use and smoking status; Model 2: as for Model 1 with additional adjustment for presence of adenomatous polyps, BMl: body mass index, WHR: waist-to-hip ratio, ABSI: a body shape index

\section{DISCUSSION}

This study investigated the interaction between variants of inflammatory genes (CRP, TNFA, and IL6), markers of adiposity, systemic inflammation (assessed using hs-CRP concentration) and CRC risk as indicated by the presence of adenomatous polyps. People with colorectal polyps had higher hs-CRP concentrations but did not differ in adiposity measures from the healthy controls. Findings from previous studies have been inconsistent; for example, in the Calcium Polyp Prevention Study, there was no 
association between hs-CRP concentration and occurrence of colorectal adenomas [29]. In contrast, several studies have reported that hs-CRP is positively associated with the presence of colorectal adenomas [30,31].

We found no differences in body weight or BMI between those with, and without, colorectal polyps. These findings differ from the conclusion that obesity is associated with colorectal adenoma risk reported in an earlier meta-analysis [32]. In contrast, in the present study, markers of abdominal adiposity, including WHR and $A B S I$, were associated with the presence of colorectal polyps. This finding supports the report from the Black Women's Health Study which showed that increased ABSI was associated with increased adenoma risk [33].

All four SNPs in three inflammatory genes have been associated with greater CRC risk in other studies [15-17]. In the present study, we showed that the GRS from a combination of SNPs at inflammatory genes was significantly higher among those with adenomatous polyps. However, when the analysis was done for each SNP individually, only participants with the GG genotype for TNFA (rs1800629) were more likely to have an adenomatous polyps. In addition, only the TNFA (rs1800629) genotype was associated with adiposity.

We observed that variants in inflammatory genes may influence the relationship between adiposity and systemic inflammation. However, there was no consistent relationship between carriage of the effect allele, i.e. the allele associated with increased plasma concentrations of the corresponding inflammatory proteins, and the likelihood that adiposity measures would correlate with hs-CRP concentration. For those with the G/G genotype of TNFA (rs1800629), C/G + G/G genotype of IL6 (rs1800795), G/G genotype of CRP (rs1800947) and T/C+T/T genotype of CRP (rs1205), there were significant relationships between adiposity measures and hs-CRP concentrations. This relationship was not seen in the opposite genetic group, suggesting that genetic variation influences the pro-inflammatory effects of increased adiposity. Across all genotypes individually, there was no relationship between ABSI and hs-CRP concentration. This is in contrast with a study of 1442 obese and overweight adults in Central China where there was a weak positive correlation between ABSI and hs-CRP concentration [34].

The findings of this study are summarized conceptually in Figure 6.1. This is in the context of evidence that lifestyle factors that increase adiposity, together with genetic factors, amplify the risk of developing CRC [35]. In the present study, we showed that BMI was not associated with risk of colorectal polyps, which are precursors of CRC, whereas WHR and ABSI (indicators of central obesity) were higher among those with colorectal polyps. The influence of central obesity on colorectal cancer risk has been reported in a recent meta-analysis of prospective studies [36]. 


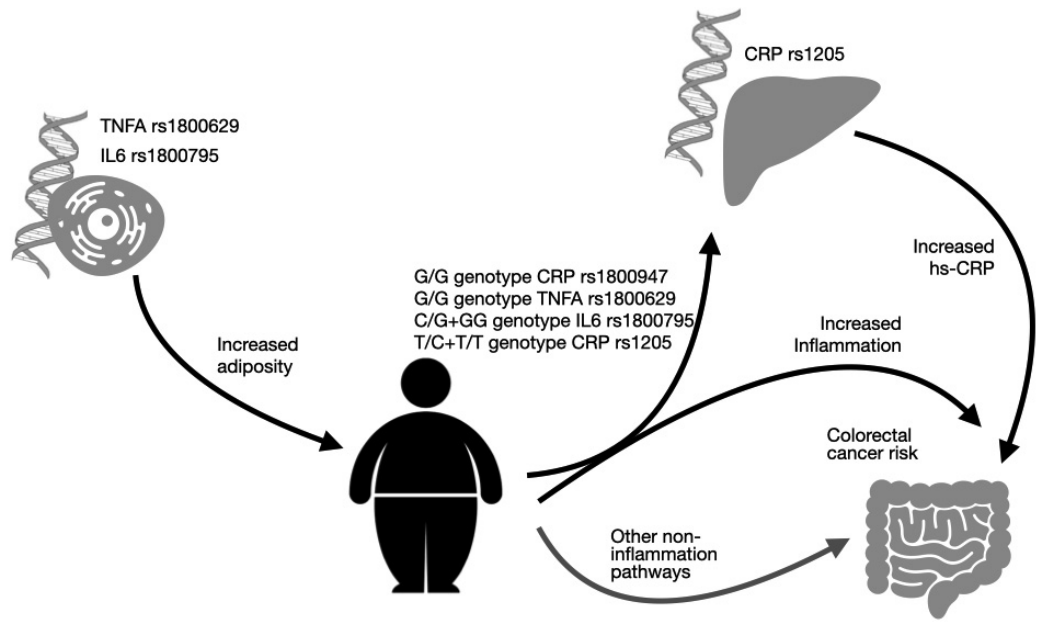

Figure 6.1. Proposed relationships between genotypes for variants in pro-inflammatory genes, adiposity, inflammation and colorectal cancer risk. hs-CRP: high sensitive $C$ reactive protein. Among the four genetic variants investigated in this study, only SNPs at TNFA and IL6 were associated with adiposity measures. For those with the G/G genotype of TNFA (rs1800629), C/G + G/G genotype of IL6 (rs1800795), G/G genotype of CRP ( $r$ 1800947) and T/C+T/T genotype of CRP (rs1205), there were significant relationships between adiposity measures and hs-CRP concentrations. The increment of hsCRP thus increase risk of colorectal polyps.

Among the four genetic variants investigated in this study, only SNPs at TNFA and IL6 were associated with adiposity measures. Individuals with the G/G genotype of TNFA had higher body weight and BMI and these associations remained significant after extensive adjustment for potential confounders. This is consistent with previous reports that the GG variant of the TNFA gene is associated with greater obesity risk [37]. The G allele of TNFA (rs1800629) is associated with increased TNFalpha protein in the circulation [23] and obesity and TNF-alpha concentration are correlated positively [38,39]. However, the mechanism through which the GG variant of the TNFA gene may increase obesity risk remains to be discovered.

Variants in TNFA (rs1800629) and CRP (rs1205) were associated with hs-CRP concentration in unadjusted analyses but these associations were weakened after adjustment for potential confounding factors. Results from this study are in line with results from other studies $[23,27,40]$. A recent meta-analysis reported no significant correlation between TNFA (rs1800629) genotype and CRC risk [41]. In contrast, in the present study, we observed that those carrying the G/G genotype of TNFA (rs1800629) had increased risk of adenomatous polyps. TNF-alpha is an inflammatory 
mediator that drives cancer progression [42]. Those with the G/G genotype of TNFA (rs1800629) have higher plasma concentration of TNF-alpha [24] that may increase risk of colorectal polyps development.

Potential limitations of this study include that the study participants were selected from those invited for a colorectal examination for gastrointestinal symptoms which may limit the generalisability of findings to a wider population, this is reflected by the Hardy-Weinberg equilibrium value. Secondly, we used a simple GRS for pro-inflammatory genes with the assumption that all gene variants had equal effects. Since each individual gene variation is likely to have a different effect size, use of a weighted approach for derivation of the GRS may have been advantageous [43]. However, with the relatively small number of genetic variants included in our score, we did not consider this more sophisticated approach was justified. A strength of this study is that we evaluated data from those with colorectal adenomatous polyps compared with those who underwent a colorectal examination and who were shown to be polyps-free (healthy participants). This minimized the likelihood of misclassification of participants. Finally, in addition to widely-used markers of adiposity, we investigated relationships with $A B S I$, a novel measure of central adiposity that is associated with CRC risk [4].

In summary, this study showed that genetic variation in inflammatory markers influenced individual response to adiposity. Variation in TNFA was associated with adiposity and the presence of colorectal polyps. In addition, SNPS at CRP, TNFA and IL6 influence the association of adiposity with systemic inflammation. These findings require confirmation in additional population-based studies. Finally, from a cancer prevention perspective, it will be important to discover whether the effects of weight loss on inflammatory markers is influenced by these genetic variants.

\section{Funding Sources}

NuGO Exchange grant 2018 


\section{REFERENCES}

1. Basen-Engquist K, Chang M. Obesity and cancer risk: recent review and evidence. Curr Oncol Rep 2011, 13(1), 71-76.

2. Ma Y, Yang $Y$, Wang $F$, et al. Obesity and risk of colorectal cancer: a systematic review of prospective studies. PLoS One 2013, 8(1), e53916.

3. Andreasson A, Hagström H, Sköldberg F, et al. The prediction of colorectal cancer using anthropometric measures: A Swedish population-based cohort study with 22 years of follow-up. United European Gastroenterol J 2019, 7(9), 1250-1260.

4. Parra-Soto S, Cowley ES, Rezende LFM. et al. Associations of six adiposity-related markers with incidence and mortality from 24 cancers-findings from the UK Biobank prospective cohort study. BMC Med 2021, 19, 7.

5. Frezza EE, Wachtel MS, Chiriva-Internati M. Influence of obesity on the risk of developing colon cancer. Gut 2006, 55(2), 285-291.

6. Martinez-Useros J, Garcia-Foncillas J. Obesity and colorectal cancer: molecular features of adipose tissue. J Transl Med 2016, 14, 21.

7. Han JM, Levings MK. Immune regulation in obesity-associated adipose inflammation. $J$ Immunol 2013, 191(2), 527-532.

8. Smith LA, O'Flanagan CH, Bowers LW, et al. Translating Mechanism-Based Strategies to Break the Obesity-Cancer Link: A Narrative Review. J Acad Nutr Diet 2018, 118(4), 652667.

9. Tarasiuk A, Mosińska P, Fichna J. The mechanisms linking obesity to colon cancer: An overview. Obes Res Clin Pract 2018, 12(3), 251-259.

10. Navarro SL, Kantor ED, Song X, et al. Factors Associated with Multiple Biomarkers of Systemic Inflammation. Cancer Epidemiol Biomarkers Prev 2016, 25(3), 521-531.

11. Eiriksdottir G, Smith AV, Aspelund T, et al. The interaction of adiposity with the CRP gene affects CRP levels: age, gene/environment susceptibility-Reykjavik study. Int J Obes 2009, 33(2), 267-272.

12. Bochud M, Marquant F, Marques-Vidal PM, et al. Association between C-reactive protein and adiposity in women. J Clin Endocrinol Metab 2009, 94(10), 3969-77.

13. Todendi PF, Possuelo LG, Klinger El, et al. Low-grade inflammation markers in children and adolescents: Influence of anthropometric characteristics and CRP and IL6 polymorphisms. Cytokine 2016, 88, 177-183.

14. Zhou B, Shu B, Yang J, et al. C-reactive protein, interleukin-6 and the risk of colorectal cancer: a meta-analysis. Cancer Causes Control 2014, 25(10), 1397-405.

15. Geng P, Sa R, Li J, et al. Genetic polymorphisms in C-reactive protein increase cancer susceptibility. Sci Rep 2016, 6, 17161.

16. Yu Y, Wang W, Zhai S, et al. IL6 gene polymorphisms and susceptibility to colorectal cancer: a meta-analysis and review. Mol Biol Rep 2012, 39(8), 8457-8463. 
17. Min L, Chen D, Qu L, et al. Tumor necrosis factor-a polymorphisms and colorectal cancer risk: a meta-analysis. PLoS One 2014, 9(1), e85187.

18. Sheu WH, Wang WC, Wu KD, et al. CRP-level-associated polymorphism rs 1205 within the CRP gene is associated with 2-hour glucose level: The SAPPHIRe study. Sci Rep 2017, 7(1), 7987.

19. Song Z, Song Y, Yin J, et al. Genetic variation in the TNF gene is associated with susceptibility to severe sepsis, but not with mortality. PLoS One 2012, 7(9), e46113.

20. Rana BK, Flatt SW, Health DD, et al. The IL-6 Gene Promoter SNP and Plasma IL-6 in Response to Diet Intervention. Nutrients 2017, 9(6), 552.

21. Tapp HS, Commane DM, Bradburn DM, et al. Nutritional factors and gender influence age-related DNA methylation in the human rectal mucosa. Aging Cell 2013, 12(1), 148155.

22. Krakauer NY, Krakauer JC. A new body shape index predicts mortality hazard independently of body mass index. PLoS One 2012, 7(7), e39504.

23. Cui G, Wang H, Li R, et al. Polymorphism of tumor necrosis factor alpha (TNF-alpha) gene promoter, circulating TNF-alpha level, and cardiovascular risk factor for ischemic stroke. J Neuroinflammation. 2012; 9: 235.

24. Noss EH, Nguyen HN, Chang SK, et al. Genetic polymorphism directs IL-6 expression in fibroblasts but not selected other cell types. Proc Natl Acad Sci USA 2015, 112(48), 14948-14953.

25. Wielińska J, Dratwa M, Świerkot J, et al. Interleukin 6 gene polymorphism is associated with protein serum level and disease activity in Polish patients with rheumatoid arthritis. HLA 2018, 92 Suppl 2, 38-41.

26. Ljungman $P$, Bellander $T$, Nyberg $F$, et al. DNA variants, plasma levels and variability of interleukin-6 in myocardial infarction survivors: results from the AIRGENE study. Thromb Res 2009, 124(1), 57-64.

27. Hage FG, Szalai AJ. C-reactive protein gene polymorphisms, C-reactive protein blood levels, and cardiovascular disease risk. J Am Coll Cardiol 2007, 50(12), 1115-1122.

28. Solé X, Guinó E, Valls J, et al. SNPStats: a web tool for the analysis of association studies. Bioinformatics 2006, 22(15), 1928-9.

29. Crockett SD, Mott LA, Barry EL, et al. C-reactive protein and risk of colorectal adenomas or serrated polyps: a prospective study. Cancer Prev Res (Phila) 2014, 7(11), 1122-1127.

30. Kigawa N, Budhathoki S, Yamaji T, et al. Association of plasma C-reactive protein level with the prevalence of colorectal adenoma: the Colorectal Adenoma Study in Tokyo. Sci Rep 2017, 7(1), 4456.

31. Lee HM, Cha JM, Lee JL, et al. High C-reactive protein level is associated with high-risk adenoma. Intest Res 2017, 15(4), 511-517.

32. Ben $\mathrm{Q}, \mathrm{An} \mathrm{W}$, Jiang $\mathrm{Y}$, et al. Body mass index increases risk for colorectal adenomas based on meta-analysis. Gastroenterology 2012, 142(4), 762-772.

33. Dash C, Yu J, Nomura S, et al. Obesity is an initiator of colon adenomas but not a promoter of colorectal cancer in the Black Women's Health Study. Cancer Causes Control 2020, 31(4), 291-302. 
34. Li G, Wu HK, Wu XW, et al. The feasibility of two anthropometric indices to identify metabolic syndrome, insulin resistance and inflammatory factors in obese and overweight adults. Nutrition 2019, 57, 194-201.

35. Marley AR, Nan H. Epidemiology of colorectal cancer. Int J Mol Epidemiol Genet 2016, 7(3), 105-114.

36. Dong Y, Zhou J, Zhu Y, et al. Abdominal obesity and colorectal cancer risk: systematic review and meta-analysis of prospective studies. Biosci Rep 2017,37(6), BSR20170945.

37. Włodarczyk M, Ciebiera M, Nowicka G. TNF- $\alpha$ G-308A genetic variants, serum CRP-hs concentration and DNA damage in obese women. Mol Biol Rep 2020, 47(2), 855-866.

38. Olszanecka-Glinianowicz M, Zahorska-Markiewicz B, Janowska J, et al. Serum concentrations of nitric oxide, tumor necrosis factor (TNF)-alpha and TNF soluble receptors in women with overweight and obesity. Metabolism 2004, 53(10), 1268-1273.

39. Rodríguez-Hernández $\mathrm{H}$, Simental-Mendía LE, Rodríguez-Ramírez $\mathrm{G}$, et al. Obesity and inflammation: epidemiology, risk factors, and markers of inflammation. Int J Endocrinol 2013, 2013, 678159.

40. Rangel-Zúñiga $O A$, Corina $A$, Lucena-Porras $B$, et al. TNFA gene variants related to the inflammatory status and its association with cellular aging: From the CORDIOPREV study. Exp Gerontol 2016, 83, 56-62.

41. Miao Z, Wang K, Wang $X$, et al. TNF- $\alpha-308 \mathrm{G} / \mathrm{A}$ polymorphism and the risk of colorectal cancer: A systematic review and an updated meta-analysis. J BUON 2018, 23(6), 16161624.

42. Xu G, Zhang J. Suppression of FasL expression in tumor cells and preventing TNF-induced apoptosis was better for immune cells survival. J Cancer Res Clin Oncol 2008; 134 (10), 1043-1049.

43. Hüls A, Krämer U, Carlsten C, et al. Comparison of weighting approaches for genetic risk scores in gene-environment interaction studies. BMC Genet 2017, 18(1), 115. 
BETWEEN INFLAMMATORY PROPERTIES OF DIET AND GENETIC VARIATION IN BODYWEIGHT REGULATION 


\section{CHAPTER 7}

\section{The Interaction of Inflammatory Gene Variations with the Association between Diet, hs-CRP, and Weight Regain in the DiOGenes Trial}

Harry Freitag Luglio Muhammad ${ }^{1,2}$, Edwin C. Mariman², Marleen A. van Baak ${ }^{2}$

${ }^{1}$ Department of Nutrition and Health, Universitas Gadjah Mada, Yogyakarta, 55281, Indonesia

${ }^{2}$ Department of Human Biology, NUTRIM School of Nutrition and Translational Research in Metabolism,

Maastricht Medical Centre+, 6200 MD Maastricht, The Netherlands 


\section{ABSTRACT}

The objective of this study was to evaluate the interaction between gene variations in pro-inflammatory genes (CRP, TNFA, and IL6) and diet and its effect on hs-CRP and weight regain following weight loss in the DIOGenes Trial. 453 participants with overweight or obesity of the DIOGenes trial, who successfully finished the weight loss and weight maintenance phases and in whom gene variations were measured, were included. During the weight maintenance phase, subjects consumed an ad libitum diet with different recommendations on protein content and glycemic index (GI). Variations in the pro-inflammatory genes CRP (rs1205 and rs1800947), TNFA (rs1800629 and rs361525) and IL6 (rs1800795) were evaluated. Variations in the $C R P$ gene were associated with hs-CRP concentration at baseline and during weight maintenance. Variations in pro-inflammatory genes were not associated with body weight at baseline, after weight loss and at the end of the weight maintenance period (all $p>0.05$ ). The positive correlation between $\mathrm{Gl}$ and changes in body weight during weight maintenance was significant among those with the $G G$ genotype $(p=0.044)$ of TNFA rs 1800629 but not in those with the GA+AA genotype ( $p=0.487)$. Percent protein intake was negatively correlated with changes of body weight only among those with the CC genotype of CRP rs 1205 ( $p=0.016$ ), CC genotype of CRP rs 1800947 $(p=0.028)$ and the $G C+G G$ genotype of IL6 rs $1800795(p=0.004)$. Variations in proinflammatory genes (CRP, TNFA, and IL6) influenced the weight regain response to the protein content and $\mathrm{Gl}$ of the diet.

Keywords: Obesity, weight loss, genetic variation, inflammation, diet. 


\section{INTRODUCTION}

Obesity is associated with increased systemic and adipose tissue inflammation due to immune cell infiltration and higher production of pro-inflammatory cytokines [1]. An increase in high-sensitive $C$ reactive protein (hs-CRP) in obesity has been shown in population-based studies [2]. Among individuals with obesity and overweight, weight loss is associated with a reduction in hs-CRP [3-6]. Changes in hs-CRP were positively correlated with changes in body weight and body fat over a 2-year period in the POUNDS LOST study [3]. In contrast to systemic inflammation, studies showed a significant increase of inflammation markers in adipose tissue immediately after a period of weight loss [7-9], and these increments were associated with subsequent weight regain. It has been argued that adipose tissue inflammation may play a role in the regulation of body weight after weight loss [10].

DiOGenes is an intervention study that consisted of a weight loss intervention and dietary modification (focusing on protein content and glycemic index (GI) of the diet) after weight loss for weight loss maintenance, and was conducted in 8 countries in Europe with an objective to evaluate factors associated with weight regain [11]. It was shown that diets with a low glycemic index (GI) were associated with less weight regain and a reduction of inflammation. Higher protein diets were also associated with less weight regain, but with less reduction of inflammation [4,12]. These findings suggest an interaction between diet, inflammation, and weight regain, which is not fully understood. Because inflammation is influenced by gene variation [13-16], analysis of variations in inflammatory genes might partly explain the role of inflammation in weight regain.

This study therefore aimed to evaluate the role of variations in proinflammatory genes on the associations between protein intake, glycemic index (GI), inflammation, and weight regain after a weight loss program in adults with overweight or obesity. Variations in genes encoding CRP, TNFA, and IL6 were selected because those were previously reported to have an effect on circulating hs-CRP as well as obesity in humans [13-16].

\section{METHODS}

\section{Study Participants}

The DiOGenes study is a randomized controlled trial conducted among families in which at least one of the parents was overweight/obese. Centers in 8 countries across Europe participated in this study: The Netherlands, Denmark, United Kingdom, Greece, Spain, Germany, Bulgaria, and the Czech Republic. The inclusion and exclusion criteria for the families have been described in detail before [17]. The 453 adults which were included in this secondary analysis were less than 65 years old and were overweight or obese (body mass index between $27 \mathrm{~kg} / \mathrm{m} 2$ and $45 \mathrm{~kg} / \mathrm{m} 2$ ) at baseline. They had all completed the weight loss and 6-month weight maintenance phase and genotyping of their DNA was available. 


\section{The Study Design}

This study was done in 2 phases: the weight loss phase and the weight maintenance phase. During weight loss phase subjects followed an 8-week low-calorie diet of 800 $\mathrm{kcal} /$ day. The diet in this phase was based on Modifast meal replacements (Nutrition \& Santé) and roughly 200 grams of vegetables per day. During the weight loss period, subjects were routinely checked for compliance and adverse effects. After 8 weeks, those who achieved $8 \%$ of weight loss from their initial weight were eligible for the weight maintenance phase.

During the 26-week weight maintenance phase, subjects were randomized to 5 different diets with variations of protein composition and glycemic index (GI): 1) high protein, low Gl; 2) high protein, high $\mathrm{Gl}$; 3) low protein, low Gl; 4) low protein, high $\mathrm{Gl}$ and 5) control. Details of the diet composition in the different groups and the way the intervention was conducted have been reported elsewhere [18]. In short, recommended protein content in the low protein groups was $13 \%$ of energy intake and $25 \%$ in the high protein groups. A difference of 15 glycemic index units was targeted between the low and high Gl groups. In the control group, subjects received recommendations according to the standard healthy diet recommendation in their own country. The recommended fat intake in all groups was $25-30 \%$ of total energy intake. There was no restriction on the total energy intake (ad libitum). For the purpose of the analysis in this paper, we merged subjects from all dietary groups and evaluated the trial as an observational study.

\section{Dietary Assessment}

Subjects reported their dietary intake using a dietary record of 3 consecutive days. This dietary assessment was done three times : at screening (baseline), at weeks 4 and at week 26 during the weight maintenance phase. Data on food intake was then translated into the intake of nutrients based on the local food composition databases. Analysis of the glycemic index was done as previously described [19]. Protein and glycemic index during the weight maintenance phase were the average of intakes at week 4 and 26 of the weight maintenance phase or of week 26 alone when week 4 data were missing.

\section{Anthropometric and Inflammation assessment}

Anthropometric measurements such as body weight and body composition were done at baseline, at the end of the weight loss phase and at the end of the weight maintenance phase. Body composition was measured either by dual-energy X-ray absorptiometry (DXA) or bioelectrical impedance analysis (BIA). Hs-CRP was measured as a marker of systemic inflammation. Serum hs-CRP was analysed using an immunoturbidimetric assay (Roche Diagnostics). Details regarding the hs-CRP analysis have been reported previously [4]. 


\section{Genotyping}

DNA for genotyping was extracted from buffy coats of blood specimens collected in EDTA-tubes. Analysis of genotypes was done using the Illumina Bead Station System (Illuminalnc) by IntegraGen. Five single nucleotide polymorphisms from 3 genes (CRP (rs1205 and rs1800947), TNFA (rs1800629 and rs361525) and IL6 (rs1800795)) were selected because of their previous involvement in the regulation of inflammation in humans. Based on the literature, we selected the effect allele as the allele that increased expression or inflammation level (Table 7.1). The analysis was done with the dominant model for the effect allele, except for CRP rs 1800947 because the number of the homozygote effect genotype (GG) was limited, thus we combined the heterozygotes with the homozygotes of the minor allele (GG+GC). Hardy Weinberg equation analysis was done using SNPstat (https://www.snpstats.net).

Table 7.1. The effect of selected gene variations in pro-inflammatory genes.

\begin{tabular}{llcclcl}
\hline Gene & $\begin{array}{c}\text { Gene } \\
\text { variation }\end{array}$ & $\begin{array}{c}\text { Allele } \\
\text { Variation }\end{array}$ & $\begin{array}{c}\text { Amino acid } \\
\text { codon }\end{array}$ & Location & $\begin{array}{c}\text { Effect } \\
\text { allele }\end{array}$ & Effect \\
\hline CRP & rs1205 & C>T & No & $\begin{array}{l}\text { Untranslated Region } \\
\text { variant }\end{array}$ & C & C allele increases hs-CRP level [13] \\
\hline CRP & rs1800947 & G>C & L [CTG] $>$ L [CTC] & $\begin{array}{l}\text { Coding Sequence } \\
\text { Variant }\end{array}$ & G & G allele increases hs-CRP level [13] \\
\hline TNFA & rs1800629 & G>A & No & $\begin{array}{l}\text { Upstream Transcript } \\
\text { Variant }\end{array}$ & G & $\begin{array}{l}\text { G allele increases TNF-alpha activity and } \\
\text { plasma level [21] }\end{array}$ \\
\hline TNFA & rs361525 & G>A & No & Promoter region & G & G allele increases TNF-alpha expression [22] \\
\hline IL6 & rs1800795 & C>G & No & $\begin{array}{l}\text { Upstream Transcript } \\
\text { Variant }\end{array}$ & C & $\begin{array}{l}\text { C allele increases IL6 transcription and IL-6 } \\
\text { level in blood [23-25] }\end{array}$ \\
\hline
\end{tabular}

\section{Statistical Analysis}

The statistical analysis was done using JASP software Version 0.8.3.1 (University of Amsterdam) [20]. The genetic dominant model was used when comparing the effect of genotypes on anthropometric measures, systemic inflammation (plasma hs-CRP). The effect of CRP (rs1205 and rs1800947), TNFA (rs1800629 and rs361525) and IL6 (rs1800795) gene variations on body weight, body composition and hs-CRP was analysed at baseline using independent t-tests. ANCOVA was used to evaluate the association between gene variations and changes in body weight and hs-CRP during weight loss (all groups) with correction for age and gender. A linear regression test was used to analyze the influence of gene variations (CRP, TNFA, and IL6) on the correlation between changes in hs-CRP and body weight during weight maintenance with correction for age, gender and study center. Factors associated with weight regain and hs-CRP were used as confounding factors. Age was used as confounding factor because it was associated with hs-CRP in the literature [21] and in this study 
gender and study center were associated with weight regain. A linear regression test was also used to evaluate the correlation between dietary $\mathrm{Gl}$ and percent protein during weight maintenance and weight changes based on gene variations with correction for gender, study center, BMI at randomization. For GI analysis, additional correction for protein was done. For protein analysis an additional correction for $\mathrm{GI}$ was done.

\section{RESULTS}

Details about allele selection and genotype grouping are presented in Table 7.1. Allele frequencies and Hardy Weinberg equilibrium are shown in Supplementary Table 7.1. Subjects were grouped based on their genotypes which include included CRP (rs1205 and rs1800947), TNFA (rs1800629 and rs361525) and IL6 (rs1800795). We analyzed data of all subjects with a dominant model, except for CRP rs1800947, because analysis with other models was hindered by the number of subjects in each genetic group.

In Table 7.2 we show that variations in the CRP gene ( $r$ 1205 and rs1800947) were associated with differences in baseline hs-CRP concentration ( $p=0.010$ and $p=0.030$, respectively). However, these gene variations were not associated with differences in anthropometric measures at baseline. Differences in changes in body weight and hs-CRP between genotype groups were not seen during the weight-loss period (Table 7.3). Changes in body weight also did not differ between genotypes during the weight maintenance phase. However, the GC + GG genotypes of CRP (rs1800947) were associated with a greater reduction in hs-CRP than the CC genotype during the weight maintenance period (Table 7.3).

Table 7.2. Baseline anthropometric variables and hs-CRP in genotypes of the CRP, TNFA and IL6 genes.

\begin{tabular}{|c|c|c|c|c|c|c|c|c|c|c|c|c|c|c|c|}
\hline \multirow[b]{2}{*}{$\begin{array}{l}\text { Baseline } \\
\text { values }\end{array}$} & \multicolumn{3}{|c|}{ CRPRS1205 } & \multicolumn{3}{|c|}{ CRPRS1800947 } & \multicolumn{3}{|c|}{ TNFA RS1800629 } & \multicolumn{3}{|c|}{ TNFA rs361525 gen } & \multicolumn{3}{|c|}{ IL6 rs1800795 } \\
\hline & $\underset{n=357}{C / C}$ & $\begin{array}{c}\mathrm{C} / \mathrm{T}+\mathrm{T} / \mathrm{T} \\
\mathrm{n}=412\end{array}$ & $\mathrm{p}^{\wedge}$ & $\underset{n=683}{C / C}$ & $\begin{array}{c}\mathrm{G} / \mathrm{C}+\mathrm{G} / \mathrm{G} \\
\mathrm{n}=86\end{array}$ & $\mathrm{p}^{\wedge}$ & $\underset{n=564}{G / G}$ & $\begin{array}{c}G / A+A / A \\
n=205\end{array}$ & $\mathrm{p}^{\wedge}$ & $\underset{n=685}{G / G}$ & $\begin{array}{c}G / A+A / A \\
n=84\end{array}$ & $\mathrm{p}^{\wedge}$ & $\underset{n=132}{C / C}$ & $\begin{array}{c}\mathrm{G} / \mathrm{C}+\mathrm{GG} \\
\mathrm{n}=637\end{array}$ & $\mathrm{p}^{\wedge}$ \\
\hline Age (years) & $41.2 \pm 6.3$ & $41.3 \pm 6.2$ & 0.83 & $41.3 \pm 6.2$ & $41.0 \pm 6.2$ & 0.45 & $41.5 \pm 6.3$ & $40.6 \pm 6.2$ & 0.05 & $41.2 \pm 6.3$ & $41.6 \pm 5.9$ & 0.62 & $41.7 \pm 6.9$ & $41.2 \pm 6.1$ & 0.28 \\
\hline Height (m) & $2.0 \pm 0.1$ & $2.0 \pm 0.1$ & 0.39 & $2.0 \pm 0.1$ & $2.0 \pm 0.1$ & 0.38 & $2.0 \pm 0.1$ & $2.0 \pm 0.1$ & 0.94 & $2.0 \pm 0.1$ & $2.0 \pm 0.0$ & N/A & $2.0 \pm 0.0$ & $2.0 \pm 0.1$ & N/A \\
\hline Weight (kg) & $99.3 \pm 17.6$ & $100.0 \pm 17.6$ & 0.81 & $99.5 \pm 17.8$ & $100.8 \pm 15.6$ & 0.44 & $99.7 \pm 17.8$ & $99.6 \pm 17.1$ & 0.87 & $99.7 \pm 17.6$ & $99.2 \pm 18.0$ & 0.67 & $100.0 \pm 19.3$ & $99.6 \pm 17.2$ & 0.94 \\
\hline BMI (kg/m2) & $34.5 \pm 5.0$ & $34.5 \pm 4.8$ & 0.94 & $34.5 \pm 4.9$ & $34.6 \pm 4.8$ & 0.90 & $34.5 \pm 4.9$ & $34.5 \pm 5.0$ & 0.99 & $34.5 \pm 4.9$ & $34.5 \pm 4.9$ & 0.87 & $34.5 \pm 5.1$ & $34.5 \pm 4.8$ & 0.86 \\
\hline Body fat (\%) & $40.5 \pm 8.1$ & $40.5 \pm 7.5$ & 0.72 & $40.7 \pm 7.8$ & $39.2 \pm 7.8$ & 0.16 & $40.4 \pm 8.0$ & $40.8 \pm 7.2$ & 0.38 & $40.4 \pm 7.8$ & $41.0 \pm 7.6$ & 0.57 & $41.0 \pm 7.9$ & $40.4 \pm 7.8$ & 0.63 \\
\hline hs-CRP & $4.6 \pm 4.2$ & $4.0 \pm 3.7$ & 0.01 & $4.4 \pm 3.9$ & $3.7 \pm 3.8$ & 0.03 & $4.4 \pm 4.2$ & $3.9 \pm 3.2$ & 0.61 & $4.3 \pm 3.9$ & $4.4 \pm 3.8$ & 0.86 & $4.2 \pm 3.8$ & $4.3 \pm 4.0$ & 0.83 \\
\hline
\end{tabular}

$\wedge$ Mann Withney test; Data are presented as mean \pm standard deviation. 
Table 7.3. Changes in body weight and hs-CRP during the low calorie and weight maintenance periods in the selected genotype groups.

\begin{tabular}{|c|c|c|c|c|c|c|c|c|c|c|c|c|}
\hline & \multicolumn{6}{|c|}{ Weight Loss Period } & \multicolumn{6}{|c|}{ Weight Maintenance Period } \\
\hline & $\mathbf{N}$ & $\begin{array}{c}\text { Body weight } \\
\text { (kg) }\end{array}$ & $p^{*}$ & $\mathbf{N}$ & $\begin{array}{l}\text { hs-CRP } \\
\text { (mg/L) }\end{array}$ & $p^{*}$ & $\mathbf{N}$ & $\begin{array}{l}\text { Body weight } \\
\text { (kg) }\end{array}$ & $p^{*}$ & $\mathbf{N}$ & hs-CRP (mg/L) & $p^{*}$ \\
\hline \multicolumn{13}{|c|}{ CRP (rs1205) } \\
\hline $\mathrm{C} / \mathrm{C}$ & 305 & $-11.2 \pm 0.2$ & 0.53 & 288 & $-1.0 \pm 0.2$ & 0.21 & 208 & $0.81 \pm 0.34$ & 0.16 & 191 & $-0.08 \pm 0.16$ & 0.28 \\
\hline $\mathrm{C} / \mathrm{T}+\mathrm{T} / \mathrm{T}$ & 339 & $-11.0 \pm 0.2$ & & 324 & $-0.7 \pm 3.0$ & & 251 & $0.07 \pm 0.38$ & & 231 & $-0.32 \pm 0.15$ & \\
\hline \multicolumn{13}{|c|}{ CRP (rs1800947) } \\
\hline $\mathrm{C} / \mathrm{C}$ & 573 & $-11.1 \pm 0.2$ & 0.46 & 545 & $-0.9 \pm 0.1$ & 0.21 & 410 & $0.43 \pm 0.27$ & 0.73 & 376 & $-0.14 \pm 0.12$ & 0.04 \\
\hline $\mathrm{G} / \mathrm{C}+\mathrm{G} / \mathrm{G}$ & 71 & $-10.8 \pm 0.4$ & & 67 & $-0.4 \pm 0.3$ & & 49 & $0.14 \pm 0.93$ & & 46 & $-0.85 \pm 0.33$ & \\
\hline \multicolumn{13}{|c|}{ TNFA (rs1800629) } \\
\hline $\mathbf{G} / \mathbf{A}+\mathbf{A} / \mathbf{A}$ & 169 & $-11.0 \pm 0.3$ & 0.82 & 162 & $-0.6 \pm 0.2$ & 0.17 & 117 & $0.94 \pm 0.48$ & 0.23 & 107 & $-0.32 \pm 0.18$ & 0.58 \\
\hline $\mathrm{G} / \mathrm{G}$ & 475 & $-11.1 \pm 0.2$ & & 450 & $-0.9 \pm 0.1$ & & 342 & $0.22 \pm 0.31$ & & 315 & $-0.18 \pm 0.13$ & \\
\hline \multicolumn{13}{|c|}{ TNFA (rs361525) } \\
\hline$G / A+A / A$ & 71 & $-10.6 \pm 0.4$ & 0.24 & 65 & $-1.0 \pm 0.4$ & 0.59 & 48 & $1.00 \pm 0.71$ & 0.43 & 43 & $-0.09 \pm 0.29$ & 0.71 \\
\hline $\mathrm{G} / \mathrm{G}$ & 573 & $-11.2 \pm 0.2$ & & 547 & $-0.8 \pm 0.1$ & & 411 & $0.33 \pm 0.28$ & & 379 & $-0.23 \pm 0.12$ & \\
\hline \multicolumn{13}{|c|}{ IL6 (rs1800795) } \\
\hline $\mathrm{C} / \mathrm{C}$ & 112 & $-11.0 \pm 3.7$ & 0.88 & 102 & $-0.5 \pm 3.0$ & 0.25 & 83 & $0.3 \pm 7.3$ & 0.72 & 75 & $-0.2 \pm 2.0$ & 0.84 \\
\hline $\mathrm{G} / \mathrm{C}+\mathrm{G} / \mathrm{G}$ & 532 & $-11.1 \pm 3.6$ & & 510 & $-0.9 \pm 2.8$ & & 370 & $0.5 \pm 5.0$ & & 345 & $-0.1 \pm 2.4$ & \\
\hline
\end{tabular}

${ }^{*}$ ANCOVA analysis

The influence of variations in the pro-inflammatory genes on the correlation between changes in hs-CRP and changes in body weight during the weight maintenance period is shown in Table 7.4. Variations in CRP ( $r s 1205$ and rs1800947), TNFA (rs1800629), and IL6 (rs1800795) genes influenced the correlations between changes in hs-CRP and body weight during the weight maintenance period in the whole group of subjects. Larger increases in hs-CRP were correlated with larger increases in body weight among the T-allele carriers of CRP rs1205 ( $\beta=0.190, p=$ 0.005), CC genotype of CRP rs1800947 ( $\beta=0.174, p=0.001), G G$ genotype of TNFA rs1800629 ( $\beta=0.175, p=0.003)$ and G-allele carriers of IL6 rs1800795 ( $\beta=0.206, p$ $<0.001)$. This correlation was not significant for the other genotypes of these genes. We found no influence of TNFA rs361525 on the correlation between hs-CRP and body weight changes. 
The Interaction of Inflammatory Gene Variations with the Association between Diet, hs-CRP, and Weight Regain in the DiOGenes Trial

Table 7.4. Correlation between changes in hs-CRP and body weight during the weight maintenance period according to gene variations in inflammatory genes

\begin{tabular}{|c|c|c|c|c|}
\hline Gene variations & Genotypes & $\mathbf{n}$ & $\operatorname{Beta} \wedge$ & $p$ \\
\hline All subjects & N/A & 420 & 0.164 & $<0.001$ \\
\hline \multirow[t]{2}{*}{ CRP rs 1205} & $\mathrm{C} / \mathrm{C}$ & 188 & 0.138 & 0.061 \\
\hline & $\mathrm{C} / \mathrm{T}+\mathrm{T} / \mathrm{T}$ & 232 & 0.175 & 0.007 \\
\hline \multirow[t]{2}{*}{ CRP rs 1800947} & $\mathrm{C} / \mathrm{C}$ & 372 & 0.179 & $<0.001$ \\
\hline & $\mathrm{G} / \mathrm{C}+\mathrm{G} / \mathrm{G}$ & 48 & 0.066 & 0.651 \\
\hline \multirow[t]{2}{*}{ TNFA rs 1800629} & G/G & 312 & 0.175 & 0.002 \\
\hline & $\mathrm{G} / \mathrm{A}+\mathrm{A} / \mathrm{A}$ & 108 & 0.118 & 0.222 \\
\hline \multirow[t]{2}{*}{ TNFA rs361525 } & G/G & 379 & 0.147 & 0.004 \\
\hline & $\mathrm{G} / \mathrm{A}+\mathrm{A} / \mathrm{A}$ & 41 & 0.368 & 0.021 \\
\hline \multirow[t]{2}{*}{ IL6 rs 1800795} & $\mathrm{C} / \mathrm{C}$ & 75 & -0.002 & 0.985 \\
\hline & $\mathrm{G} / \mathrm{C}+\mathrm{G} / \mathrm{G}$ & 345 & 0.211 & $<0.001$ \\
\hline
\end{tabular}

$\wedge$ Linear regression test with correction for age, gender and study center

Variations in pro-inflammatory genes also might influence the association between self-reported protein intake and dietary $\mathrm{Gl}$ and weight changes during the weight maintenance phase. In Table 7.5 it is shown that the positive correlation between $\mathrm{Gl}$ and changes in body weight during weight maintenance was significant among those with the GG genotype $(p=0.044)$ of TNFA rs1800629, but not in A-allele carriers $(p=0.487)$ or any of the other genotypes. Percent protein intake was negatively correlated with changes of body weight only among those with the CC genotype of CRP rs1205 ( $p=0.016)$, CC genotype of CRP rs1800947 ( $p=0.028)$ and the G-allele carriers of IL6 rs1800795 ( $p=0.004)$. Among those with other genotypes percent protein intake was not correlated with the change in body weight (all $p>0.05$ ). There was no influence of the gene variations in CRP, TNFA and IL6 on the interaction between GI or protein intake with changes in hs-CRP (Supplementary Table 7.2).

Table 7.5. Correlation between Gl or protein intake (\% of total energy intake) with changes in body weight during the weight maintenance period based on gene variations in inflammatory genes.

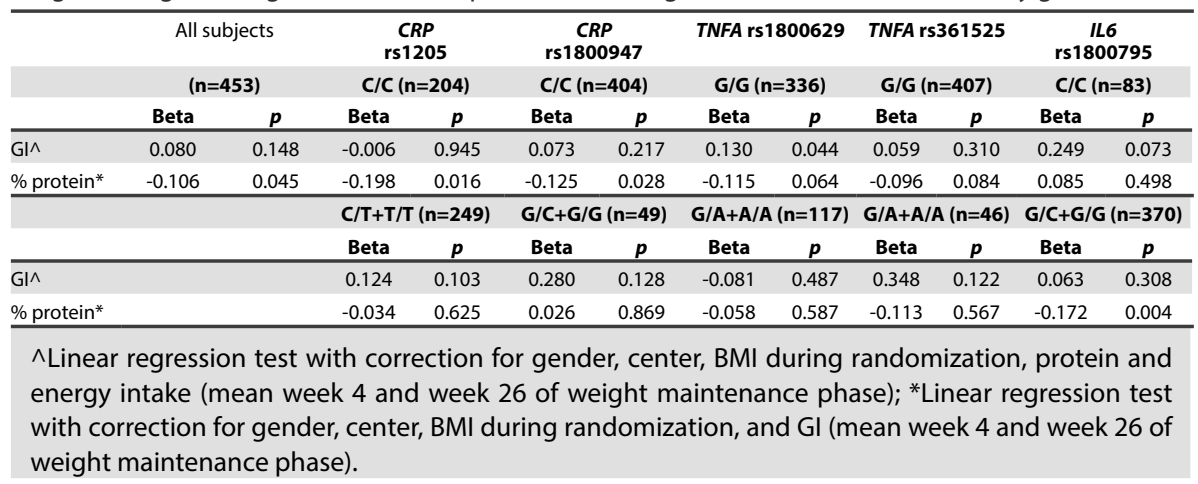




\section{DISCUSSION}

Inflammation has been suggested to play a role in weight regain following weight loss. Therefore we hypothesized that variations in inflammatory genes could influence variations in weight regain after weight loss among individuals with overweight/ obesity. In this study, we showed that variation in inflammatory genes was not directly associated with body weight at baseline and with weight changes during the weight loss or the weight maintenance period. However, variations in inflammatory genes influenced the interaction between diet and weight regain.

We found that individuals with the CC genotypes of the CRP gene (rs1205 and rs1800947) had higher hs-CRP levels at baseline. This result is in line with an observational study in Iceland [27] that showed that individuals with the dominant genotype of CRP rs1205 had higher hs-CRP levels than those with other genotypes. Rs1205 shows after gene expression as a G>A polymorphisms in the CRP mRNA, which is located at the $3^{\prime}$ untranslated region. Therefore, this region could be involved in the regulation of the RNA transcription process, and may affect RNA stability as well as translation and localization [28]. It has been suggested that RNA produced by the $A$ allele is less stable than that produced by the dominant $G$ allele and this could explain the higher hs-CRP concentration in CC genotype of rs 1205 and GG genotype of rs1800947) [27,29]. Hage et al [14] reviewed the effect of variation occurring at several locations in the CRP gene, rs1205 and rs1800947, among others, on hsCRP concentration. Based on findings from the literature, they suggested that the C allele of rs1205 and the $\mathrm{G}$ allele of rs1800947 were associated with higher hs-CRP concentrations [14]. These patterns were also seen in this study at baseline.

Besides findings showing that obesity is associated with increased inflammation, it is also suggested that inflammation plays a role in development of obesity. This theory is supported by reports showing that variations in proinflammatory genes are associated with the risk of obesity [13,14, 30-32]. However, to our knowledge there are no previous reports indicating that variations in pro-inflammatory genes are associated with weight loss or weight regain after weight loss. We found no direct association between gene variations in CRP, TNFA and IL6 and body weight at baseline, weight loss and weight regain. However, we showed that the correlation between changes in hs-CRP and weight regain was influenced by variation in inflammatory genes. In those with the CRP increasing allele genotypes of the CRP gene, CC for rs 1205 and G/C+G/G for rs1800947, changes in hs-CRP were not correlated with changes in body weight.

Variations in the TNFA gene might influence the correlation between $\mathrm{GI}$ and weight regain. In contrast to the report of the full DiOGenes trial where participants randomized to the higher $\mathrm{Gl}$ groups regained more weight than those in the low Gl groups (Larsen et al [12]), we found that a higher Gl of the diet, based on selfreport by means of dietary records, during weight maintenance was not correlated with more weight regain. This might due to several factors, including the use of less reliable self-report of the GI of diet, the observational analysis, as well as smaller 
number of subjects in the whole analysis (not all subjects filled in the dietary records and not all were genotyped). However, the genotype of TNFA rs1800629 differentially affected this correlation. Interestingly, this genotype was also the one that influenced the correlation between changes in hs-CRP and weight regain. This might indicate that the influence of $\mathrm{Gl}$ of the diet on weight regain is modulated by TNF-alpha concentrations. It was previously reported that a higher GI was associated with weight regain via up-regulation of inflammation markers, including TNF-alpha [33]. Unfortunately, TNF-alpha concentrations were not measured in the DiOGenes trial.

We found a negative correlation between percent protein intake during weight maintenance and body weight regain, as in the full DiOGenes trial (Larsen et al [12]). Gene variations at CRP (rs1205 and rs1800947), and IL6 (rs1800795) influenced this correlation. Among those with the CC genotype of CRP rs1205, CC genotype of CRP rs1800947 and the GC+GG genotype of IL6 rs1800795, percent protein intake was significantly negatively correlated with weight regain, in the other genotypes the negative correlations did not reach statistical significance. A recent publication from the longitudinal Framingham Heart Study Offspring Cohort [34]. reported that a higher dietary protein intake was associated with a smaller increase in inflammation. By contrast, in the DiOGenes study a high protein diet was not associated with changes in hs-CRP [4]. To our knowledge, this is the first study that observes a role for variations in pro-inflammatory genes in the correlation between protein intake and weight regain following weight loss. Further studies are needed to evaluate the mechanism behind this effect.

There were several limitations to this study. Firstly, although the DiOGenes trial was a randomized controlled trial with 5 different dietary groups, the reported analysis was done by merging all data and perform the analysis as an observational study. Subjects were only separated based on genotype. This was due to the small number of subjects when subjects were divided into diet $x$ genotype groups. Secondly, dietary intake was self-reported using food records which might influence the accuracy of data. Lastly, the number of subjects in a specific genotype group was limited. It is recommended for an observational study to have at least 500 subjects per effect allele [35]. Thus, further study with a larger sample size is needed to confirm the results of this analysis.

In summary, this study provides some preliminary evidence for the influence of variations in inflammatory genes on the interaction between dietary intake, inflammation and weight regain following weight loss. This finding supports the previous notion that inflammation plays a role in weight regain following weight loss. Gene variations in CRP, TNFA and IL6 genes were not associated with body weight at baseline, weight loss and weight regain. However, these gene variations influenced the correlation between protein intake and $\mathrm{Gl}$ of the diet and weight regain following weight loss. Further study is needed to evaluate mechanisms on how protein and GI of the diet and variation of inflammatory genes interact. 


\section{REFERENCES}

1. Han JM, Levings MK. Immune regulation in obesity-associated adipose inflammation. J Immunol 2013, 191(2), 527-532.

2. Choi J, Joseph L, Pilote L. Obesity and C-reactive protein in various populations: a systematic review and meta-analysis. Obes Rev 2013, 14(3), 232-244.

3. Nicklas JM, Sacks FM, Smith SR, et al. Effect of dietary composition of weight loss diets on high-sensitivity c-reactive protein: the Randomized POUNDS LOST trial. Obesity. 2013, 21(4), 681-689.

4. Gögebakan O, Kohl A, Osterhoff MA, et al. Effects of weight loss and long-term weight maintenance with diets varying in protein and glycemic index on cardiovascular risk factors: the diet, obesity, and genes (DiOGenes) study: a randomized, controlled trial. Circulation 2011, 124(25), 2829-2838.

5. Selvin E, Paynter NP, Erlinger TP. The effect of weight loss on C-reactive protein: a systematic review. Arch Intern Med 2007, 167(1), 31-9.

6. Belza A, Toubro S, Stender S, et al. Effect of diet-induced energy deficit and body fat reduction on high-sensitive CRP and other inflammatory markers in obese subjects. Int $J$ Obes 2009, 33(4), 456-464.

7. Roumans NJ, Camps SG, Renes J, et al. Weight loss- induced stress in subcutaneous adipose tissue is related to weight regain. Br J Nutr 2016, 115, 913-920.

8. Capel F, Klimcáková E, Viguerie N, et al. Adipose Tissue Gene Expression and Insulin Sensitivity During Calorie Restriction and Weight Stabilization. Diabetes 2009, 58, 15581567.

9. Márquez-Quiñones A, Mutch DM, Debard C, et al. Adipose tissue transcriptome reflects variations between subjects with continued weight loss and subjects regaining weight 6 mo after caloric restriction independent of energy intake. Am J Clin Nutr 2010, 92(4), 975-984.

10. van Baak MA, Mariman ECM. Mechanisms of weight regain after weight loss - the role of adipose tissue. Nat Rev Endocrinol 2019, 15(5), 274-287.

11. Saris WH, Harper A. DiOGenes: a multidisciplinary offensive focused on the obesity epidemic. Obes Rev 2005, 6(2), 175-6.

12. Larsen TM, Dalskov SM, van Baak M, et al. Diets with High or Low Protein Content and Glycemic Index for Weight-Loss Maintenance. N Engl J Med 2010, 363(22), 2102-2113.

13. Joffe YT, Collins M, Goedecke JH. The relationship between dietary fatty acids and inflammatory genes on the obese phenotype and serum lipids. Nutrients 2013 5(5): 16721705.

14. Hage FG, Szalai AJ. C-Reactive Protein Gene Polymorphisms, C-Reactive Protein Blood Levels, and Cardiovascular Disease Risk. J Am Coll Cardiol 2007, 50, 1115-1122.

15. Klimushina MV, Gumanova NG, Kutsenko V, et al. Association of common polymorphisms in IL-6 and IL6ST genes with levels of inflammatory markers and coronary stenosis. Meta Gene 2019, 21, 100593. 
16. Liaquat A, Asifa GZ, Zeenat A, et al. Polymorphisms of tumor necrosis factor-alpha and interleukin-6 gene and C-reactive protein profiles in patients with idiopathic dilated cardiomyopathy. Ann Saudi Med 2014, 34(5), 407-414.

17. Larsen TM, Dalskov S, van Baak M, et al. The Diet, Obesity and Genes (Diogenes) Dietary Study in eight European countries - a comprehensive design for long-term intervention. Obes Rev 2010, 11(1), 76-91.

18. Moore CS, Lindroos AK, Kreutzer $M$, et al. Dietary strategy to manipulate ad libitum macronutrient intake, and glycaemic index, across eight European countries in the Diogenes Study. Obes Rev 2010, 11(1), 67-75.

19. Aston LM, Jackson D, Monsheimer S, et al. Developing a methodology for assigning glycaemic index values to foods consumed across Europe. Obes Rev 2010, 11, 92-100.

20. JASP Team (2020). JASP (Version 0.13)[Computer software].

21. Cui G, Wang H, Li R, et al. Polymorphism of tumor necrosis factor alpha (TNF-alpha) gene promoter, circulating TNF-alpha level, and cardiovascular risk factor for ischemic stroke. $J$ Neuroinflammation 2012, 9, 235.

22. Kaluza $W$, Reuss $E$, Grossmann $S$, et al. Different transcriptional activity and in vitro TNF-alpha production in psoriasis patients carrying the TNF-alpha 238A promoter polymorphism. J Invest Dermatol 2000, 114(6), 1180-1183.

23. Noss EH, Nguyen HN, Chang SK, et al. Genetic polymorphism directs IL-6 expression in fibroblasts but not selected other cell types. Proc Natl Acad Sci USA 2015, 112(48): 14948-14953.

24. Wielińska J, Dratwa M, Świerkot J, et al. Interleukin 6 gene polymorphism is associated with protein serum level and disease activity in Polish patients with rheumatoid arthritis. HLA 2018, 92 Suppl 2, 38-41.

25. Ljungman $P$, Bellander $T$, Nyberg $F$, et al. DNA variants, plasma levels and variability of interleukin-6 in myocardial infarction survivors: results from the AIRGENE study. Thromb Res 2009, 124(1), 57-64.

26. Wang Z, Wang X, Chen Z, et al. Distribution of High-Sensitivity C-Reactive Protein and Its Relationship with Other Cardiovascular Risk Factors in the Middle-Aged Chinese Population. Int J Environ Res Public Health 2016, 13(9), 872.

27. Eiriksdottir G, Smith AV, Aspelund T, et al. The interaction of adiposity with the CRP gene affects CRP levels: age, gene/environment susceptibility-Reykjavik study. Int J Obes (Lond) 2009, 33(2), 267-272.

28. Steri $\mathrm{M}$, Idda $\mathrm{ML}$, Whalen $\mathrm{MB}$, et al. Genetic variants in mRNA untranslated regions. Wiley Interdiscip Rev RNA 2018, 9(4), e1474.

29. Danik JS, Ridker PM. Genetic determinants of C-reactive protein. Curr Atheroscler Rep 2007, 9, 195-203.

30. Martínez-Calleja A, Quiróz-Vargas I, Parra-Rojas I, et al. Haplotypes in the CRP gene associated with increased BMI and levels of CRP in subjects with type 2 diabetes or obesity from Southwestern Mexico. Exp Diabetes Res 2012, 982683. 
31. Flores-Alfaro E, Fernández-Tilapa G, Salazar-Martínez E, et al. Common variants in the CRP gene are associated with serum C-reactive protein levels and body mass index in healthy individuals in Mexico. Genet Mol Res 2012, 11(3), 2258-2267.

32. Włodarczyk M, Ciebiera M, Nowicka G. TNF- $\alpha$ G-308A genetic variants, serum CRP-hs concentration and DNA damage in obese women. Mol Biol Rep 2020, 47(2), 855-866.

33. Kelly KR, Haus JM, Solomon TP, et al. A low-glycemic index diet and exercise intervention reduces TNF(alpha) in isolated mononuclear cells of older, obese adults. J Nutr 2011, 141(6), 1089-1094.

34. Hruby A, Jacques PF. Dietary Protein and Changes in Biomarkers of Inflammation and Oxidative Stress in the Framingham Heart Study Offspring Cohort. Curr Dev Nutr. 2019, 3(5), nzz019.

35. Grimaldi KA, van Ommen B, Ordovas JM, et al. Proposed guidelines to evaluate scientific validity and evidence for genotype-based dietary advice. Genes Nutr 2017, 12, 35. 
Supplementary Table 7.1. Allelic distribution and HWE of all genotypes.

\begin{tabular}{lllll}
\hline Gene & Rs number & Major Allele & Minor Allele & HWE $p$ \\
\hline CRP & RS1205 & $\mathrm{C}(\mathrm{n}=1043)$ & $\mathrm{T}(\mathrm{n}=495)$ & 0.56 \\
CRP & RS1800947 & $\mathrm{C}(\mathrm{n}=1450)$ & $\mathrm{G}(\mathrm{n}=88)$ & 1.0 \\
TNFA & $\mathrm{rs} 1800629$ & $\mathrm{G}(\mathrm{n}=1306)$ & $\mathrm{A}(\mathrm{n}=232)$ & 0.011 \\
TNFA & $\mathrm{rs361525}$ & $\mathrm{G}(\mathrm{n}=1452)$ & $\mathrm{A}(\mathrm{n}=86)$ & 1.0 \\
IL6 & $\mathrm{rs} 1800795$ & $\mathrm{G}(\mathrm{n}=929)$ & $\mathrm{C}(\mathrm{n}=609)$ & 0.083 \\
\hline
\end{tabular}

Supplementary Table 7.2. Correlation between GI and protein intake (\% of total energy intake) with changes in hs-CRP concentration during the weight maintenance period based on variations in proinflammatory genes.

\begin{tabular}{|c|c|c|c|c|c|c|c|c|c|c|c|c|}
\hline & \multirow{2}{*}{\multicolumn{2}{|c|}{$\begin{array}{l}\text { All subjects } \\
(n=0.420)\end{array}$}} & \multirow{2}{*}{\multicolumn{2}{|c|}{$\begin{array}{l}\text { CRP rs } 1205 \\
C / C(n=204)\end{array}$}} & \multirow{2}{*}{\multicolumn{2}{|c|}{$\begin{array}{l}\text { CRP rs } 1800947 \\
C / C(n=404)\end{array}$}} & \multirow{2}{*}{\multicolumn{2}{|c|}{$\begin{array}{c}\text { TNFA } \\
\text { rs1800629 } \\
\text { G/G }(n=336)\end{array}$}} & \multirow{2}{*}{\multicolumn{2}{|c|}{$\begin{array}{c}\text { TNFA } \\
\text { rs361525 } \\
\text { G/G (n=407) }\end{array}$}} & \multirow{2}{*}{\multicolumn{2}{|c|}{$\begin{array}{l}\text { IL6 rs } 1800795 \\
\text { C/C (n=83) }\end{array}$}} \\
\hline & & & & & & & & & & & & \\
\hline & $\boldsymbol{\beta}$ & $p$ & $\boldsymbol{\beta}$ & $p$ & $\beta$ & $p$ & $\beta$ & $p$ & $\beta$ & $p$ & $\beta$ & $p$ \\
\hline $\mathrm{Gl} \wedge$ & 0.099 & 0.100 & 0.028 & 0.723 & 0.069 & 0.240 & 0.019 & 0.768 & 0.027 & 0.633 & 0.007 & 0.963 \\
\hline \multirow[t]{3}{*}{$\%$ protein* } & -0.005 & 0.929 & -0.066 & 0.389 & -0.003 & 0.962 & -0.029 & 0.621 & -0.010 & 0.855 & 0.159 & 0.218 \\
\hline & & & \multicolumn{2}{|c|}{$C / T+T / T(n=249)$} & \multicolumn{2}{|c|}{$G / C+G / G(n=49)$} & \multicolumn{2}{|c|}{$\begin{array}{l}G / A+A / A \\
(n=117)\end{array}$} & \multicolumn{2}{|c|}{$\begin{array}{l}G / A+A / A \\
(n=46)\end{array}$} & \multicolumn{2}{|c|}{$\begin{array}{l}G / C+G / G \\
(n=370)\end{array}$} \\
\hline & & & $\boldsymbol{\beta}$ & $p$ & $\beta$ & $p$ & $\beta$ & $p$ & $\boldsymbol{\beta}$ & $p$ & $\beta$ & $p$ \\
\hline $\mathrm{G}^{\wedge} \wedge$ & & & 0.054 & 0.482 & -0.109 & 0.564 & 0.121 & 0.296 & 0.216 & 0.268 & 0.842 & 0.400 \\
\hline$\%$ protein* & & & 0.045 & 0.517 & -0.020 & 0.903 & -0.047 & 0.635 & 0.059 & 0.733 & -0.029 & 0.612 \\
\hline
\end{tabular}

$\wedge$ Linear regression test with correction for age, sex, center, BMI during randomization, protein and energy intake (DI mean week 4 - week 26); ${ }^{*}$ Linear regression test with correction for age, sex, center, BMI during randomization, and GI (DI mean week 4 - week 26). 
CHAPTER 8

General Discussion 
Inflammation might play a part in body weight regulation. Previous studies showed that circulating inflammatory markers [1,2], inflammatory properties of the diet $[3,4]$, and genetic variation in inflammatory markers [5-7] are associated with obesity. To date, it is not known whether the interaction between inflammation and obesity could also be targeted in the context of weight change during and after a weight loss program and whether diet might influence this association.

The general objective of this thesis was to evaluate the influence of diet and inflammatory gene variations on inflammation and body weight changes in obesity. The objective was specified into 4 aims: 1) To evaluate the association of the inflammatory properties of the diet with weight regain after a weight loss program as well as with the risk for obesity in a population-based study; 2) To develop a new low calorie dietary regime with low inflammatory property for weight loss and evaluate the association between the inflammatory properties of the diet and weight regain; 3) To examine the influence of inflammatory gene variations on the association between obesity and inflammation; 4) To evaluate the interaction between inflammatory gene variations and diet composition and its effect on weight regain after weight loss.

\section{THE EFFECT OF DIET ON INFLAMMATION AND BODY WEIGHT: AN OBSERVATIONAL ANALYSIS}

The habitual dietary pattern affects circulating inflammatory markers in adults [8]. The Dietary Inflammatory Index (DII) has been developed to assess the inflammatory properties of the diet by calculation of intake of nutrient and non-nutrient components of the diet [9]. The score on this index has been shown to be associated with systemic inflammation [10-12] as well as weight gain and obesity $[13,14]$.

We investigated the association between DII, adiposity, and leptin concentration among Indonesian adults in a cross-sectional manner. As presented in Chapter 2 we found that the DII score was not correlated with any of the adiposity measures. Several reasons might explain this negative result. First, there was a lack of DII components compared to the Global Diet (as reported by Shivappa et al) due to limited nutrients data on found abundantly in Indonesian foods. Second, there could be some data quality issues including accuracy of dietary assessment using a semi-quantitative food frequency questionnaire. Lastly, other factors that were not measured in this study also contribute to body mass index and obesity status.

Interestingly, we showed that the DII was positively correlated with plasma leptin concentration after correction for age, sex and BMI, energy intake, and physical activity. Leptin is produced by adipocytes with an ability to induce production of inflammation markers such as which TNF-alpha and IL-6 $[15,16]$. The concentration of leptin increases as adiposity increases [17] and leptin has been proposed as a key link between obesity, inflammation and metabolic diseases. This is supported by several studies, which showed that a higher leptin concentration was associated with increased risk for cardiovascular diseases $[18,19]$. Although in our cross-sectional 
study we showed that DII was not associated with adiposity, the positive correlation between DII and leptin indicated that here may be a connection between diet and inflammation, which might impose a risk of weight gain and/or cardiovascular diseases later in life.

We further investigated the effect of the inflammatory properties of diet on weight regain following weight loss among Dutch adults with obesity (Chapter 3 ). In this study we showed that the DII was positively correlated with weight regain, suggesting that inflammation may play a role in the regulation of body weight after weight loss. Additionally, we also showed that the intake of several individual micronutrients with anti-inflammatory properties, such as magnesium, folate, and riboflavin, were negatively correlated with weight regain. However, results from this study should be interpreted with caution. Since the analysis was done in an observational manner, no cause-effect relationship can be derived from this correlation.

Results from those 2 studies support the notion that inflammatory properties of diet might have a role in weight regulation, and possibly through regulation of inflammatory markers in the circulation as well as in adipose tissue (as marked by leptin concentration). In addition, results from these studies provide a practical implication to reduce the inflammatory properties of diet among individuals in the study population. This includes several key components of DIl which influence weight gain such as magnesium, folate, and riboflavin. Those nutrients are rich in vegetables, nuts, and seeds.

The information generated at Chapter 2 and Chapter 3 provides some evidence that diet can influence inflammation as well as weight gain after weight loss, which might be interconnected. Those studies also provide us with key components to focus on regarding dietary modifications which might influence inflammation which includes increasing intake of fruits and vegetables, white meat, and legumes and reduction of red meat and processed foods. To test the hypothesis that the inflammatory properties of the diet play a role in weight management, a new dietary regimen for weight loss needs to be developed to reduce the inflammatory properties of the diet and thus influence the inflammatory response to weight loss, which might also be beneficial to prevent weight regain after weight loss.

\section{THE EFFECT OF DIET ON INFLAMMATION AND BODY WEIGHT: AN INTERVENTION STUDY}

To further investigate whether the inflammatory markers had an influence on weight loss, we developed a new low-calorie diet, called low calorie low inflammatory diet (LCID). The main objective of the study presented in Chapter 4 was to investigate the effect of weight loss on different inflammatory markers and whether this effect is modifiable by diet (LCID) in adults with obesity. We hypothesized that when reduction of inflammation by dietary modification can have influence on weight loss, this can prove that indeed, inflammation affects weight loss. 
We found that after 8 weeks of the weight loss program there was an increase in plasma TNF-alpha and IL- 6 concentrations. Subjects in the LCID group had a greater reduction in hs-CRP at the end of the intervention compared to those in the conventional low-calorie diet (LCD) group, but no differences were seen in changes of TNF-alpha and IL- 6 concentrations between groups. The LCID induced reductions in body weight, body fat, and metabolic syndrome parameters without significant difference compared to LCD.

The controversies around the influence of weight loss on changes in inflammation markers have been reported before [20-27]. We showed that the hs-CRP concentration was on average not affected in the total group, but that it was reduced in the LCID group compared to the LCD group. By contrast, no group difference was found for the changes in TNF-alpha and IL-6. TNF-alpha and IL- 6 are markers of adipose tissue inflammation while hs-CRP is a marker of liver inflammation $[28,29]$. Thus, it is speculated that the weight loss-induced increase in the inflammatory status of the adipose tissue is not sensitive to short term changes in the inflammatory properties of the diet. By contrast, the liver remains responsive to the dietary composition under the conditions of energy restriction.

The study in chapter 4 also shows that there is a challenge in optimizing the compliance to a weight loss diet that is being delivered to Indonesian adults with obesity. The adherence to the LCD and LCID regime was relatively low and this resulted in a small weight loss. During the personal meetings with the nutritionist, dietary recommendations were given by explaining the principles of the diet and providing a one-day meal plan that could be followed by the participant. Moreover, different from LCD which focused solely on reducing energy intake, LCID focused in addition on changing the dietary pattern. Crucial components such as eating vegetables in every main meal, increasing fish intake, and using oil with less saturated fat (i.e. olive oil) are hard to achieve in Indonesia and there was a significant variability in compliance among subjects. Despite the fact that 2-weekly meetings with nutritionists were included in the intervention, further effort is needed to improve compliance to prescribed dietary intake by incorporating behaviour change techniques.

The DII was used to estimate the inflammatory property of the diet in chapters 2 and 3, but no longer used in the subsequent chapters. There are several reasons for this. First, the DII was developed for use in observational studies and relies on self-reported data. This technique is known to have a questionable validity and reliability for measurement of dietary intake [30]. Second, the DII is highly dependent on energy intake. As chapter 4 evaluated the impact of calorie-restricted diets, the DII values changed and became incoherent. Third, there was a lack of DII components compared to the Global Diet due to limited nutrient data for Indonesian foods. For instance, we did not have complete data of several fatty acids (i.e. omega 3 and omega 6 ) in some Indonesian foods. This might influence the accuracy of DII calculation. Lastly, there are some unsettled controversies whether certain nutrients 
are pro-inflammatory or anti-inflammatory. In the DII list, vitamin B12 is regarded as proinflammatory but several studies have reported that vitamin B12 is conversely associated with inflammation [31,32]. In addition, DIl acknowledges alcohol as an anti-inflammatory component, but the influence of alcohol intake on inflammation is controversial. While a moderate intake of alcohol is associated with a reduction of inflammation [33,34], heavy alcohol intake is associated with increased inflammation [34]. This suggests that the correlation between alcohol intake and inflammation is U-shaped rather than linear, as assumed in DII.

The impact of LCID on weight loss and inflammation markers was evaluated and presented in Chapter 4. Despite the reduction of body weight due to dietary modification, changes in dietary intake were not strong enough to influence weight regain after weight loss. This analysis suffered from loss to follow up. This was due to several issues including: 1) loss of engagement in study participants, nutritionists and the research team; 2) follow-up was not pre-planned: the study was offered as a weight loss program, thus participants lost their interest once weight loss was achieved; 3) no direct financial incentive for participants after finishing the weight loss protocol; 4) some participants had a hard time reducing weight, so they hesitated to be remeasured. Innovations to increase motivation of study participants during a weight loss program and weight maintenance are necessary. The use of technology such as social media or mobile applications might help tackle this issue. Creating a supportive community might be necessary to prevent drop-out and improve engagement of study participants.

\section{THE INFLUENCE OF DIET ON GENOMIC HEALTH}

In addition, to evaluate the influence of LCD or LCID on inflammation markers and weight changes during weight loss, we also evaluated whether LCD or LCID were associated with markers of genomic health such as relative telomere length (RTL) and mitochondrial DNA copy number (mtDNA-CN). The reason for this analysis was that both RTL and mtDNA-CN are altered by chronic inflammation [35-37]. Increased inflammation induces shortening of RTL and reduction of mIDNA-CN [35-38] which are regarded as markers of aging. Interestingly, these markers of genomic health are associated with weight gain in adults [39]. In this study (Chapter 5), we showed that weight loss was associated with elongation of RTL but had no influence on mIDNA$\mathrm{CN}$. In addition, we also showed that those in the LCID group had a greater elongation of RTL compared to those in the LCD group. This analysis showed that modification of dietary composition during a weight loss program could improve health beyond inflammation, by improvement of genomic health. Since telomere shortening may predispose individuals to age-related diseases and increased mortality, the slowing down of this process by diet can help protect from degenerative diseases and improve wellbeing. 


\section{THE INFLUENCE OF INFLAMMATORY GENE VARIATIONS ON THE INTERACTION BETWEEN BODY WEIGHT AND INFLAMMATION}

Low-grade systemic inflammation is induced by several factors including environmental exposures (diet, physical activity, pollutants) and genetic background [38]. There is evidence that variants of inflammation-related genes influence the interactions between adiposity and inflammation. For example, Eiriksdottir et al. [40] reported that variants of the CRP gene modulate the relationship between body mass index and high-sensitive $C$ reactive protein (hs-CRP). This was supported by other studies $[41,42]$ showing the role of variations at the CRP gene on the interaction between obesity and hs-CRP. The objective of Chapter 6 was to investigate associations between SNPS at TNFA, CRP, and IL6 and measures of adiposity, as well as the correlation between adiposity and hs-CRP among adults living in Northeast England.

In this analysis we report that variation in TNFA (rs1800629) was associated with adiposity, but variations in CRP (rs1800947, rs1205) and IL6 (rs1800795) were not. We also reported that variation in pro-inflammatory genes plays a role in the interaction between adiposity measures and hs-CRP. Among subjects with the GG genotype of TNFA (rs1800629), CG+GG genotype of IL6 (rs1800795), GG genotype in CRP ( $\mathrm{rs1800947)}$ and CT+TT genotype of CRP (rs1205), the correlation between adiposity measures and hs-CRP was significant.

To further confirm the influence of inflammatory gene variations on the correlation between hs-CRP and body weight, an analysis was performed among individuals who undertook a weight loss program in the DiOGenes Study (Chapter 7). Similarly, we evaluated the influence of gene variations in TNFA, CRP and IL6 on the correlation between changes in body weight and hs-CRP concentration during the weight maintenance period. In this study, we showed that among those with the CT+TT genotype of CRP (rs1205), CC genotype of CRP (rs1800947), GG genotype of TNFA (rs1800629), and CG+GG genotype of IL6 (rs1800795) changes in body weight were positively correlated with hs-CRP during the weight maintenance period. These data confirm the observational study in Northeast England which showed that variations in CRP, TNFA and IL6 genes influence the correlation between body weight and hs-CRP.

\section{THE INFLUENCE OF INFLAMMATORY GENE VARIATIONS ON THE INTERACTION BETWEEN DIET AND WEIGHT REGAIN FOLLOWING WEIGHT LOSS}

In Chapter 7, we investigated the interaction between inflammatory gene variations, diet and weight gain after weight loss in DiOGenes Study. This was to examine the hypothesis that inflammatory genes play a role in the regulation of body weight by affecting the correlation between diet and weight gain. In this study we showed that variations in inflammation genes were not directly associated with body weight at 
baseline and with weight changes during the weight loss or the weight maintenance period. However, these variations influenced the interaction between diet and weight regain. Among those with the CC genotype of CRP rs1205, CC genotype of CRP rs1800947, and the GC+GG genotype of IL6 rs1800795, percent protein intake was negatively correlated with weight regain, in the other genotypes the negative correlations did not reach statistical significance. In contrast, the correlation between $\mathrm{Gl}$ and changes in body weight during weight maintenance was significant among those with the GG genotype of TNFA rs1800629 but not in those with the GA+AA genotype. These findings show that the individual weight responses to a specific diet composition differ and that variations in inflammation genes might be involved in this variation. Findings from this study could, if replicated, perhaps be used in a clinical setting to improve dietary treatment by matching with an individual's genetic background. By matching dietary recommendations with individual genetic background, we could personalize dietary advice to optimise results.

\section{STUDY LIMITATIONS}

There were several limitations in this study. First, the analysis of the influence of inflammatory properties of diet on adiposity and weight gain was done as an observational study. Thus, no cause-effect relation could be derived from those studies. Second, an effort to reduce inflammation by dietary modification was done in an intervention study. However, such an attempt has limitations due to a relatively short research period, small differences in dietary patterns between intervention and control groups, as well as the difficulty to comply with the LCID regime. Lastly, analysis on the influence of inflammatory genes variation on adiposity and weight gain was done in an observational manner.

Further studies are required to clarify findings from this study. A randomized controlled trial with a sufficient number of subjects is needed to test whether variation on inflammatory genes could influence the effect of high protein/GI or low protein diet/GI on weight regain. In addition, a longer intervention duration is needed to evaluate the impact of LCID during a low-calorie diet intervention and its follow-up. Compliance with dietary recommendations is an issue and this might be so because of the current model of dietary practice in Indonesia, where clients receive all dietary instructions at the same time and have to integrate them with their daily lifestyle. The future dietary intervention might take benefit from mobile applications that integrate daily recommendations with virtual lifestyle coaching. By using mobile technology, the dietary recommendations can be delivered one at a time with a pace adjusted by clients, not the other way around. In addition, this technology also allows more personalized and real-time consultation as problems with diet occur. 
All in all, the data presented in this thesis support the hypothesis that inflammation plays a role in the regulation of body weight. We showed that dietary factors associated with inflammation could influence weight regain following weight loss. We also reported that pro-inflammatory gene variation was associated with body weight. In this thesis, we indicated that there was an interaction between diet and gene on the association between inflammation and body weight.

\section{CONCLUSION}

In summary, we showed that the inflammation property of the diet is associated with adipose tissue inflammation, marked by leptin concentration, and partially explains variations in weight regain following weight loss. The modification of a low-calorie diet to reduce inflammation (LCID) in the short term lowers hs-CRP, but does not influence changes in TNF-alpha, IL-6, or weight loss. The LCID was also not associated with weight regain after weight loss. However, the LCID had a positive impact on improving genomic health by elongation of RTL. We showed that gene variations in inflammatory genes such as CRP, TNFA, and IL6 influenced the correlation between obesity and inflammation. Variation in these genes also influenced the correlation between diet composition, e.g. protein and glycemic index of diet, and weight regain following weight loss. 


\section{REFERENCES}

1. Kong LC, Wuillemin PH, Bastard JP, et al. Insulin resistance and inflammation predict kinetic body weight changes in response to dietary weight loss and maintenance in overweight and obese subjects by using a Bayesian network approach. Am J Clin Nutr 2013, 98(6), 1385-1394.

2. Gentile M, Panico S, Rubba F, et al. Obesity, overweight, and weight gain over adult life are main determinants of elevated hs-CRP in a cohort of Mediterranean women. Eur J Clin Nutr 2010, 64(8), 873-878.

3. Kord Varkaneh H, Fatahi S, Tajik S, et al. Dietary inflammatory index in relation to obesity and body mass index: A meta-analysis. Nutr Food Sci 2018, 48, 702-721.

4. Ramallal R, Toledo E, Martínez JA, et al. Inflammatory potential of diet, weight gain, and incidence of overweight/obesity: The SUN cohort. Obesity 2017, 25, 997-1005.

5. Sookoian SC, González C, Pirola CJ. Meta-analysis on the G-308A tumor necrosis factor alpha gene variant and phenotypes associated with the metabolic syndrome. Obes Res 2005, 13(12), 2122-2131.

6. Hu M, Yu Z, Luo D, et al. Association between $-174 G>C$ polymorphism in the IL- 6 promoter region and the risk of obesity: A meta-analysis. Medicine (Baltimore). 2018, 97(33), e11773.

7. Martínez-Calleja A, Quiróz-Vargas I, Parra-Rojas I, et al. Haplotypes in the CRP gene associated with increased BMI and levels of CRP in subjects with type 2 diabetes or obesity from Southwestern Mexico. Exp Diabetes Res 2012, 2012, 982683.

8. Cavicchia PP, Steck SE, Hurley TG, et al. A New Dietary Inflammatory Index Predicts Interval Changes in Serum High-Sensitivity C-Reactive Protein. J Nutr 2009, 139, 2365-2372.

9. Shivappa N, Steck SE, Hurley TG, et al. Designing and developing a literature- derived, population-based dietary inflammatory index. Public Health Nutr 2014, 17, 1689-1696.

10. Shivappa N, Steck SE, Hurley TG, et al. A population- based dietary inflammatory index predicts levels of C-reactive protein in the Seasonal Variation of Blood Cholesterol Study (SEASONS). Public Health Nutr 2014, 17, 1825-1833.

11. Shivappa N, Hébert JR, Rietzschel ER, et al. Associations between dietary inflammatory index and inflammatory markers in the Asklepios Study. Br J Nutr 2015, 113, 665-671.

12. Tabung FK, Smith-Warner SA, Chavarro JE, et al. An Empirical Dietary Inflammatory Pattern Score Enhances Prediction of Circulating Inflammatory Biomarkers in Adults. J Nutr 2017, 147, 1567-1577.

13. Ruiz-Canela M, Zazpe I, Shivappa N, et al et al. Dietary inflammatory index and anthropometric measures of obesity in a population sample at high cardiovascular risk from the PREDIMED (PREvención con Dleta MEDiterránea) trial. Br J Nutr 2015, 113, 984-995.

14. Ramallal R, Toledo E, Martínez JA, et al. Inflammatory potential of diet, weight gain, and incidence of overweight/obesity: The SUN cohort. Obesity 2017, 25, 997-1005.

15. likuni N, Lam QL, Lu L, et al. Leptin and Inflammation. Curr Immunol Rev 2008, 4, 70-79. 
16. Wellen KE, Hotamisligil GS. Inflammation, stress, and diabetes. J Clin Investig 2005, 115, 1111-1119.

17. Considine RV, Sinha MK, Heiman ML, et al. Serum immunoreactive-leptin concentrations in normal-weight and obese humans. N Engl J Med 1996, 334, 292-295.

18. Fortuño A, Bidegain J, Baltanás $A$, et al. Is leptin involved in phagocytic NADPH oxidase overactivity in obesity? Potential clinical implications. J Hypertens 2010, 28, 1944-1950.

19. Hou N, Luo JD. Leptin and cardiovascular diseases. Clin Exp Pharmacol Physiol 2011, 38, 905-913.

20. Nicklas JM, Sacks FM, Smith SR, et al. Effect of dietary composition of weight loss diets on high-sensitivity c-reactive protein: the Randomized POUNDS LOST trial. Obesity 2013, 21(4), 681-689.

21. Gögebakan O, Kohl A, Osterhoff MA, et al. Effects of weight loss and long-term weight maintenance with diets varying in protein and glycemic index on cardiovascular risk factors: the diet, obesity, and genes (DiOGenes) study: a randomized, controlled trial. Circulation 2011, 124(25), 2829-2838.

22. Selvin E, Paynter NP, Erlinger TP. The effect of weight loss on C-reactive protein: a systematic review. Arch Intern Med 2007, 167(1), 31-39.

23. Mediano MF, Neves FA, Cunha AC, et al. Changes in body weight, C-reactive protein, and total adiponectin in non-obese women after 12 months of a small-volume, home-based exercise program. Clinics (Sao Paulo) 2013, 68(8), 1121-1127.

24. Belza A, Toubro S, Stender S, et al. Effect of diet-induced energy deficit and body fat reduction on high-sensitive CRP and other inflammatory markers in obese subjects. Int $\mathrm{J}$ Obes 2009; 33(4), 456-464.

25. Snel M, van Diepen JA, Stijnen T, et al. Immediate and long-term effects of addition of exercise to a 16-week very low calorie diet on low-grade inflammation in obese, insulindependent type 2 diabetic patients. Food Chem Toxicol 2011, 49(12), 3104-3111.

26. Vink RG, Roumans NJ, Čajlaković M, et al. Diet-induced weight loss decreases adipose tissue oxygen tension with parallel changes in adipose tissue phenotype and insulin sensitivity in overweight humans. Int J Obes 2017, 41(5), 722-728.

27. Siklova-Vitkova M, Klimcakova E, Polak J, et al. Adipose tissue secretion and expression of adipocyte-produced and stromavascular fraction-produced adipokines vary during multiple phases of weight-reducing dietary intervention in obese women. J Clin Endocrinol Metab 2012, 97(7), 1176-1181.

28. Rodríguez-Hernández $\mathrm{H}$, Simental-Mendía LE, Rodríguez-Ramírez $\mathrm{G}$, et al. Obesity and inflammation: epidemiology, risk factors, and markers of inflammation. Int J Endocrinol. 2013, 2013, 678159.

29. Yudkin JS. Adipose tissue, insulin action and vascular disease: inflammatory signals. Int J Obes Relat Metab Disord 2003, 27 Suppl 3, S25-S28.

30. Subar AF, Freedman LS, Tooze JA, et al. Addressing Current Criticism Regarding the Value of Self-Report Dietary Data. J Nutr 2015, 145(12), 2639-2645. 
31. Al-Daghri NM, Rahman S, Sabico S, et al. Association of Vitamin B12 with Pro-Inflammatory Cytokines and Biochemical Markers Related to Cardiometabolic Risk in Saudi Subjects. Nutrients 2016, 8(9), 460.

32. Lee YJ, Wang MY, Lin MC, et al. Associations between Vitamin B-12 Status and Oxidative Stress and Inflammation in Diabetic Vegetarians and Omnivores. Nutrients 2016, 8(3), 118.

33. Imhof A, Woodward M, Doering A, et al. Overall alcohol intake, beer, wine, and systemic markers of inflammation in western Europe: results from three MONICA samples (Augsburg, Glasgow, Lille). Eur Heart J 2004, 25(23), 2092-2100.

34. Chiva-Blanch G, Badimon L. Benefits and Risks of Moderate Alcohol Consumption on Cardiovascular Disease: Current Findings and Controversies. Nutrients 2019,12(1),108.

35. Wu IC, Lin CC, Liu CS, et al. Interrelations Between Mitochondrial DNA Copy Number and Inflammation in Older Adults. J Gerontol A Biol Sci Med Sci 2017, 72(7), 937-944.

36. Wong JY, De Vivo I, Lin X, et al. The relationship between inflammatory biomarkers and telomere length in an occupational prospective cohort study. PLoS One 2014, 9(1), e87348.

37. Yang $M$, Jiang $P$, Jin $C$, et al. Longer Telomere Length and its Association with Lower Levels of C-Peptide. Front Endocrinol (Lausanne) 2017, 8, 244.

38. Navarro SL, Kantor ED, Song X, et al. Factors Associated with Multiple Biomarkers of Systemic Inflammation. Cancer Epidemiol Biomarkers Prev 2016, 25(3), 521-531.

39. Meng S, Wu S, Liang L, Liang G, et al. Leukocyte mitochondrial DNA copy number, anthropometric indices, and weight change in US women. Oncotarget 2016, 7(37), 60676-60686.

40. Eiriksdottir G, Smith AV, Aspelund T, et al. The interaction of adiposity with the CRP gene affects CRP levels: age, gene/environment susceptibility-Reykjavik study. Int J Obes (Lond) 2009, 33(2), 267-272.

41. Bochud M, Marquant F, Marques-Vidal PM, et al. Association between C-reactive protein and adiposity in women. J Clin Endocrinol Metab 2009, 94(10), 3969-3977.

42. Todendi PF, Possuelo LG, Klinger El, et al. Low-grade inflammation markers in children and adolescents: Influence of anthropometric characteristics and CRP and IL6 polymorphisms. Cytokine 2016, 88, 177-183. 
BETWEEN INFLAMMATORY PROPERTIES OF DIET AND GENETIC VARIATION IN BODYWEIGHT REGULATION 


\section{IMPACT}

A low-calorie diet has been a long-standing practice among nutritionists and dieticians as a core component of a weight loss program. The concept is when our diet provides less energy than needed, our body will start to break down fat to fulfill the energy demand. With regards to calorie counting, several methods have been developed in several decades such as calorie restriction (reducing $300 \mathrm{kcal} /$ day), a low-calorie diet (1500 kcal/day), and a very low-calorie diet ( $800 \mathrm{kcal} /$ day). However, these methods also showed that the pitfall of an energy deficit diet is the tendency to weight regain after weight loss is achieved.

\section{Study Objectives and Conclusion}

Scientific findings in recent years have indicated that there are several mechanism that lead to weight regain, one of them is inflammation. Inflammation is a signal produced by cells in our body that has an influence on the behaviour of other cells, including immune cells. Traditionally, inflammation is seen as immune reaction to pathogen infection. However, in recent years it has become evident that inflammation also has an influence on other elements of human physiology including energy and substrate metabolism. The impact of inflammation on metabolism might explain its role in the mechanism of weight regain following weight loss.

The main objective of this research is to investigate whether inflammation play a role in body weight regulation based on population and intervention studies. In this thesis, we support other evidence that inflammation plays a role in body weight regulation. Inflammation can be triggered by several factors including diet and genetics. In a weight loss program conducted in The Netherlands, we showed that when dietary intake was more likely to increase inflammation, individuals were more likely to gain weight following weight loss. We further created a new dietary regime for weight loss with the aim not only to reduce calorie intake but also to reduce inflammation, a low calorie-low inflammatory diet (LCID). Although we showed that the new diet may reduce inflammation over a short period of time, this diet did not significantly improve body weight loss compared to the conventional low-calorie diet.

Because diet is not the only factor that triggers inflammation, we further evaluated whether genetic variation might play a role in the interaction between diet and weight gain. In this study, we showed that the individual response to a diet was influenced by variations in selected pro-inflammatory genes. These genes encode proteins that are direct pro-inflammatory signals. The weight regain response to a high protein diet or a low glycemic index diet, which were previously shown to reduce weight regain, was different according to genetic variation. 


\section{Potential Scientific Contribution}

There are several main messages to society that can be obtained by the studies in this dissertation. First, dietary modification to reduce calorie intake and inflammation is possible by not only focusing on reduction of the amount of food consumed but also on improved dietary habits. This can be done by selecting foods that are high in nutrients such as vitamins (vitamin A, B, C, and E) and minerals (magnesium, zinc, selenium), which are anti-inflammatory, and reducing consumption of foods that have pro-inflammatory properties (such as energy-dense, high saturated and trans fat foods). Such efforts have been successfully reported in the Mediterranean diet.

Second, if reproducible, this finding can be further developed into a personalized nutrition approach for weight management. Despite controversies among academia, dietary recommendations based on gene variations are currently being developed in real-world setting by several tech start-ups. There are "personalized nutrition" services that integrate data of gene variations in dietetic consultation or nutritional services. International tech company such as Nutrigenomix, DNAfit, DNAnudge, and Gini have successfully developed their own nutrigenetic approach for personalized nutrition. The rise of direct to costumer genetic testing, such as 23 andme, may give personalized nutrition a place in the future of dietetics. In Indonesia, there are 2 providers of personalized nutrition services based on genetic variation, namely Kalbe Nutrigen-me and Prodia Nutrigenomics. While the services are available, scientific studies are needed to expand our current knowledge on gene-diet interaction as well as providing accurate information regarding dietary recommendations based on genetic profiles.

The "personalized nutrition" approach using genetic information raises some social challenges. It has been criticized that current marketing strategies seem to overpromise the result of personalized nutrition to their clients. On the other side, the area of service seems to lack regulation at the national and international level. Further action is needed by governments, academics and industry in the regulation and commercialization of personalized nutrition.

\section{Target Audience of The Scientific Findings}

Obesity is global health problem that costs millions of dollars for treatment as well as treatment of diseases related to obesity. This research aimed to contribute to alleviating this problem by development of a weight loss program using a different approach, by dietary modification and genetic analysis. Results from this study can be used by those who work in the health sector as well as wellness industry. This study focused on one of the most challenging problems facing obesity treatment, namely the weight regain following weight loss.

Dietitians and nutritionists are two major target audiences for this study. We provided information on modification of the diet during a weight loss program. This included the role of inflammation on weight regain and how an individual can 
response differently due to its genetic background. This information is aimed to educate practitioners in the health and wellness industry to not only focus on reducing calorie intake but also to improve the diet quality. Fellow scientists working in the areas of nutrition and nutrigenetics all around the world are also target audience of this study. It is hoped that results from this study can be used as a basis for the development of methods to reduce inflammation during a weight loss program.

\section{Activities for Result Dissemination}

The main outlet of this research is the scientific publication of the studies that are currently done within this thesis. This will provide scientific insight on how the studies were conducted and conclusions that were generated and their strengths and limitations. Results from this study has been presented at several conferences including Asia Pacific Nutrigenomic and Nutrigenetic Conference (China, 2020), NuGO Week (United Kingdom, 2018), Dutch Nutrition Science Day (The Netherlands, 2018), European Conference on Obesity (Austria, 2018). I also wrote a book with title "Diet Mediterania: Teori dan Aplikasi Bagi Masyarakat Indonesia" or "Mediterranean diet: Theory and Application for Indonesians". The book is a guide on how to adapt Mediterranean diet principle to Indonesians. The Mediterranean diet itself has been an important insight with respect to the dietary approach to reduce inflammation which inspired the development of the low-calorie-low-inflammatory diet.

In addition to the book and journals, I also plan to create a 10 minutes education video for 3 topics : 1 ) the influence of dietary habits on inflammation; 2 ) the importance of keeping inflammatory low when dieting; and 3) individual response to diet based on gene variations. The video will be an animated version of this thesis and made in English and will be broadcasted my YouTube page "Gizi Gama". By doing this, I can provide information from this research freely to the public, practitioners in the health and wellness industry, as well as fellow academics. 


\section{ACKNOWLEDGEMENTS}

To work in the scientific field, having a Ph.D. degree is the basic requirement. And after 4 years of undergoing the educational system, I now understand why it is important. Studying in a doctoral school teaches us how to understand the phenomenon and obtaining knowledge from its own source. And being a Maastricht University Ph.D. student gave me a tremendous experience not only to how to understand how to conduct research better, but also present it in a paper and presentation, and have a collaboration with fellow scientists in the field.

This dissertation is written by a Ph.D. student with an external Ph.D. scheme which means I do not have a full-term scholarship or fixed research grant to support what I did in the last 4 years. Thus, this program cannot be happening without "tons" of supports from individuals and organizations that cross this path.

I would like to express my gratitude to Prof Marleen van Baak for the help, support, and guidance through 4 years of Ph.D. activities. Its is a humbling experience working with human experiment conducting a lifestyle modification program. Her experiences working in these fields really help me a lot in understanding the context of what I did. I also would like to thank Prof. Edwin Mariman for his help during the Ph.D. program. Help me guided my research from the very beginning on the molecular aspect of obesity. Thank you for believing me, especially that I can finish this doctoral school on time.

Both of my promotors not only providing me with guidance but also showing me the way of research and development in this topic. And also to point out several things that are missing in the literature. What they did inspires me to keep working in this direction. I remembered in 2011, when I was a master's student of Biomedical Sciences at Maastricht University, deciding to work in their lab. And 10 years later, I graduated from the same supervisor with a similar research topic. I surely would continue working in the area of genetic and obesity with an emphasis on weight loss.

Thank you Prof. dr. E.E. Blaak, Prof. dr. J. Plat, Prof. dr. A. Salis, Prof. Dr. R. Mensink, Dr. Marleen van Greevenbroek and Dr. ir. R. Stienstra for taking the time and effort to review this thesis and being present at the official Ph.D. defense.

We thank Perdana Samekto and Adriyan Pramono for every helps you both done to make sure defence run smoothly. In this challenging time, I really appreciate your support.

Thank you, Prof John Mathers and Dr. Fiona Malcomson for the research collaboration and support during my research project at Newcastle University. I really appreciate with the opportunity to work with BORICC study and this experience teach me a lot regarding conducting a cohort study and evaluation of diet, genetic, obesity, and disease in the community. 
To Dr. Safarina, Wina, Sukma, and Asha from The Eijkman Institute, I would thank the opportunity of learning from your lab on molecular analysis as one of the topics in this study. Working at one of the prestigious Indonesian laboratories for molecular biology is really a moment of pride for me. When I was in high school, I used to dream of working there as a scientist. And those are the moment when dreams do come true.

Thank you, Prof Wan Manan and Dr. Yi Yi Lee, from Universiti Sains Malaysia (International Medical University) who in the early stage of this research supported me with the research collaboration. A study was initially conducted in 2016 is developing into a Ph.D. project. On this note, I also would like to thank Dr. Emy and Miss Dian for their collaboration and commitment to this project.

Thank you Dr. Toto Sudargo and Dr. Susetyowati, The Head and Secretary of The Department of Nutrition, Universitas Gadjah Mada who at times believe in the external Ph.D. program that I took and provide with a flexible working arrangement so I can come to Maastricht University about $1 / 3$ of the year. I also would like to thank Dr. Yodi Mahendradhata as the vice Dean of Research and Prof Ova Emilia as the Dean Faculty of Medicine, Public Health, and Nursing for understanding the uniqueness of this Ph.D. program and provide me with support.

I would thank several organizations that in the past few years helping me with financial supports so that I can finish my Ph.D. Badan Penerbit dan Publikasi Universitas Gadjah Mada, World Obesity Federation, The European Nutrigenomic Organization, and European Association for Study Obesity.

While studying at Maastricht University for a Ph.D., I met a significant amount of people that not only help me through the journey but also make this process memorable. To Adriyan, who I met for the first time in Maastricht that help me out through my journey and amazing moment with his family Fadhlan, Mima and Uchi. And the lunch people Manuel, Kenneth, Rens, Sultan, Lars, and Jehad, thank you for all the talks during lunch hours. You all will be missed. I thank Pak Fauzan and his family who help me while I am there. I feel like I found a home a way from home. Thank you Cleo and Claudia for helping me with anything needed during my stay at Maastricht University.

Going back and forth between Indonesia and The Netherlands is not always easy. Thus to friends in Maastricht that I know for a decade, Ivo, Birke, Monica, Dennie, Nico, and Thijs, thank you for making Maastricht feels like a second home to me. Thank you for all the dinner invitations and movie nights and the hangouts (or baby day out). Nuria, thank you for all the support and perspective on things in life and in nutrition-wise that you generously share.

I would also like to share this gratitude to friends who had the same experiences from the very beginning, mbak Ita, mbak Sinta, Yuda, and generally. Even some of us are no longer here, thank you to keep the light on especially at the moment I am not sure if I can pull it off. 
To my family, my parents, and my brother, thank you for all your support. To my extended family in Yogyakarta, Avi, Dana, Diana, Emma, Ira, Naafi, and Sarah, thank you for just be amazing.

To Satwika, Maya, and Cita, thank you for helping me with the research projects. I would like to thank all staff of The Department of Nutrition and Health, Universitas Gadjah Mada who made this journey possible. 


\section{ABOUT THE AUTHOR}

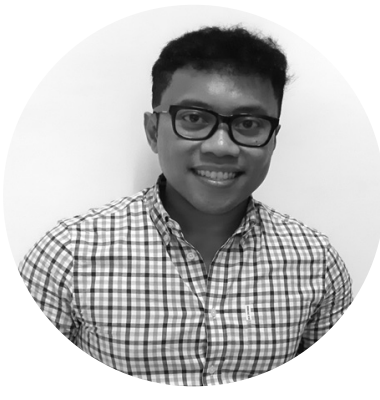

HARRY FREITAG LUGLIO MUHAMMAD

\author{
Research Department \\ Department of Human Biology, \\ Maastricht UMC+
}

Research School

NUTRIM School of Nutrition and Translational Research in

Metabolism

PhD Period

2017-2021

Promotors

Prof. Marleen van Baak

Prof. Edwin C Mariman
Harry Freitag Luglio Muhammad was born on 11 July 1986 in Dili, Timor Leste. After the independence of Timor Leste, his family chooses to live in Indonesia. Here, Harry finished his high school and bachelor's degree in Java island. He received bachelor of Nutrition from Universitas Gadjah Mada, Yogyakarta, Indonesia in 2008. In 2009, he finished his dietetic internship program.

In 2011, he continue his study on Master of Biomedical Sciences at Maastricht University with a specialization in nutrition and metabolism. His thesis is under the supervision of Prof Marleen van Baak. After finishing his master's degree, he return to Indonesia in 2013. At the Department of Nutrition and Health, Universitas Gadjah Mada, he teaches bachelor students of nutrition as well as to conducts scientific studies. Since then until recently, he published around 40 publications in national and international peerreviewed journals, 5 academic books, and 1 book chapter.

November 2017 is when he started his Ph.D. at Maastricht University. Between 2017 and 2021, he received several grants and awards including Travel Grant from Badan Penerbit dan Publikasi, Universitas Gadjah Mada, Scope School Scholarship, World Obesity Federation, NuGO Students Exchange Grant, European Association for Study Obesity Travel grant. Those grants were necessary for his Ph.D. because this allowed him to conduct research as well as to travel within his Ph.D. program.

In addition to conducting research and teaching student, Harry is also involved in several organizations. Including Asia Pacific Nutrigenomic Nutrigenetic Organization, Nutrigenomic Early Career Scientist, and World Obesity Federation.

Harry is active on social media. He now has YouTube, Instagram, Twitter, Spotify and a website (gizigama.com), in which he routinely posts educational materials for the general public. He is also currently working with several start-ups and company including the Indonesian Nutrition and Fitness app FITA as a "Signature Coach" as well as Cordlife Genetic as an educator for direct-to-customer genetic tests for the general public and professionals. 


\section{LIST OF PUBLICATIONS}

1. Muhammad HFL, Pahdarina D, Zahara NP, Nugrahen F, Hanny TA, Ermamilia A, Huriyati E. Diet or exercise: The role of diet and/or exercise on changes of proinflammatory markers during a weight loss program in adult women with overweight. Clinical Nutrition ESPEN, 2021, 44:337-341.

2. Muhammad HFL, Pramono A, Rahman NH. The safety and efficacy of supervised exercise on pregnant women with overweight/obesity: A systematic review and meta-analysis of randomized controlled trials. Clinical Obesity. 2021, 11(2):e12428.

3. Muhammad HFL, Sulistyoningrum DC, Huriyati E, Lee YY, Wan Muda WAM. The Interaction between Energy Intake, Physical Activity and UCP2 -866G/A Gene Variation on Weight Gain and Changes in Adiposity: An Indonesian Nutrigenetic Cohort (INDOGENIC). British Journal of Nutrition, 2021, 125(6), 611-617.

4. Muhammad HFL, Pratama SA, Sulistyoningrum DC, Hartono MN, Huriyati E, Lee YY, Wan Muda WAM. The Association Between Sleep Quality and Duration on Leptin, Adiposity and Blood Pressure. Medical Journal of Indonesia, 2020;29(4):417-21.

5. Muhammad HFL, Sulistyoningrum DC, Huriyati E, Lee YY, Wan Muda WAM. Variation of uncoupling protein $2(-866 \mathrm{G} / \mathrm{A})$, dietary fat intake and blood pressure: an Indonesian Nutrigenetic Cohort. European Heart Journal, 2020, 41, Supplement_2, ehaa946.2795.

6. Muhammad HFL. Prevention of weight gain during self-isolation in COVID-19 pandemic era: a narrative review. Journal of Community Empowerment for Health, 2020, 3(2), 123-129.

7. E Huriyati, HF Luglio, AH Sadewa, M Juffrie. The Interaction between KCNJ11 Gene Polymorphism and Refined Carbohydrates Intake on Obesity in Indonesian Adolescents. Current Nutrition \& Food Science, 2020, 16(2), 185-189.

8. PP Arfines, HF Luglio, N Kusumawardani. Prevalence and Lifestyle Risk Factors of Overweight and Obesity Among Indonesian Adolescents: An Analysis of Global School-Based Health Survey 2007 and 2015. Advances in Health Sciences Research, 2020, 22, 512-518.

9. Muhammad HFL Baak MAv, Mariman EC, Sulistyoningrum DC, Huriyati E, Lee YY, Wan Muda WAM. Dietary Inflammatory Index Score and Its Association with Body Weight, Blood Pressure, Lipid Profile, and Leptin in Indonesian Adults. Nutrients, 2019, 11.

10. Marliya, Muhammad HFL. Introducing The New Nutrition Guideline to Indonesian Overweight/ Obese Adolescents Using A Short Movie: The Impact on Nutritional Knowledge, Eating Habit and Dietary Intake. Progress in Nutrition. 2019; 21 (Suppl 1):227233.
11. Muhammad HFL, Fitria AL, Kusumawardhani DA, Amalia R, Hapsari DD, Susilowati R, et al. The effect of lesser yam based cookies on fasting glucagon-like peptide 1, appetite, and dietary intake in overweight/ obese with ad libitum diet. Indonesian Journal of Clinical Nutrition, 15(3), 83-88.

12. Muhammad HFL, Safika EL, Wahyuni FC, Ermamilia A, Huriyati E. The Effect of Zumba Training on Body Composition, Dietary Intake, Sleep Quality and Duration in Adult Sedentary Women with Overweight. Topics in Clinical Nutrition. 2019;34(4):277-286.

13. Muhammad HFL, Pratama SA, Hartono MN. The Differential Response to Intermittent Fasting Diet versus Low Calorie Diet with Exercise Based on -866 G/A UCP2 Gene Variation In Adults with Overweight/ Obesity. Mediterranean Journal of Nutrition and Metabolism, 12 (2019) 325-333.

14. Muhammad HFL. Pemanfaatan Sekolah Sebagai Sarana Pencegahan Obesitas Sejak Dini pada Remaja (The Central Role of School for Obesity Prevention among Adolescents). Journal of Community Empowerment for Health. 2019;1(2):107-114.

15. Muhammad HFL, Sulistyoningrum DC, Huriyati E, Lee YY, Wan Muda WAM. The Interaction between Coffee - Caffeine Consumption, UCP2 Gene Variation and Adiposity In Adults: A Cross-Sectional Study. Journal of Nutrition and Metabolism, 2019, 2019:9606054.

16. Susetyowati, Huriyati E, Kandarina BJI, Muhammad HFL, Faza F. Prevalence and determinants of high blood glucose in urban and rural Indonesian adult population. International Journal of Diabetes in Developing Countries, 2019, https://doi. org/10.1007/s13410-019-00721-6.

17. Iskandar K, Patria SY, Huriyati E, Luglio HF, Julia $M$, Susilowati R. Effect of FTO rs9939609 variant on insulin resistance in obese female adolescents. BMC Res Notes, 2018, 11:300.

18. Muhammad HFL, Latifah FN, Susilowati R. The yo-yo effect of Ramadan fasting on overweight/ obese individuals in Indonesian: A prospective study. Mediterranean Journal of Nutrition and Metabolism, 2018, 11(2), 127-133.

19. Muhammad HFL. Obesity as the Sequel of Childhood Stunting: Ghrelin and GHSR Gene Polymorphism Explained. Acta Medica Indonesiana, 2018, 50(2):159-164.

20. Sudargo T, Muhammad HFL, Kandarina I, Putri N, Irianto SE, Pranoto YA, et al. Effect of Additional Egg Supplementation on Vitamin and Mineral Fortification Program on Growth, Cognitive Development and Hemoglobin in Indonesian Underweight and Stunting Children. Nutrition and Food Science, 2018, https://doi.org/10.1108/NFS01-2018-0009

21. Luglio $H F$, Sulistyoningrum $D C$, Huriyati $E$, Lee $Y Y$, Wan Muda WAM. The gene-lifestyle interaction on leptin sensitivity and lipid metabolism in adults: A population based study. Nutrients, 2017, 9, 716 
22. Muhammad HFL, Vink RG, Roumans NJT, Arkenbosch LAJ, Mariman EC, Baak MAv. Dietary Intake after Weight Loss and the Risk of Weight Regain: Macronutrient Composition and Inflammatory Properties of the Diet. Nutrients, 2017, 9, 1205.

23. Luglio HE, Sulistyoningrum DC, Apriliana NL, Putri SE, Larasati A, Tsani AFA, et al. The effect of a combination of aerobic and strength training on a weight loss and metabolic profile: Development an effective lifestyle based weight loss program. Topics in Clinical Nutrition, 2017, 32, 152-160.

24. Sulistyoningrum $D C$, Susilowati $R$, Huriyati $E$, Witar NPD, Luglio HF, Julia M. Tumor necrosis factor-alpha and risk of cardiovascular diseases among overfat Indonesian adolescents. Asia Pacific Journal of Clinical Nutrition, 2017, 26, S50.

25. Luglio HF, FZ Nisa, MHST Penggalih, Helmyati $\mathrm{S}$, Arsanti L, Utami SB, et al. Socioeconomic determinants of obesity among women living in Indonesian remote islands, Raas and Sapudi. Pakistan Journal of Nutrition, 2017, 16, 279-284.

26. Luglio $H F$, Sulistyoningrum DC, Huriyati E. Leptin, appetite and weight rebound in overweight/ obesity individuals undertook weight loss program using a low calorie diet with or without exercise. Mediterranean Journal of Nutrition and Metabolism, 2017, 10, 223-233.

27. Luglio HF Huriyati $E$. The role of genetic variation in TCF7L2 and KCNJ11, dietary intake, and physical activity on fasting plasma glucagon-like peptide-1 in male adolescents. Paediatrica Indonesiana, 2017, 57, 239-45.

28. Susilowati $R$, Sulistyoningrum DC, Witari NPD,

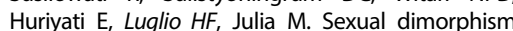
in interleukin 17A and adipocytokines and their association with insulin resistance among obese adolescents in Yogyakarta, Indonesia. Asia Pacific Journal of Clinical Nutrition, 2016, 25, S93-S101.

29. Luglio $H F$, Fitria AL, Kusumawardhani DA, Amalia R, Hapsari DD, Susilowati R, et al. Lesser yam (Dioscorea esculenta) based cookies improves lipid profile in overweight/obese adults with an ad libitum diet via glucagon like peptide 1. Nutrition and Food Science, 2016, 46, 3.

30. Luglio HF. Genetic Variation of de novo lipogenesis pathway and individual susceptibility to obesity. Immunology, Endocrine and Metabolic Agents in Medicinal Chemistry, 2016, 16(1), 31-38.

31. Huriyati $E$, Luglio HF, Ratrikaningtyas PD, Tsani AFA, Sadewa AH, Juffrie M. Dyslipidemia, Insulin resistance and dietary fat intake in obese and normal weight adolescents: The role of uncoupling protein 2 gene polymomrphism. International Journal of Molecular Epidemiology \& Genetics, 2016, 7(1), 67-73.

32. Luglio HF. Genetic variation of fatty acid oxidation and obesity, a literature review. International Journal of Biomedical Sciences, 2016, 12(1), 1-8.
33. Luglio $H F$, Eurike $D$, Huriyati $E$, Julia $M$, Susilowati R. Gene-lifestyle interaction: The role of SNPs in UCP2 $-866 \mathrm{G} / \mathrm{A}$ and UCP3 $-55 \mathrm{C} / \mathrm{T}$ on dietary intake and physical activity in Indonesian obese female adolescents. Mediterannean Journal of Nutrition and Metabolism, 2016, 9, 87-93.

34. Luglio HF, Sulistyoningrum DC, Susilowati R. The role of genes involved in lipolysis on weight loss program in overweight and obese individuals. Journal of Clinical Biochemistry and Nutrition, 2015, 57, 2.

35. Sunarti, Kusuma RJ, Luqlio HF. Cytochrome oxidase 1 expression and plasma adenosine triphosphate (ATP) concentration in diabetic rats after Dioscorea esculenta treatment. Mediterranean Journal of Nutrition and Metabolism 2015, 8, 3 .

36. Luglio HF. Estrogen and body weight regulation in women: The role of estrogen receptor alpha (ER- $a$ ) on adipocyte lipolysis. Acta Medica Indonesiana, $2014,46,4$

37. Luglio HE Inggriyani CG, Huriyati E, Julia M, Susilowat R. Association of SNPs in GHSR rs292216 and rs509035 on dietary intake in Indonesian obese female adolescents. International Journal of Molecular Epidemiology and Genetic, 2014, 5, 4.

38. Luglio HF, Sulistyoningrum DC. Single nucleotide polymorphism in FTO rs9939609 and obesity among asians and caucasians: A meta-analysis. Immunology, Endocrine and Metabolic Agents in Medicinal Chemistry, 2014, 14, 1.

39. Susilowati $R$, Septyaningtrias $D E$, Inggriyani CG, Muhammad HFL, Julia M. Association between insulin resistance with UCP2 -866G/A, UCP2 45BP INS/DEL, UCP3 -55C/T, GHSR1A RS2922126, GHSR1A RS509035 and PRO12ALA PPARY2 gene polymorphisms in obese female adolescents in Yogyakarta, Indonesia. International Journal of Pediatric Endocrinology, 2013, (Suppl 1) :036.

40. Eurike D, Muhammad HFL, Susilowati R, Julia M. UCP3 gene polymorphism and insulin resistance in obese female adolescents. Paediatrica Indonesiana, 2013, $52 / 3$.

41. Hartriyanti Y, Suyoto PST, Muhammad HFL, Palupi IR Nutrient Intake of Pregnant Women in Indonesia: A Review. Malaysian Journal of Nutrition, 2012, 18, 1.

42. Muhammad HFL, Huriyati E, Susilowati $R$, Julia $M$. Magnesium Intake and Insulin Resistance in Obese Adolescent Girls. Paediatrica Indonesiana, 2009,5/4.

\section{Q}

1. The Effect of a Low Calorie Low Inflammatory Diet on Inflammation, Telomere Length and Mitochondrial DNA among Obese Adults (eNUGOweek 2021 European Nutrigenomic Organization, 6-8 September 2021, online)

2. The Effect of a Low Calorie Low Inflammatory Diet on Inflammation, Telomere Length and Mitochondrial DNA among Obese Adults (Asia Pacific Nutrigenomic 
and Nutrigenetic Conference 2020, 1-2 Desember 2020, Online)

3. The Interaction Between Energy Intake, Physical Activity and -866G/A UCP2 Gene Variation on Weight Gain and Changes in Adiposity: An Indonesian Nutrigenetic Cohort (INDOGENIC) (Asia Oceania Conference on Obesity, 29 Agustus - 2 September 2019, Seoul, South Korea).

4. The Interaction Between Uncoupling Protein 2 Gene Variation and Inflammatory Properties of Diet on Blood Pressure in Adults (NuGO Week, 3-6 September 2018, Newcastle, United Kingdom).

5. Assessment of a low calorie low inflammatory diet for weight loss of adults with obesity. (at Dutch Nutrition Science Day, 11-12 Oktober 2018, Heeze, The Netherlands).

6. Nutrigenomics and Nutrigenetics Aspect of Obesity and Body Weight Management. (Indonesian Nutrigenomics and Nutrigenetics Association meeting, 18-19 Oktober 2017, Bali, Indonesia).

7. Unravel The Ramadan Fasting Yoyo Effect : Indonesian Prospective Study on Overweight/Obesity Individuals. (World Obesity 14th Stock Conference, 31 March 2017, Sydney, Australia).

8. Gene-Lifesyle Interaction and Individual Predisposition to Obesity: Untangle the Complexity. (Asia Pacific Nutrigenomic and Nutrigenetic Conference 2016, 5-6 December 2016, Gyeong Ju, South Korea).

9. The Role of Genetic Variation in TCF7L2 and KCNJ11, Dietary Intake and Physical Activity on Fasting Plasma Glucagon Like Peptide - 1 in Male Adolescents. (Annual Indonesian Society of Human Genetic Conference, 2628 November 2016, Semarang, Indonesia).

10. Gene-lifestyle interaction: the role of snps in UCP2 -866G/A and UCP3 -55C/tondietary intake and physical activity in indonesian obese female adolescents. (6th International Symposium on Wellness Healthy Lifestyle and Nutrition, 25-27 November 2015, Kota Bharu, Malaysia).

\section{욘}

AWARDS

2015 : ERASMUS MUNDUS AREAS+ for visiting scholar at KU Leuven, Belgium

2015

: MPV awards International Symposium on Wellness Healthy Lifestyle and Nutrition

2016

2017

2017

2017

2018

2018

2019
: ILSI South East Asia Travel Grant

: Australian Award Fellowship

: Australia Indonesia Centre Travel Grant

: Asia Oceania Association for Study Obesity Travel Grant

: European Association for Study Obesity Travel Grant

: NUGO student Exchange Grant

: Scope School Scholarship from World Obesity Federation
BOOKS (BAHASA INDONESIA)

2018 : Imunologi gizi, Gadjah Mada University Press

2018 : Obesitas translasional: aspek klinis \& molekuler dari kejadian obesitas, Gadjah Mada University Press

2020 : Pedoman personalized nutrition advice berbasis variasi genetik untuk pencegahan penyakit kardiovaskuler, Gadjah Mada University Press

2021 : Diet mediterania : teori dan aplikasi bagi masyarakat Indonesia, Gadjah Mada University Press

2021 : Buku ajar nutrigenomik dan nutrigenetik bagi mahasiswa gizi, Gadjah Mada University Press

2021 (in press)

: NUTRIGENETIK

: Rekomendasi Kebutuhan Energi dan Zat Gizi Makro Berbasis Genetik Untuk Layanan Personalized Nutrition

\section{BOOK CHAPTER (ENGLISH)}

2019 : Muhammad HFL, Dickinson KC. Nutrients, Energy Values and Health Impact of Conventional Beverages (Book chapter : NUTRIENTS IN BEVERAGES, edited by Grumezescu AM and Holban AM). Woodhead Publishing (Elsevier): United Kingdom.

\section{\& SOCIAL Media}

- Youtube : Gizi Gama (around 1K subscribers and 300 educational videos, since May 2020)

2 Spotif : Gizi Hari Ini

(O) Instagram : Gizi_Gama

- Twitter : @gizigama

$\mathcal{O}$ Website : gizigama.com 